\title{
Development of Novel Supported Gold Catalysts: A Materials Perspective
}

\author{
Zhen $\mathrm{Ma}^{1}(\bowtie)$ and Sheng $\mathrm{Dai}^{2}(\bowtie)$ \\ ${ }^{1}$ Department of Environmental Science and Engineering, Fudan University, Shanghai 200433, China \\ ${ }^{2}$ Chemical Sciences Division, Oak Ridge National Laboratory, Oak Ridge, TN 37831, USA \\ Received: 28 June 2010 / Revised: 28 July 2010 / Accepted: 31 July 2010 \\ C The Author(s) 2010. This article is published with open access at Springerlink.com
}

\begin{abstract}
Since Haruta et al. discovered that small gold nanoparticles finely dispersed on certain metal oxide supports can exhibit surprisingly high activity in $\mathrm{CO}$ oxidation below room temperature, heterogeneous catalysis by supported gold nanoparticles has attracted tremendous attention. The majority of publications deal with the preparation and characterization of conventional gold catalysts (e.g., $\mathrm{Au} / \mathrm{TiO}_{2}$ ), the use of gold catalysts in various catalytic reactions, as well as elucidation of the nature of the active sites and reaction mechanisms. In this overview, we highlight the development of novel supported gold catalysts from a materials perspective. Examples, mostly from those reported by our group, are given concerning the development of simple gold catalysts with single metal-support interfaces and heterostructured gold catalysts with complicated interfacial structures. Catalysts in the first category include active $\mathrm{Au} / \mathrm{SiO}_{2}$ and $\mathrm{Au} /$ metal phosphate catalysts, and those in the second category include catalysts prepared by pre-modification of supports before loading gold, by post-modification of supported gold catalysts, or by simultaneous dispersion of gold and an inorganic component onto a support. $\mathrm{CO}$ oxidation has generally been employed as a probe reaction to screen the activities of these catalysts. These novel gold catalysts not only provide possibilities for applied catalysis, but also furnish grounds for fundamental research.
\end{abstract}

\section{KEYWORDS}

Gold, nanoparticles, catalyst design, catalyst support, functionalization, promotion, CO oxidation

\section{Introduction}

Nanoscience and nanotechnology play an important role in the design of novel heterogeneous catalysts [1-8]. When the sizes of supported or unsupported metal particles are decreased down to a few nanometers, these nanoparticles may exhibit unprecedented physicochemical and catalytic properties [9-14]. This is the case for supported gold nanoparticles. One of the most important discoveries in catalysis research is that finely divided gold nanoparticles on certain metal oxide supports can be very active for $\mathrm{CO}$ oxidation below room temperature [15-17]. This discovery has changed the traditional impression that gold is neither active nor useful in catalysis, and has pinpointed "gold mines" in catalysis research. Supported gold catalysts have ample applications in environmental catalysis (CO oxidation, de- $\mathrm{NO}_{x}$, catalytic combustion

Address correspondence to Zhen Ma, zhenma@fudan.edu.cn; Sheng Dai, dais@ornl.gov 
of volatile organic compounds (VOCs), photocatalysis), energy processing (the water-gas shift reaction, selective $\mathrm{CO}$ oxidation in excess $\mathrm{H}_{2}$ ), and chemical synthesis (selective hydrogenation, selective oxidation, carbon-carbon coupling, oxidation of $\mathrm{H}_{2}$ to form $\mathrm{H}_{2} \mathrm{O}_{2}$ ), with tangible commercial prospects [18-25].

The recent decade has witnessed an explosion of publications in the field of gold catalysis. The bulk of publications deal with the preparation and characterization of conventional gold catalysts (e.g., $\mathrm{Au} / \mathrm{TiO}_{2}$ ), the applications of gold catalysts in different reactions, as well as elucidation of the nature of the active sites and reaction mechanisms [26-33]. Many papers have elaborated on the effects of different preparation methods (e.g., deposition-precipitation, coprecipitation, colloidal deposition) and synthesis details (e.g., $\mathrm{pH}$ value and temperature of the synthesis mixture, duration of aging, gold loading, calcination temperature) on catalyst properties and catalytic performance [34-40], and have furnished firm grounds for a scientific understanding of catalyst preparation. Nevertheless, further development calls for the innovative design of novel gold catalysts with more complex structures or with the input from materials synthesis techniques [41-63]. Such design, interesting for both materials researchers and catalysis workers, is not only important for the development of better catalysts with tailored structures and catalytic properties, but also useful for understanding structureproperty correlations from a fundamental perspective.

Our group at Oak Ridge National Laboratory embarked on the development of nanostructured gold catalysts in the early 2000s, and published our first relevant paper on the synthesis of mesoporous $\mathrm{SiO}_{2}$-supported gold catalysts in 2003 [64]. Since then, advances have been made centering around the synthesis of novel supported gold catalysts from a materials perspective [64-95], i.e., adopting a materialsdriven research strategy. Gold has been loaded onto various commercial or functionalized inorganic solid supports via deposition-precipitation or colloidal deposition, and the catalytic performance of the resulting catalysts, often with complicated interfacial structures, has been evaluated using $\mathrm{CO}$ oxidation and other reactions as probe reactions. Structureproperty correlations have been established with the aid of conventional characterization tools.

Herein, we review some advanced ways of designing gold-based nanocatalysts. In Section 2 we highlight the synthesis of gold catalysts with single metalsupport interfaces. In Section 3 we review the engineering of interfacial structures of gold catalysts via pre-modification of supports, post-modification of supported gold catalysts, and simultaneous deposition of both gold and an inorganic component onto the support. We end in Section 4 by furnishing our assessment and perspectives. Overall, the focus of our review is not intended to be on catalytic reactions or reaction mechanisms, but on novel gold catalysts with interesting structures and/or delicate synthesis procedures. Furthermore, this review is not intended to be comprehensive. Rather, the examples highlighted are mostly from those reported by our group. Although there are a number of reviews on various aspects of gold catalysis [18-33], few have specifically focused on the development of novel gold catalysts from a materials perspective [89].

\section{Gold catalysts with single metal-support interfaces}

\subsection{General considerations}

Supported gold catalysts are often prepared by loading gold onto pristine supports, such as $\mathrm{TiO}_{2}$, $\mathrm{CeO}_{2}, \mathrm{Fe}_{2} \mathrm{O}_{3}, \mathrm{ZrO}_{2}, \mathrm{Al}_{2} \mathrm{O}_{3}, \mathrm{SiO}_{2}$, and $\mathrm{C}$ via depositionprecipitation, coprecipitation, or colloidal dispersion. Pristine supports are often used, because these supports are commercially available, and it is relatively easy to establish the structure-property correlation if a supported catalyst is composed of only a metal and a pristine support. Plus, in the initial publications of Haruta and co-workers [15-17], they used pristine supports, so most subsequent researchers have continued to use such supports to load gold.

In general, solid supports can disperse and stabilize gold nanoparticles, provide active sites at the metalsupport boundary, and influence the oxidation state of gold. Efforts have been made to improve the structural properties and catalytic activity of existing gold catalysts by adjusting the synthesis details [34-40]. It would be interesting to ask: (1) can we 
make materials traditionally viewed as inactive (e.g., $\mathrm{Au} / \mathrm{SiO}_{2}$ ) into active catalysts for $\mathrm{CO}$ oxidation by applying new synthesis methods or unconventional synthesis techniques? (2) can we find active gold catalysts based on previously overlooked supports (e.g., metal phosphates)? In addition, the effects of the crystal phase [65, 82, 96-100], size [99, 101-108], and shape $[45,108-114]$ of solid supports on the catalytic performance are also of interest. Below we first present the development of $\mathrm{Au} / \mathrm{SiO}_{2}$ and $\mathrm{Au} /$ metal phosphate catalysts in our group, and then highlight recent findings on the effects of the particle size and shape of solid supports.

\section{$2.2 \mathrm{Au} / \mathrm{SiO}_{2}$}

$\mathrm{SiO}_{2}$ has been widely used as a support to prepare supported metal catalysts (e.g., $\mathrm{Pt} / \mathrm{SiO}_{2}$ ) owing to its high surface area, thermal stability, mechanical strength, and non-reducibility, but it is challenging to make $\mathrm{Au} / \mathrm{SiO}_{2}$ active for $\mathrm{CO}$ oxidation. $\mathrm{Au} / \mathrm{SiO}_{2}$ catalysts prepared by the impregnation of $\mathrm{SiO}_{2}$ with $\mathrm{HAuCl}_{4}$ or $\mathrm{AuCl}_{3}$ have relatively large gold particles because the residual chloride ions facilitate the sintering of gold nanoparticles on calcination [115]. $\mathrm{Au} / \mathrm{SiO}_{2}$ prepared by deposition-precipitation has a low gold loading because, under the basic conditions used to hydrolyze $\mathrm{HAuCl}_{4}$ to $\mathrm{Au}(\mathrm{OH})_{4}^{-}$, the $\mathrm{SiO}_{2}$ surface is also negatively charged due to the low isoelectric point of $\mathrm{SiO}_{2}$ (IEP 2). The negatively charged $\mathrm{Au}(\mathrm{OH})_{4}^{-}$species is difficult to adsorb onto the negatively charged $\mathrm{SiO}_{2}$, so the catalytic activity of the resulting $\mathrm{Au} / \mathrm{SiO}_{2}$ in $\mathrm{CO}$ oxidation is often quite low [66].

To tackle these issues, our group employed the regular template-mediated synthesis of mesoporous $\mathrm{SiO}_{2}$ in the presence of both $\mathrm{Au}^{3+}$ as the gold source and $\left(\mathrm{CH}_{3} \mathrm{O}\right)_{3} \mathrm{Si}\left(\mathrm{CH}_{2}\right)_{3} \mathrm{NH}\left(\mathrm{CH}_{2}\right)_{2} \mathrm{NH}_{2}$ as a bifunctional ligand to interact with both $\mathrm{Au}^{3+}$ and the $\mathrm{SiO}_{2}$ matrix [64]. The as-synthesized Au/MCM-41 was ionexchanged with $\mathrm{NH}_{4} \mathrm{Cl}$, and then reduced in $\mathrm{H}_{2}$. Although small gold particles were confined in the pore channels, the catalyst was not active for $\mathrm{CO}$ oxidation when the reaction temperature was below $100{ }^{\circ} \mathrm{C}$ [116]. In contrast, $\mathrm{Au} /$ mesoporous $\mathrm{TiO}_{2}$ exhibited complete CO conversion at room temperature [116].

The failure to obtain high activity may lead one to generalize that $\mathrm{SiO}_{2}$ is inherently a bad support for making active gold catalysts for $\mathrm{CO}$ oxidation [116]. Indeed, $\mathrm{Fe}_{2} \mathrm{O}_{3}, \mathrm{TiO}_{2}, \mathrm{NiO}_{x}$, and $\mathrm{CoO}_{x}$ have been classified as "active" supports because they are reducible and can activate and store oxygen, whereas $\mathrm{Al}_{2} \mathrm{O}_{3}$ and $\mathrm{SiO}_{2}$ were classified as "inert" supports because they may not be able to supply reactive oxygen for $\mathrm{CO}$ oxidation [117]. Nevertheless, $\mathrm{Au} / \mathrm{Al}_{2} \mathrm{O}_{3}$ $[82,109,118,119]$ and $\mathrm{Au} / \mathrm{SiO}_{2}[93,95,120-125]$ can be active for $\mathrm{CO}$ oxidation. For example, $\mathrm{Au} / \mathrm{SiO}_{2}$ prepared via gas-phase grafting of dimethyl gold acetylacetonate exhibited high activity in $\mathrm{CO}$ oxidation [120-122]. The grafting of alkylammonium ions [123] or aminosilane [124] onto mesoporous $\mathrm{SiO}_{2}$ could facilitate the uptake of a gold precursor on the grafted $\mathrm{SiO}_{2}$ surface, and the resulting catalysts were active for $\mathrm{CO}$ oxidation. Alternatively, gold particles capped with alkanethiol and alkoxysilane groups can undergo polymerization with tetraethyl orthosilicate to form an $\mathrm{Au} / \mathrm{SiO}_{2}$ material active for $\mathrm{CO}$ oxidation after calcination [125]. These interesting findings concerning the high activities of $\mathrm{Au} / \mathrm{Al}_{2} \mathrm{O}_{3}$ and $\mathrm{Au} / \mathrm{SiO}_{2}$ catalysts lead to the conclusion that a rigid classification into "active supports" and "inactive supports" cannot be the whole story.

Our group prepared $\mathrm{Au} /$ mesoporous $\mathrm{SiO}_{2}(\mathrm{Au} / \mathrm{SBA}-15$ and $\mathrm{Au} / \mathrm{MCM}-41$ ) catalysts using $\mathrm{Au}(\mathrm{en})_{2} \mathrm{Cl}_{3}$ (en = ethylenediamine) as the precursor (Fig. 1) $[75,83]$. The same precursor has also been used by others to prepare $\mathrm{Au} / \mathrm{NaHY}$ [126], $\mathrm{Au} / \mathrm{TiO}_{2}$ [35], $\mathrm{Au} / \mathrm{C}$ [127], and Au/clay mineral [128] catalysts. The Au/SBA-15 and $\mathrm{Au} / \mathrm{MCM}-41$ catalysts prepared at $\mathrm{pH}>8.0$ were found to be very active for low-temperature $\mathrm{CO}$ oxidation $[75,83]$. These catalysts are among the most active $\mathrm{Au} / \mathrm{SiO}_{2}$ catalysts reported; normally $\mathrm{Au} / \mathrm{SiO}_{2}$ catalysts reported in the literature do not show $\mathrm{CO}$ conversion when the reaction temperature is below $0{ }^{\circ} \mathrm{C}$. A similar preparation method was used by Zanella and coworkers to prepare gold nanoparticles supported on Aerosil fumed $\mathrm{SiO}_{2}$, but no reaction data were reported [129].

Our group also loaded gold onto Cab-O-Sil fumed $\mathrm{SiO}_{2}$ using $\mathrm{Au}(\mathrm{en})_{2} \mathrm{Cl}_{3}$ as the precursor [76]. Figure 2 shows the $\mathrm{CO}$ conversion as a function of reaction temperature and a TEM image of the catalyst. The catalyst had to be pretreated in $\mathrm{O}_{2}-\mathrm{He}$ at $500{ }^{\circ} \mathrm{C}$ to 

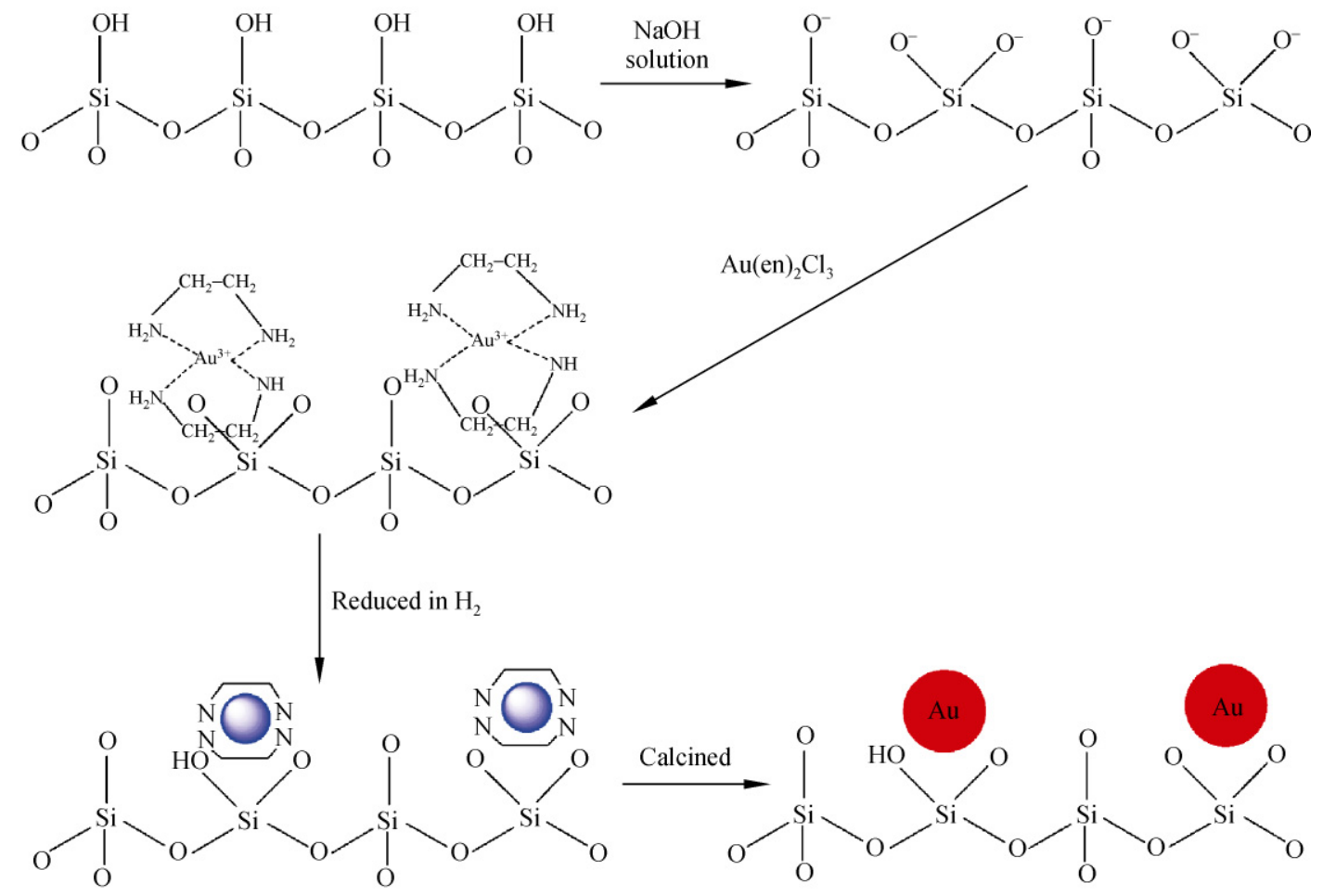

Figure 1 The preparation of $\mathrm{Au} / \mathrm{SiO}_{2}$ catalysts using $\mathrm{Au}(\mathrm{en})_{2} \mathrm{Cl}_{2}$ as the precursor in basic media. Reproduced by permission of Elsevier from Ref. [76]

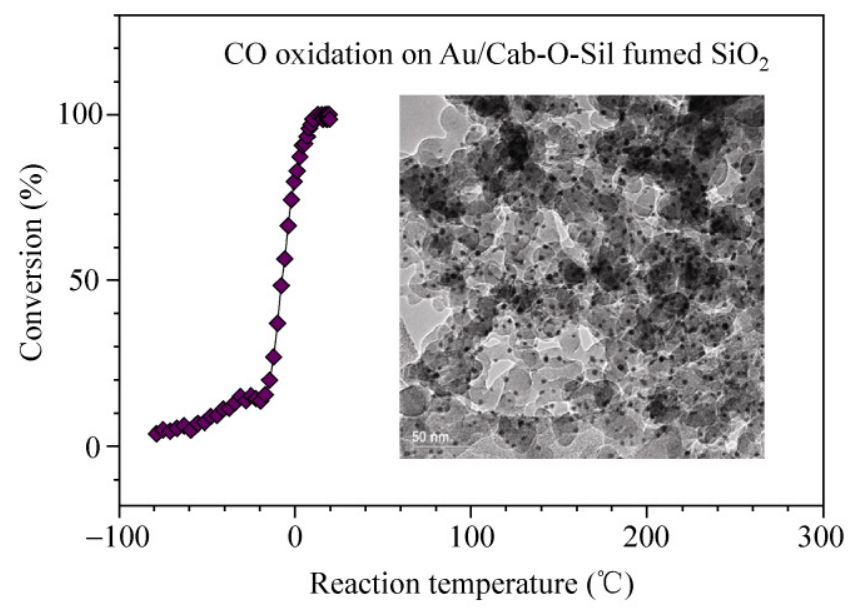

Figure 2 A conversion curve showing the performance of an $\mathrm{Au} /$ fumed $\mathrm{SiO}_{2}$ catalyst in $\mathrm{CO}$ oxidation. The inset shows a TEM image of the catalyst. Reproduced by permission of Elsevier from Ref. [76]

burn off residual organic species in order to obtain high activity, since the catalyst obtained without such a pretreatment was not active when the reaction temperature was below $300{ }^{\circ} \mathrm{C}$ [76]. The high activity of $\mathrm{Au} /$ fumed $\mathrm{SiO}_{2}$ below room temperature shows that highly active $\mathrm{Au} / \mathrm{SiO}_{2}$ catalysts can be obtained without employing the ordered pore channels of mesoporous $\mathrm{SiO}_{2}$ to stabilize small gold particles. Apparently, $\mathrm{SiO}_{2}$ is not inherently a bad support for gold catalysts, and many conventional methods have masked the real value of $\mathrm{SiO}_{2}$ as a support for the synthesis of active gold catalysts.

The development of $\mathrm{Au}(\mathrm{en})_{2} \mathrm{Cl}_{3}$-derived $\mathrm{Au} / \mathrm{SiO}_{2}$ catalysts has facilitated subsequent fundamental research. Wu et al. conducted a detailed FTIR study of $\mathrm{CO}$ oxidation on $\mathrm{Au} /$ fumed $\mathrm{SiO}_{2}[130,131]$. They found that the thermal treatment of $\mathrm{Au} / \mathrm{SiO}_{2}$ in $\mathrm{O}_{2}$ resulted in the formation of gold nanoparticles on the $\mathrm{SiO}_{2}$ support, as demonstrated by TEM. However, the predominant gold species on the gold surface is cationic gold, as probed by $\mathrm{CO}$ adsorption experiments and FTIR spectroscopy. Treatment with $\mathrm{H}_{2}$ or $\mathrm{CO}$ can reduce the cationic gold species and enhance the catalytic activity. They concluded that metallic gold species are responsible for the high catalytic activity of $\mathrm{Au} / \mathrm{SiO}_{2}$. They also found that the presence of 
water or hydroxyl groups can activate oxygen and facilitate the reduction of cationic gold species [130, 131]. This work is relevant, because it is based on very active, rather than not-so-active, $\mathrm{Au} / \mathrm{SiO}_{2}$ catalysts.

In other work, our group studied the thermal behavior of Au/SBA-15 after pretreatment at various temperatures, focusing on the structural aspects of both gold and the support [132]. It was found that $\mathrm{Au} / \mathrm{SBA}-15$ pretreated in $\mathrm{N}_{2}$ at $500{ }^{\circ} \mathrm{C}$ was active for $\mathrm{CO}$ oxidation below room temperature. In contrast, the catalyst pretreated at $900{ }^{\circ} \mathrm{C}$ was not active when the reaction temperature was below $100{ }^{\circ} \mathrm{C}$. This was not because there were no small gold nanoparticles present, but rather because these small gold nanoparticles were unexpectedly encapsulated by the restructured and crystallized $\mathrm{SiO}_{2}$ matrix, and such restructuring was facilitated by the exposure to $\mathrm{NaOH}$ used to adjust the $\mathrm{pH}$ value of aqueous $\mathrm{Au}(\mathrm{en})_{2} \mathrm{Cl}_{3}$ [132]. Strategic aqua regia leaching and SEM/TEM experiments were coupled to demonstrate the encapsulation of gold nanoparticles by the restructured $\mathrm{SiO}_{2}$ matrix. Gold nanoparticles could also be encapsulated in the restructured $\mathrm{SiO}_{2}$ matrix when using Cab-O-Sil fumed silica as the precursor, but that process only took place under much higher temperatures [132]. These findings provide a new explanation for the deactivation of supported $\mathrm{Au} / \mathrm{SiO}_{2}$ catalysts under high-temperature conditions; it should be noted, however, that the treatment temperature was much higher than those encountered in applied catalysis.

\section{$2.3 \mathrm{Au} /$ metal phosphates}

The majority of supported gold catalysts have been prepared by loading gold on metal oxide supports. However, metal salts have been seldom used as supports for making gold catalysts [73, 133-144]. This is so, not only because the bulk of gold catalysis papers have been following the classic work of Haruta and co-workers who used metal oxide supports [15-17], but also because compared with metal salts, metal oxides are more frequently encountered in heterogeneous catalysis. Among examples of metal saltbased gold catalysts, Lian et al. found that $\mathrm{Au} / \mathrm{BaCO}_{3}$ was active for $\mathrm{CO}$ oxidation at room temperature [134]. In addition, $\mathrm{Au} / \mathrm{Ca}_{10}\left(\mathrm{PO}_{4}\right)_{6}(\mathrm{OH})_{2}$ catalysts were found to be active for the water-gas shift reaction [133], CO oxidation [135], wet oxidation of organic compounds [136], deoxygenation of epoxides to give alkenes [144], and direct tandem synthesis of imines and oximes [138]. Li and coworkers found that an $\mathrm{Au} / \mathrm{LaVO}_{4}$ nanocomposite was active for $\mathrm{CO}$ oxidation when the reaction temperature was below $50{ }^{\circ} \mathrm{C}$ [137]. Our group found that gold nanoparticles supported on nanosized $\mathrm{LaPO}_{4}(6-8 \mathrm{~nm})$ were active for low-temperature $\mathrm{CO}$ oxidation [73]. The $\mathrm{LaPO}_{4}$ nanoparticles were obtained through delicate ultrasonic synthesis.

If $\mathrm{LaPO}_{4}$ can be used as a support for loading gold, then it is tempting to enquire whether other metal phosphates can be used for that purpose. This idea is similar to the development of superconductors where a metal component (e.g., La) of a superconductor is often replaced by another metal to see what happens. We systematically prepared an array of $\mathrm{Au} / \mathrm{M}-\mathrm{P}-\mathrm{O}$ catalysts via deposition-precipitation [86]. Apart from $\mathrm{Zr}-\mathrm{P}-\mathrm{O}$ which was prepared by precipitation, the other $\mathrm{M}-\mathrm{P}-\mathrm{O}$ supports were purchased from a commercial supplier. We found that $\mathrm{Au} / \mathrm{M}-\mathrm{P}-\mathrm{O}(\mathrm{M}=$ $\mathrm{Ca}, \mathrm{Fe}, \mathrm{Co}, \mathrm{Y}, \mathrm{La}, \mathrm{Pr}, \mathrm{Nd}, \mathrm{Sm}, \mathrm{Eu}, \mathrm{Ho}, \mathrm{Er})$ showed high $\mathrm{CO}$ conversions when the reaction temperature was below $50^{\circ} \mathrm{C}$, whereas $\mathrm{Au} / \mathrm{M}-\mathrm{P}-\mathrm{O}(\mathrm{M}=\mathrm{Mg}, \mathrm{Al}, \mathrm{Zn}, \mathrm{Zr})$ were not active (Fig. 3). Gold particles supported on $\mathrm{Zr}-\mathrm{P}-\mathrm{O}$ were quite large, whereas small gold nanoparticles could be well dispersed on some metal phosphate supports (Fig. 4). However, the size of the gold particles was not the only factor determining the catalytic activity, because $\mathrm{Au} / \mathrm{Mg}-\mathrm{P}-\mathrm{O}, \mathrm{Au} / \mathrm{Al}-\mathrm{P}-\mathrm{O}$, and $\mathrm{Au} / \mathrm{Zn}-\mathrm{P}-\mathrm{O}$ all had small gold nanoparticles, but they were not particularly active for $\mathrm{CO}$ oxidation [86]. Therefore, the so-called "support effect" is also important. The "support effect" is merely a vague term that describes the observed phenomenon, however, and it is still not clear why $\mathrm{Au} / \mathrm{Mg}-\mathrm{P}-\mathrm{O}$, $\mathrm{Au} / \mathrm{Al}-\mathrm{P}-\mathrm{O}$, and $\mathrm{Au} / \mathrm{Zn}-\mathrm{P}-\mathrm{O}$ were not active for $\mathrm{CO}$ oxidation.

In subsequent work, we prepared $\mathrm{Au} / \mathrm{M}-\mathrm{P}-\mathrm{O}(\mathrm{M}=\mathrm{Al}$, $\mathrm{Ca}, \mathrm{Fe}, \mathrm{Zn}, \mathrm{La}, \mathrm{Eu}, \mathrm{Ho}$ ) catalysts using dodecanethiolcapped gold nanoparticles as the precursor. These catalysts were pretreated in $\mathrm{O}_{2}-\mathrm{He}$ at 300 or $500{ }^{\circ} \mathrm{C}$ because we found that as-synthesized $\mathrm{Au} / \mathrm{La}-\mathrm{P}-\mathrm{O}$ (without any thermal pretreatment) was not active 


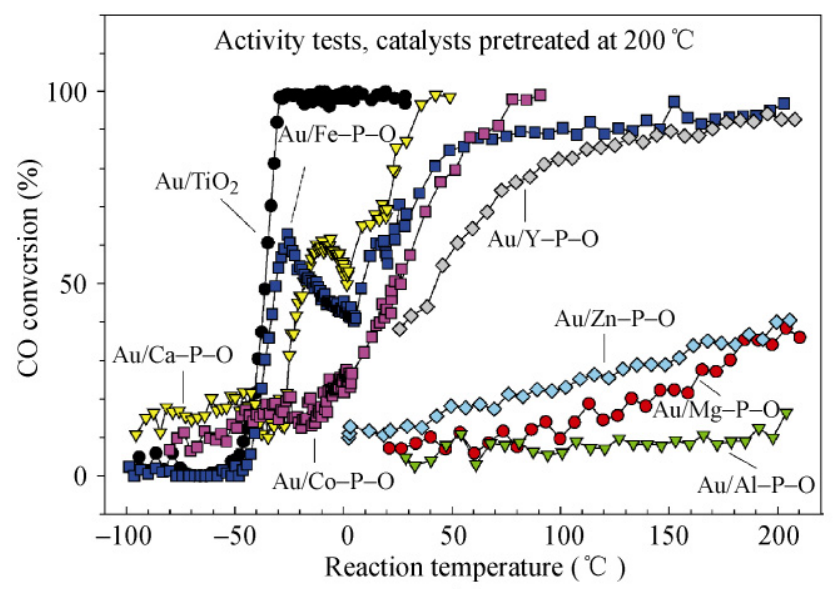

(a)

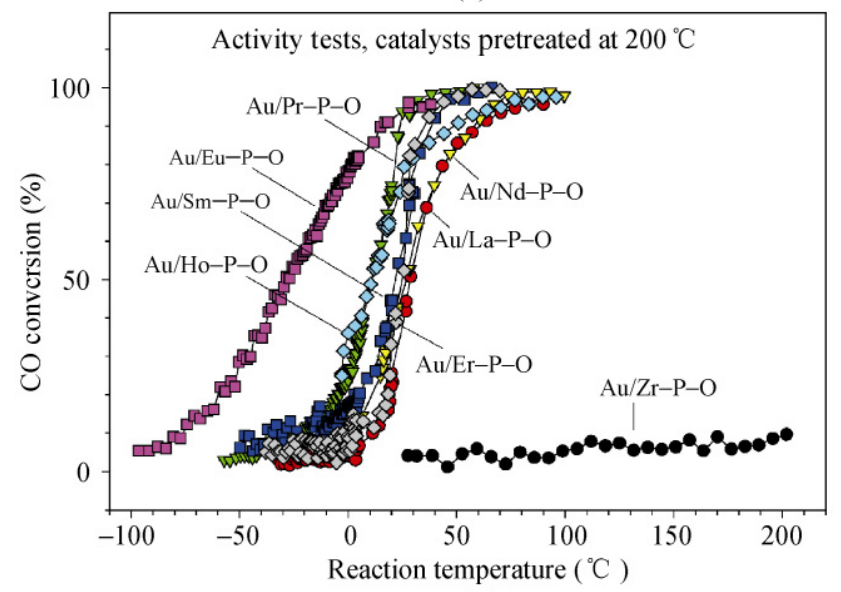

(b)

Figure $3 \mathrm{CO}$ conversion curves of $\mathrm{Au} / \mathrm{TiO}_{2}$ and $\mathrm{Au} / \mathrm{M}-\mathrm{P}-\mathrm{O}$ catalysts pretreated at $200{ }^{\circ} \mathrm{C}$. Reproduced by permission of Springer from Ref. [86]

when the reaction temperature was below $200{ }^{\circ} \mathrm{C}$, due to the influence of the capping agents, whereas the pretreatment at $300-500{ }^{\circ} \mathrm{C}$ was sufficient to activate the $\mathrm{Au} / \mathrm{La}-\mathrm{P}-\mathrm{O}$ catalyst. After testing all of these $\mathrm{Au} / \mathrm{M}-\mathrm{P}-\mathrm{O}$ samples, we found that only $\mathrm{Au} / \mathrm{La}-\mathrm{P}-\mathrm{O}$ was active for $\mathrm{CO}$ oxidation below room temperature [94]. Therefore, the activities of supported gold nanoparticles are not only related to the size of gold nanoparticles, but also influenced by the support and the preparation method. The presumed different levels of residual sulfur may also subtly influence the catalytic performance, although the residual sulfur contents were not measured. Considering the multiple functionalities of these catalysts (i.e., gold has its own catalytic function, and metal phosphates have acid-base properties [145]), we believe that

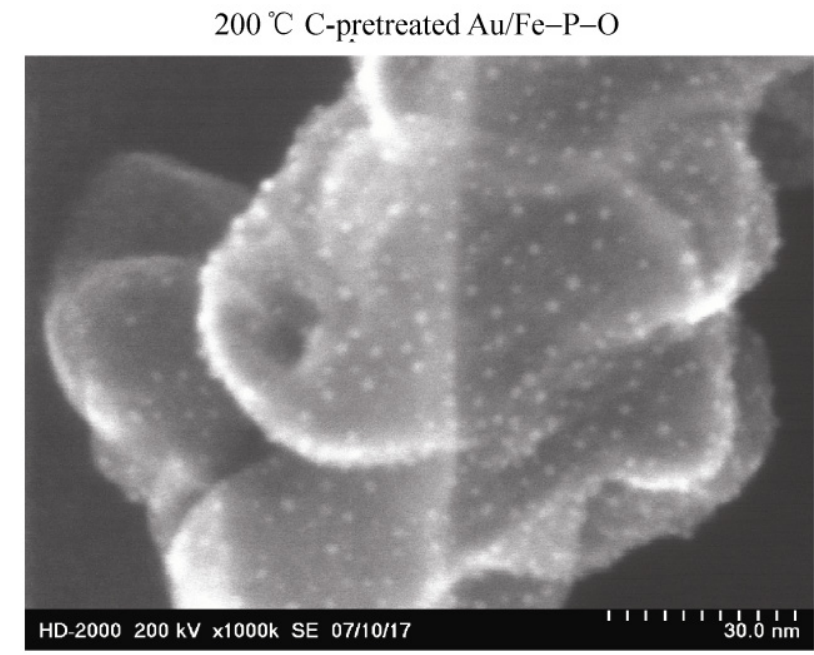

(a)

$200{ }^{\circ} \mathrm{C}$ C-pretreated $\mathrm{Au} / \mathrm{Eu}-\mathrm{P}-\mathrm{O}$

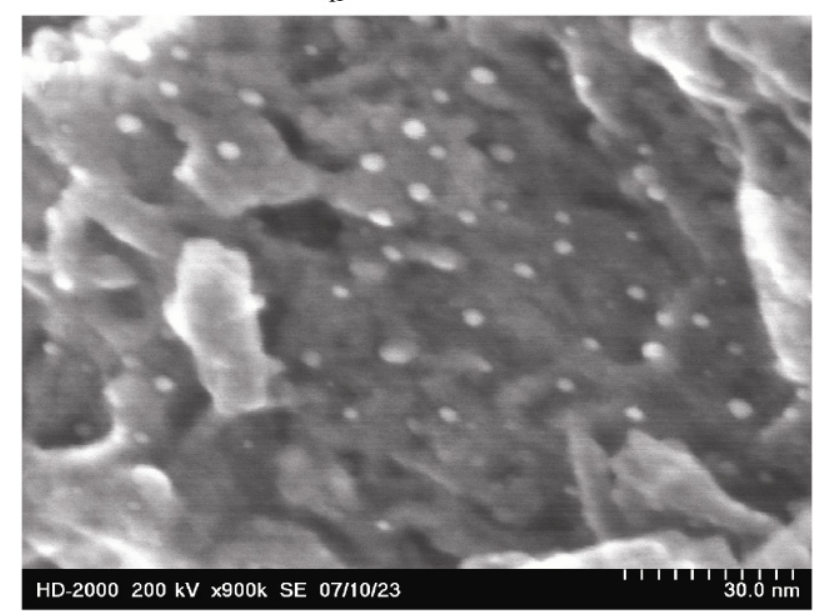

(b)

Figure 4 SEM images of $\mathrm{Au} / \mathrm{Fe}-\mathrm{P}-\mathrm{O}$ (A) and $\mathrm{Au} / \mathrm{Eu}-\mathrm{P}-\mathrm{O}$ (B) catalysts collected after pretreatment at $200{ }^{\circ} \mathrm{C}$ and subsequent reaction testing. Reproduced by permission of Springer from Ref. [86]

these catalysts may find applications in organic catalysis.

The development of $\mathrm{Au} / \mathrm{M}-\mathrm{P}-\mathrm{O}$ catalysts has provided new possibilities for fundamental research. Overbury and co-workers studied CO adsorption and oxidation on deposition-precipitation-derived $\mathrm{Au} / \mathrm{Fe}-\mathrm{P}-\mathrm{O}$ using FTIR spectroscopy [146]. They found that the catalyst pretreated in $\mathrm{O}_{2}$ at $200{ }^{\circ} \mathrm{C}$ contained both metallic and cationic gold species on the gold nanoparticle surfaces, and the subsequent exposure of the catalyst to $\mathrm{CO}$ at room temperature could reduce some, but not all, of the cationic gold species. The authors proved that metallic gold 
species on $\mathrm{Au} / \mathrm{Fe}-\mathrm{P}-\mathrm{O}$ were important for $\mathrm{CO}$ oxidation, and they identified two reaction channels: (1) a redox channel where the $\mathrm{FePO}_{4}$ support supplied active oxygen; (2) a direct channel involving either a Langmuir-Hinshelwood or Rideal-Eley mechanism [146]. It should be mentioned that the $\mathrm{Au} / \mathrm{Fe}-\mathrm{P}-\mathrm{O}$ catalyst made by deposition-precipitation contained a significant amount of residual $\mathrm{K}(9 \mathrm{wt} \%)$, and it is not clear whether the conclusion would still be valid if no $\mathrm{K}$ was present. The relative contributions of each channel are not clear, either. Even for the direct channel defined by the authors, it is still not clear whether a Langmuir-Hinshelwood mechanism or Rideal-Eley mechanism is dominant. In addition, the fact that two reaction channels (a redox channel and a direct channel) coexist on $\mathrm{Au} / \mathrm{Fe}-\mathrm{P}-\mathrm{O}$ does not necessarily mean that a catalyst requires two reaction channels to work properly, and it does not guarantee that the same result would be observed on other phosphate-based gold catalysts. Further systematic experiments are still needed to address these issues.

\subsection{Effect of the particle size of the support}

So far, we have described the development of active $\mathrm{Au} / \mathrm{SiO}_{2}$ and $\mathrm{Au} /$ metal phosphate catalysts by our group, mostly using commercial supports, but the effects of particle size and shape of the supports were often not addressed in our studies. Although $\mathrm{Au} /$ support catalysts have simple metal-support interfaces, the size and shape of support particles may have a profound influence on the performance of supported gold catalysts, and these parameters may be controlled with the help of materials synthesis techniques.

Rolison and co-workers fabricated $\mathrm{Au}-\mathrm{TiO}_{2}$ composite aerogels by adding gold colloids $(\sim 2 \mathrm{~nm})$ to a $\mathrm{TiO}_{2}$ sol before gelation [101, 102]. The size of the gold nanoparticles increased to $\sim 6 \mathrm{~nm}$ after calcination to remove the organic capping agents, and the size of the anatase crystallizes was about $10-12 \mathrm{~nm}$, comparable to that of the gold nanoparticles. The resulting catalyst was very active in CO oxidation. The authors proposed that gold nanoparticles can make contact with multiple domains of small sized $\mathrm{TiO}_{2}$ particles, leading to the creation of more interfacial active sites
[101, 102]. The amount of active sites is expected to be much less when the size of the support is much larger than that of gold nanoparticles.

To take advantage of the size effect of supports, Corma and co-workers used nanocrystalline $\mathrm{CeO}_{2}$ $\left(\sim 4 \mathrm{~nm}\right.$, surface area $\left.180 \mathrm{~m}^{2} / \mathrm{g}\right)$ as a support for gold, and demonstrated that the activity of the resulting gold catalyst in $\mathrm{CO}$ oxidation was two orders of magnitude higher than that of a gold catalyst prepared by loading gold on a conventional $\mathrm{CeO}_{2}$ support (surface area $70 \mathrm{~m}^{2} / \mathrm{g}$ ) [103]. They also found that nanocrystalline and mesostructured $\mathrm{Y}_{2} \mathrm{O}_{3}$ could be used as supports for making active gold catalysts [104]. In subsequent work, Corma and co-workers characterized $\mathrm{Au} /$ nanocrystalline $\mathrm{CeO}_{2}$ and $\mathrm{Au} /$ nanocrystalline $\mathrm{Y}_{2} \mathrm{O}_{3}$ in detail, and concluded that the existence of reactive peroxides at the gold-support interfaces was beneficial for enhancing the activity in CO oxidation $[147,148]$.

$\mathrm{Xu}$ and co-workers explored the size effect of zirconia in $\mathrm{Au} / \mathrm{ZrO}_{2}$ catalysts for $\mathrm{CO}$ oxidation [105]. They found that nanocomposite $\mathrm{Au} / \mathrm{ZrO}{ }_{2}$ catalysts with comparably sized gold particles $(4-5 \mathrm{~nm})$ and $\mathrm{ZrO}_{2}$ nanoparticles $(5-15 \mathrm{~nm}$ ) were much more active in $\mathrm{CO}$ oxidation than those containing similarly sized gold particle but larger $\mathrm{ZrO}_{2}$ particles $(40-200 \mathrm{~nm}$ ). They authors proposed that the reduction in the particle size of the support may not only create more contact between the metal and support, but also create more oxygen vacancies so that oxygen can be activated and migrate more easily [105]. Similarly, Shen and co-workers prepared several gold catalysts with similar gold particle sizes on $\mathrm{ZrO}_{2}$ supports with different particle sizes, and found that the activity in the water-gas shift reaction decreased when the size of $\mathrm{ZrO}_{2}$ support particles was increased [107].

In the above papers, the authors varied the particle size of the metal oxide supports, assuming that the sizes of gold nanoparticles on the different supports were not drastically different or at least not a major concern. Some TEM experiments were carried out to demonstrate that this assumption was valid. In contrast, Bokhimi and co-workers provided another perspective on the particle size effect of supports [106]. They prepared nanosized rutile $\mathrm{TiO}_{2}$, divided the sample into five parts, and heated each sample of the support at different temperatures $(300,400,500$, 
600 , and $700{ }^{\circ} \mathrm{C}$ ). The surface area of the $\mathrm{TiO}_{2}$ support decreased with increasing treatment temperature, whereas the crystallite size of the support increased from 10 to $76 \mathrm{~nm}$. Gold was loaded onto these supports using deposition-precipitation with urea, and the gold particle size was analyzed by XRD. It was found that the size of gold nanoparticles increased with increasing treatment temperature of the support. Therefore, larger rutile support particles with lower surface area may lead to higher local concentrations of gold species and fewer pinning centers on the support surface, resulting in more obvious sintering of the gold nanoparticles and lower activity in $\mathrm{CO}$ oxidation.

A similar observation was made by Dai and co-workers [99]. They prepared nanosized $\mathrm{FeO}_{x}$ (shown by $\mathrm{XRD}$ to be $\mathrm{Fe}_{3} \mathrm{O}_{4}$ ) by a hydrothermal method, and then calcined the material at different temperatures. The samples calcined at 550, 600, and $700^{\circ} \mathrm{C}$ were found to be mainly $\alpha-\mathrm{Fe}_{2} \mathrm{O}_{3}$, with decreasing surface areas $\left(35,30\right.$, and $14 \mathrm{~m}^{2} / \mathrm{g}$, respectively) and increasing particle sizes (as shown by XRD data). The gold nanoparticles on these supports also had increasing particle sizes (5.1, 7.1, and $7.6 \mathrm{~nm}$, respectively), thus leading to decreasing turnover frequency (TOF) in the oxidative dehydrogenation of 1,4-butanediol (250, 79 , and $21 \mathrm{~h}^{-1}$, respectively) [99]. The effect of the particle size of the supports is difficult to assess in these cases where both particle size of the support and the size of gold nanoparticles are varied.

\subsection{Effect of the particle morphology of the support}

The particle shape or morphology of the support has been found to influence the catalytic activity of the resulting gold catalysts. That is intriguing, considering that $\mathrm{Au}$ /support catalysts with differently shaped support particles have gold-support interfaces with similar chemical components. Although some earlier studies employed supports with exotic morphologies (e.g., nanotubes) to load gold, either no comparison with regular gold catalysts was made, or the catalytic activities of both the exotic gold catalysts and regular gold catalysts were low. Essentially, sometimes one is comparing a bad catalyst with a worse one, so we refrain from reviewing these inconclusive data.

Among conclusive and typical examples, Han and co-workers found that gold nanoparticles supported on $\gamma-\mathrm{Al}_{2} \mathrm{O}_{3}$ nanofibers were much more active than those supported on commercial $\gamma-\mathrm{Al}_{2} \mathrm{O}_{3}$ in $\mathrm{CO}$ oxidation [109]. The authors proposed, based on diffuse reflectance infrared Fourier transform spectroscopy (DRIFTS) data, that the $\mathrm{OH}$ groups bonding to $\gamma-\mathrm{Al}_{2} \mathrm{O}_{3}$ nanofibers may facilitate $\mathrm{CO}$ oxidation. Zhong and co-workers dispersed gold colloids onto porous $\alpha-\mathrm{Fe}_{2} \mathrm{O}_{3}$ nanorods, and found that the resulting catalyst was more active than gold nanoparticles dispersed on commercial $\alpha-\mathrm{Fe}_{2} \mathrm{O}_{3}$ [45]. Cao and coworkers found that the activity of $\mathrm{Au} / \beta-\mathrm{MnO}_{2}$ nanorods was higher than that of $\mathrm{Au} / \mathrm{commercial} \beta-\mathrm{MnO}_{2}$ particulates in the solvent-free aerobic oxidation of alcohol [111]. The authors ascribed the high activity of $\mathrm{Au} / \mathrm{\beta}-\mathrm{MnO}_{2}$ nanorods to the beneficial presence of more cationic gold species and surface oxygen vacancies resulting from the strong interaction between gold and the reactive surface of the $\mathrm{MnO}_{2}$ nanorods.

Flytzani-Stephanopoulos and co-workers synthesized $\mathrm{CeO}_{2}$ nanorods, nanocubes, and nanopolyhedra via hydrothermal synthesis, and subsequently loaded gold via deposition-precipitation [110]. As shown in Fig. 5, the width of the $\mathrm{CeO}_{2}$ nanorods was $10.1 \mathrm{~nm} \pm$ $2.8 \mathrm{~nm}$, and their length was in the range $50-200 \mathrm{~nm}$. The length of the sides of the $\mathrm{CeO}_{2}$ nanocubes was $29.5 \mathrm{~nm} \pm 10.6 \mathrm{~nm}$, and the diameter of the $\mathrm{CeO}_{2}$ nanopolyhedra was $11.0 \mathrm{~nm} \pm 2.1 \mathrm{~nm}$. The nanorods had exposed (110) and (100) crystal planes, the nanocubes had exposed (100) crystal planes, and the nanopolyhedra had exposed (111) and (100) crystal planes. Interestingly, the authors found that the activity in the water-gas shift reaction followed the sequence $\mathrm{Au} / \mathrm{CeO}_{2}$ nanorods $>\mathrm{Au} / \mathrm{CeO}_{2}$ nanopolyhedra $>\mathrm{Au} / \mathrm{CeO}_{2}$ nanocubes. The lowest activity of the $\mathrm{Au} / \mathrm{CeO}_{2}$ nanocubes was explained by the predominance of metallic gold species on the support surface and the negligible metal-support interaction, as demonstrated by X-ray photoelectron spectroscopy (XPS) and hydrogen-temperature programmed reduction $\left(\mathrm{H}_{2}-\mathrm{TPR}\right)$ [110]. Subsequently, Yuan and co-workers found that the activity in the preferential $\mathrm{CO}$ oxidation in $\mathrm{H}_{2}$-rich gas followed the same trend mentioned above [112, 114]. Cao and co-workers demonstrated that the activity of $\mathrm{Au} / \mathrm{CeO}_{2}$ nanorods in $\mathrm{CO}$ oxidation was much higher than that of $\mathrm{Au} / \mathrm{CeO}_{2}$ nanoparticles [113]. 


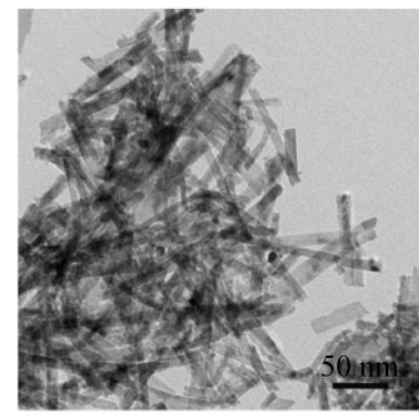

(a)

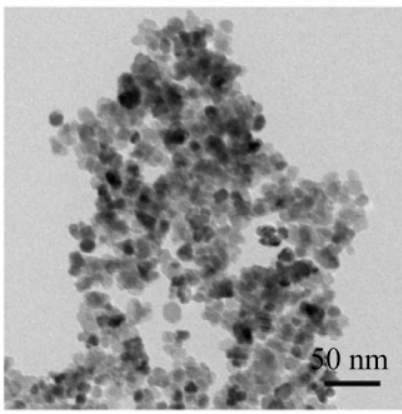

(c)

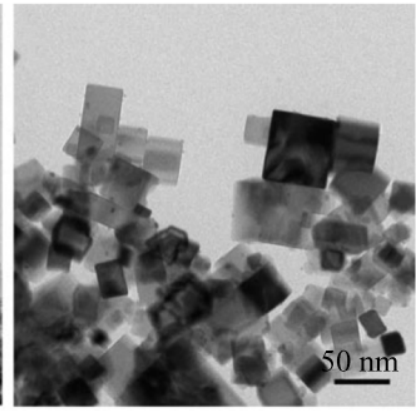

(b)

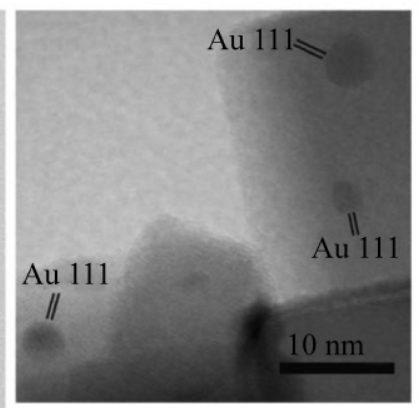

(d)
Figure 5 TEM (a)-(c) and HRTEM (d) images of 1\% Au on $\mathrm{CeO}_{2}$ nanorods (a), $\mathrm{CeO}_{2}$ nanocubes ((b), (d)), and $\mathrm{CeO}_{2}$ nanopolyhedra (c). Reproduced by permission of Wiley-VCH from Ref. [110]

$\mathrm{Li}$ and co-workers synthesized spindle-shaped $\mathrm{Fe}_{2} \mathrm{O}_{3}$ nanoparticles using acidic amino acid additives, and they also prepared rhombohedral $\mathrm{Fe}_{2} \mathrm{O}_{3}$ nanoparticles using basic amino acids [108]. The particle size of the $\mathrm{Fe}_{2} \mathrm{O}_{3}$ supports could also be controlled by changing the concentration of the amino acids. They loaded gold nanoparticles on these supports by colloidal deposition, and concluded that the spindleshaped $\mathrm{Au} / \mathrm{Fe}_{2} \mathrm{O}_{3}$ showed higher activity than the rhombohedral $\mathrm{Au} / \mathrm{Fe}_{2} \mathrm{O}_{3}$, although the sizes of gold nanoparticles on the two supports were comparable (3-4 nm) and the particle sizes of the supports were also very similar (about 80 and $77 \mathrm{~nm}$, respectively). The authors suggested that the rough surfaces or edges or defects of the spindle-shaped $\mathrm{Fe}_{2} \mathrm{O}_{3}$ may lead to the higher catalytic activity.

Although variations in catalytic activity are clearly observed in the above-mentioned studies, the fundamental reasons for the observed shape effect are still not clear. Theoretical studies are still needed to determine why the shape of support particles exerts such a dramatic influence on the catalytic performance of the resulting gold catalysts. Besides, the preparation of solid supports with different particle shapes often involves different preparation methods, different synthesis details, and different levels of residual organic or inorganic species on support surfaces. It is difficult to exclude the possibility that these differences influence the catalytic activity. The same critical concerns are also valid when seeing the claim that different crystal phases of $\mathrm{TiO}_{2}$ (anatase, rutile, brookite) influence the activity of supported gold catalysts [65]. Although the difference in catalytic activity is real, one should question whether the difference in catalytic activity as a function of the crystal phase of support is intrinsic, i.e., whether the catalytic activities of $\mathrm{Au} / \mathrm{brookite}$ (or $\mathrm{Au} /$ anatase, $\mathrm{Au} / \mathrm{rutile)}$ catalysts themselves would be the same, if several brookite (or anatase, rutile) supports prepared by different methods were used to load gold. There may be an interplay between size effects, shape effects, crystal phase effects, impurity effects, and other unknown factors such as different synthesis procedures or synthesis details, and it is dangerous to attribute the difference in catalytic activity to one single factor.

\section{Interfacial structure engineering}

\subsection{General considerations}

The majority of reported gold catalysts have been prepared by loading gold nanoparticles on commercially available supports. To enhance the diversity of available catalysts, tune the catalytic properties, and establish structure-property correlations, it is desirable to build up more complex catalytic architectures by incorporating additional components (e.g., modifiers, additives). The promotion of heterogeneous catalysts in this way is standard practice in the field of heterogeneous catalysis [149].

Three strategies have been adopted to make such heterostructured gold catalysts, depending on the sequence of introducing gold and the modifier or additive. In the pre-modification strategy, a catalyst support is first treated by a modifier, and gold is subsequently deposited onto the pre-modified support. In the post-modification strategy, gold is loaded onto 
a support, and a modifier is subsequently introduced. In the co-addition strategy, gold and an inorganic component are simultaneously deposited onto the support. Therefore, metal-support, metal-modifier, and modifier-support interfaces are all constructed. As a result, new active sites may be created, and gold nanoparticles may be stabilized at these relatively complex interfaces.

\subsection{Pre-modification of supports}

\subsubsection{Pre-modification of $\mathrm{SiO}_{2}$ supports}

$\mathrm{SiO}_{2}$ is not suitable for loading gold nanoparticles via deposition-precipitation because $\mathrm{SiO}_{2}$ has a low isoelectric point (IEP $\sim 2$ ), so the $\mathrm{Au}(\mathrm{OH})_{4}^{-}$species cannot effectively adsorb onto the negatively charged $\mathrm{SiO}_{2}$ surface under basic conditions. One way to overcome this obstacle is to introduce a highisoelectric-point metal oxide onto the $\mathrm{SiO}_{2}$ surface. As a result, $\mathrm{Au}(\mathrm{OH})_{4}^{-}$species may adsorb more efficiently onto the functionalized support.

Our group modified mesoporous and fumed $\mathrm{SiO}_{2}$ surfaces with amorphous $\mathrm{TiO}_{2}$ via a surface-sol-gel technique under non-aqueous conditions (Fig. 6) [66, 72]. $\mathrm{Ti}\left(\mathrm{OC}_{4} \mathrm{H}_{9}\right)_{4}$ was used as the precursor to load surface $\mathrm{TiO}_{2}$, and methanol and toluene were used as the solvents. Gold nanoparticles were loaded onto $\mathrm{TiO}_{2} / \mathrm{SiO}_{2}$, and the activity of $\mathrm{Au} / \mathrm{TiO}_{2} / \mathrm{SiO}_{2}$ in $\mathrm{CO}$ oxidation was found to be much higher than that of $\mathrm{Au} / \mathrm{SiO}_{2}$. The enhanced activity is not only due to the higher gold loading of $\mathrm{Au} / \mathrm{TiO}_{2} / \mathrm{SiO}_{2}$ compared to that of $\mathrm{Au} / \mathrm{SiO}_{2}$, but also due to the presence of an active $\mathrm{Au}-\mathrm{TiO}_{2}$ interface. The resulting $\mathrm{Au} / \mathrm{TiO} \mathrm{S}_{2} / \mathrm{SiO}_{2}$ catalysts should not be classified as " $\mathrm{SiO}_{2}$ supported gold catalysts", and may be more appropriately described as " $\mathrm{SiO}_{2}$-based gold catalysts". Since the presence of $\mathrm{TiO}_{2}$ increases the catalytic activity and the $\mathrm{Au} / \mathrm{TiO}_{2} / \mathrm{SiO}_{2}$ catalyst is merely an $\mathrm{Au} / \mathrm{TiO}_{2}$ catalyst supported on $\mathrm{SiO}_{2}$, one may question why $\mathrm{Au} / \mathrm{TiO}_{2}$ was not used for $\mathrm{CO}$ oxidation in the first place and why we need $\mathrm{Au} / \mathrm{TiO}_{2} / \mathrm{SiO}_{2}$. To respond to these questions, we comment here that this work demonstrates a new way to make functionalized mesostructured catalysts, and these catalysts with their nanosized pores may be useful for shapeselective organic catalysis.

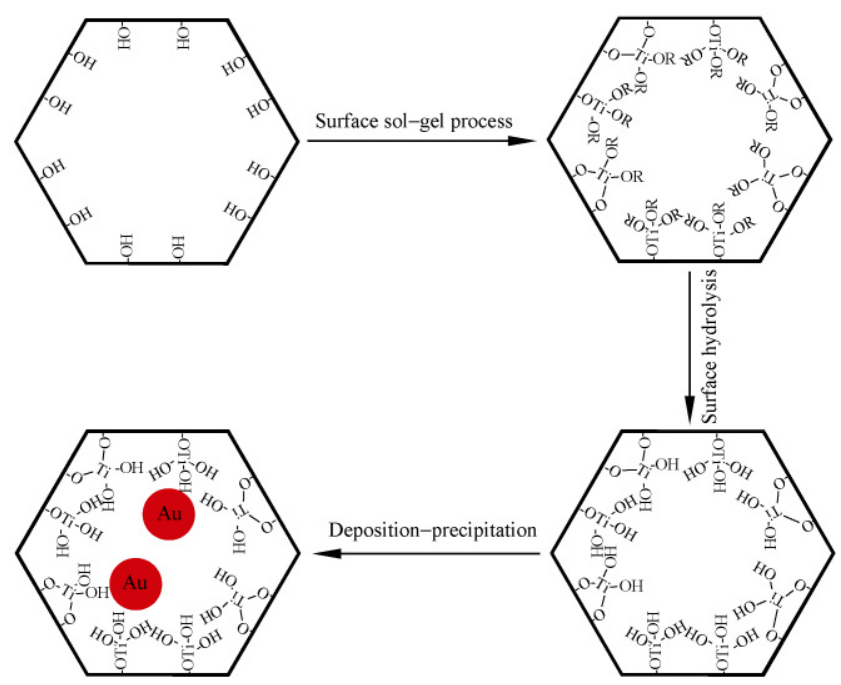

Figure 6 The modification of mesoporous $\mathrm{SiO}_{2}$ by $\mathrm{TiO}_{2}$ using a surface-sol-gel approach for loading gold nanoparticles. Reproduced by permission of the American Chemical Society from Ref. [66]

The pre-modification strategy has also been used by others to prepare $\mathrm{SiO}_{2}$-based gold catalysts, such as $\mathrm{Au} / \mathrm{Al}_{2} \mathrm{O}_{3} / \mathrm{SiO}_{2}$ [72, 150], $\mathrm{Au} / \mathrm{TiO}_{2} / \mathrm{SiO}_{2}$ [151-165], $\mathrm{Au} / \mathrm{FeO}_{x} / \mathrm{SiO}_{2}$ [150, 166, 167], $\mathrm{Au} / \mathrm{CoO}_{x} / \mathrm{SiO}_{2}$ [150, 168-171], $\mathrm{Au} / \mathrm{ZnO} / \mathrm{SiO}_{2}$ [172], $\mathrm{Au} / \mathrm{LaO}_{x} / \mathrm{SiO}_{2}$ [168], and $\mathrm{Au} / \mathrm{CeO}_{2} / \mathrm{SiO}_{2}[159,173-175]$. Even though the addition of certain promoters can enhance the catalytic activity, most of the resulting catalysts were not particularly active in $\mathrm{CO}$ oxidation, presumably because the deposition-precipitation method does not work well for making active $\mathrm{Au} / \mathrm{SiO}_{2}$ catalysts. Therefore, the development of catalysts based on a better starting point (such as highly active $\mathrm{Au} / \mathrm{SiO}_{2}[75,76]$ ) should be considered.

Our group prepared a series of $\mathrm{M}_{x} \mathrm{O}_{y} / \mathrm{SiO}_{2}(\mathrm{M}=\mathrm{Mg}$, $\mathrm{Al}, \mathrm{Fe}, \mathrm{Ni}, \mathrm{Zn}, \mathrm{Ba}, \mathrm{La}, \mathrm{Ce}$ ) supports either by impregnation or by using $\mathrm{NaOH}$ as the precipitating agent [76]. A $\mathrm{TiO}_{2} / \mathrm{SiO}_{2}$ support was prepared by grafting a $\mathrm{Ti}_{16} \mathrm{O}_{16}(\mathrm{OEt})_{32}$ precursor onto $\mathrm{SiO}_{2}$. Gold was loaded onto these functionalized supports using $\mathrm{Au}(\mathrm{en})_{2} \mathrm{Cl}_{3}$ as the precursor. It was found that $\mathrm{Au} / \mathrm{FeO}_{x} / \mathrm{SiO}_{2}$, $\mathrm{Au} / \mathrm{TiO}_{2} / \mathrm{SiO}_{2}$, and $\mathrm{Au} / \mathrm{BaO} / \mathrm{SiO}_{2}$ were more active in low-temperature $\mathrm{CO}$ oxidation than $\mathrm{Au} / \mathrm{SiO}_{2}$ with a comparable gold loading [76]. However, the local interfacial structures were not characterized, and the reasons for the activity enhancement were not clarified. It is not clear whether the promotional effect is due to 
the modification of the oxidation state of gold, the size of gold nanoparticles, or the creation of new gold-modifier interfaces.

\subsubsection{Pre-modification of $\mathrm{TiO}_{2}$ supports}

$\mathrm{Au} / \mathrm{TiO}_{2}$ is very active for $\mathrm{CO}$ oxidation below room temperature, but gold nanoparticles on $\mathrm{TiO}_{2}$ can sinter easily at high temperature, even more easily than those on $\mathrm{SiO}_{2}$ [176]. Our group found that modification of the $\mathrm{TiO}_{2}$ support by amorphous $\mathrm{Al}_{2} \mathrm{O}_{3}$ followed by loading of gold could alleviate the sintering problem [71]. The $\mathrm{Al}_{2} \mathrm{O}_{3} / \mathrm{TiO}_{2}$ support was synthesized by surface-sol-gel processing of $\mathrm{Al}$ (sec$\left.\mathrm{OC}_{4} \mathrm{H}_{9}\right)_{3}$ on $\mathrm{TiO}_{2}$ followed by controlled hydrolysis. Whereas $\mathrm{Au} / \mathrm{TiO}_{2}$ underwent significant thermal deactivation at $500{ }^{\circ} \mathrm{C}$, ascribed to the agglomeration of gold particles, $\mathrm{Au} / \mathrm{Al}_{2} \mathrm{O}_{3} / \mathrm{TiO}_{2}$ underwent minimal thermal deactivation at the same temperature. This can be ascribed to the stabilization of gold nanoparticles by the amorphous $\mathrm{Al}_{2} \mathrm{O}_{3}$ coating, as clearly shown by TEM images.

Since $\mathrm{Au} / \mathrm{Al}_{2} \mathrm{O}_{3} / \mathrm{TiO}_{2}$ is a successful catalyst, it is interesting to know whether other metal oxide additives can play a role similar to $\mathrm{Al}_{2} \mathrm{O}_{3}$. In subsequent work, we loaded various metal oxide additives onto the $\mathrm{TiO}_{2}$ support via excess-solution impregnation of soluble precursors followed by calcination, and established that $\mathrm{Au} / \mathrm{M}_{x} \mathrm{O}_{y} / \mathrm{TiO}_{2}(\mathrm{M}=\mathrm{Ca}, \mathrm{Ni}, \mathrm{Zn}, \mathrm{Ga}, \mathrm{Y}$, $\mathrm{Zr}, \mathrm{La}, \mathrm{Pr}, \mathrm{Nd}, \mathrm{Sm}, \mathrm{Eu}, \mathrm{Gd}, \mathrm{Dy}, \mathrm{Ho}, \mathrm{Er}$, or $\mathrm{Yb}$ ) all retained significant activity in $\mathrm{CO}$ oxidation at ambient temperature even after pretreatment at $500{ }^{\circ} \mathrm{C}$ [78]. The stabilizing effect of these metal oxide additives was demonstrated by XRD and TEM. As shown in Fig. 7, $\mathrm{Au} / \mathrm{TiO}_{2}$ collected after pretreatment at $500{ }^{\circ} \mathrm{C}$ and subsequent use in the water-gas shift reaction contained mostly large gold particles, whereas $\mathrm{Au} / \mathrm{ZnO} / \mathrm{TiO}_{2}$ retained small gold nanoparticles after pretreatment at $500{ }^{\circ} \mathrm{C}$ [92]. Although we ascribed the difference in catalytic activity to the size of the gold nanoparticles in our publications [78, 92], we now believe that different metal oxide additives may also have different redox properties, and may even change the oxidation states of gold and create new active sites. The pre-modification strategy has also been used by others to prepare $\mathrm{TiO}_{2}$-based gold catalysts, such as $\mathrm{Au} / \mathrm{MgO} / \mathrm{TiO}_{2}$ [177], $\mathrm{Au} / \mathrm{MnO}_{2} / \mathrm{TiO}_{2}$ [178],

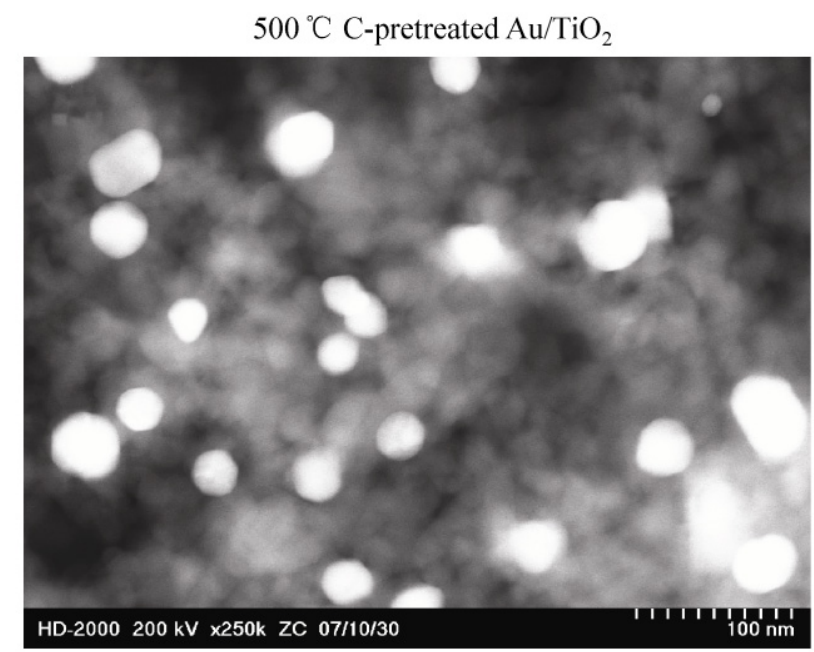

(a)

$500{ }^{\circ} \mathrm{C}$ C-pretreated $\mathrm{Au} / \mathrm{ZnO} / \mathrm{TiO}_{2}$

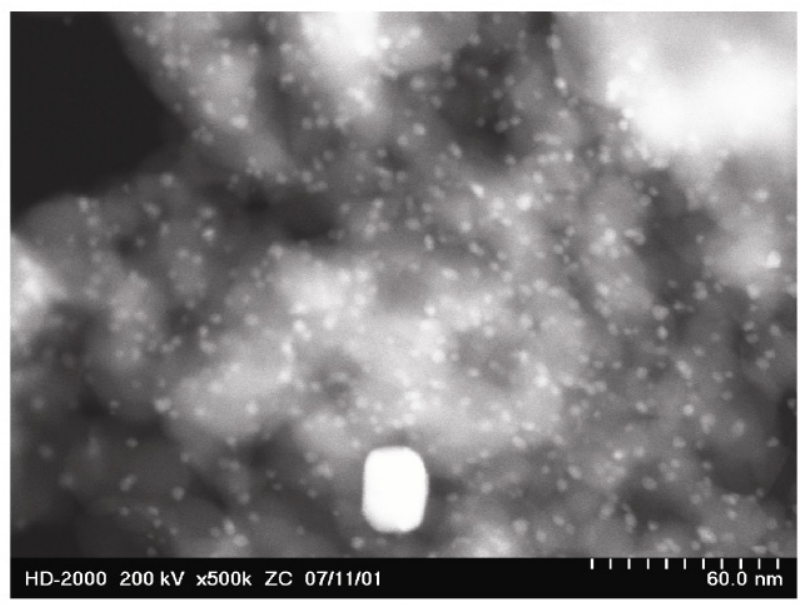

(b)

Figure 7 Dark-field TEM images of $\mathrm{Au} / \mathrm{TiO}_{2}$ and $\mathrm{Au} / \mathrm{ZnO} / \mathrm{TiO}{ }_{2}$ catalysts collected after pretreatment at $500{ }^{\circ} \mathrm{C}$ followed by use in the water-gas shift reaction. Reproduced by permission of Springer from Ref. [92]

$\mathrm{Au} / \mathrm{FeO}_{x} / \mathrm{TiO}_{2}[179,180], \mathrm{Au} / \mathrm{CuO}_{x} / \mathrm{TiO}_{2}$ [181], $\mathrm{Au} / \mathrm{ZnO} /$ $\mathrm{TiO}_{2}$ [182], and $\mathrm{Au} / \mathrm{CeO}_{x} / \mathrm{TiO}_{2}[183,184]$. However, the local interfacial structures were often not characterized sufficiently. In addition, we need to point out that the stabilization of metal nanoparticles by adding a suitable modifier on a support is a general phenomenon. In 1990, Xie and Tang mentioned in a review that the modification of an $\mathrm{Al}_{2} \mathrm{O}_{3}$ support by $\mathrm{La}_{2} \mathrm{O}_{3}$ could stabilize metallic nickel particles for $\mathrm{CO}$ methanation [185].

The development of $\mathrm{Au} / \mathrm{M}_{x} \mathrm{O}_{y} / \mathrm{TiO}_{2}$ catalysts has led to some subsequent fundamental research. By means of density functional theory (DFT) calculations,

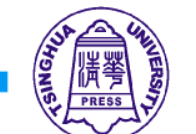

黑 Springer 
Liu and co-workers found that the binding of gold on $\mathrm{Al}_{2} \mathrm{O}_{3} / \mathrm{TiO}_{2}$ was much stronger than that of gold on $\mathrm{TiO}_{2}$ [186]. Although they assumed that $\mathrm{Al}_{2} \mathrm{O}_{3}$ was dispersed homogeneously on $\mathrm{TiO}_{2}$ support when calculating the binding energy, and the conclusions at that point were consistent with the proposed antisintering behavior of $\mathrm{Au} / \mathrm{Al}_{2} \mathrm{O}_{3} / \mathrm{TiO}_{2}$ catalysts, their calculations also showed that the activity of $\mathrm{CO}$ oxidation on $\mathrm{Au} / \mathrm{Al}_{2} \mathrm{O}_{3} / \mathrm{TiO}_{2}$ was low if $\mathrm{TiO}_{2}$ was fully coated by $\mathrm{Al}_{2} \mathrm{O}_{3}$. Therefore, they concluded that the $\mathrm{TiO}_{2}$ should not be fully coated by $\mathrm{Al}_{2} \mathrm{O}_{3}$, so that gold nanoparticles are in contact with both the $\mathrm{TiO}_{2}$ support and $\mathrm{Al}_{2} \mathrm{O}_{3}$ patches [186]. Although we think that the coating of $\mathrm{Al}_{2} \mathrm{O}_{3}$ on $\mathrm{TiO}_{2}$ support may not be homogeneous and several $\mathrm{Au} / \mathrm{Al}_{2} \mathrm{O}_{3} / \mathrm{TiO}_{2}$ catalysts with a range of $\mathrm{Al}_{2} \mathrm{O}_{3}$ contents are all active catalysts [78], we need to point out that the assumption in the calculations that the $\mathrm{Au}-\mathrm{Al}_{2} \mathrm{O}_{3}$ interface is not active for $\mathrm{CO}$ oxidation [186] should be treated with caution, because experimentally, $\mathrm{Au} / \mathrm{Al}_{2} \mathrm{O}_{3}$ catalysts were found to be active for $\mathrm{CO}$ oxidation $[82,109,118$, 119]. Indeed, Liu and co-workers recently found that the presence of moisture could assist the activation of oxygen, thus promoting $\mathrm{CO}$ oxidation on $\mathrm{Au} / \mathrm{Al}_{2} \mathrm{O}_{3}$ [187].

Hagaman and co-workers conducted a solid-state ${ }^{27} \mathrm{Al}$ magic angle spinning (MAS) and triple quantum magic angle spinning (3QMAS) NMR investigation of a series of $\mathrm{Al}_{2} \mathrm{O}_{3} / \mathrm{TiO}_{2}$ supports with different $\mathrm{Al}_{2} \mathrm{O}_{3}$ loadings which were calcined at different temperatures [188]. These supports were used in our previous work [78] to prepare $\mathrm{Au} / \mathrm{Al}_{2} \mathrm{O}_{3} / \mathrm{TiO}_{2}$ catalysts. The highest catalytic activity and the smallest gold particle size reported in our previous paper [78] showed a good correlation with maximum number of monolayer-type octahedral $\mathrm{Al}_{2} \mathrm{O}_{3}$ species on the $\mathrm{TiO}_{2}$ support. It was also found that there was no difference between the dispersed $\mathrm{Al}_{2} \mathrm{O}_{3}$ species obtained by excess-solution impregnation or surfacesol-gel methods [188].

\subsubsection{Pre-modification of $\mathrm{Al}_{2} \mathrm{O}_{3}$ supports}

The pre-modification of $\mathrm{Al}_{2} \mathrm{O}_{3}$ supports by metal oxides followed by assembly of gold nanoparticles has also been studied. Gold catalysts based on oxidemodified $\mathrm{Al}_{2} \mathrm{O}_{3}$ supports include $\mathrm{Au} / \mathrm{MgO} / \mathrm{Al}_{2} \mathrm{O}_{3}$
[189-191], $\mathrm{Au} / \mathrm{MnO}_{x} / \mathrm{Al}_{2} \mathrm{O}_{3}$ [192-194], $\mathrm{Au} / \mathrm{FeO}_{x} / \mathrm{Al}_{2} \mathrm{O}_{3}$ [192-196], $\mathrm{Au} / \mathrm{CoO}_{x} / \mathrm{Al}_{2} \mathrm{O}_{3}$ [192, 194], $\mathrm{Au} / \mathrm{ZnO} / \mathrm{Al}_{2} \mathrm{O}_{3}$ [192, 197], $\mathrm{Au} / \mathrm{SnO}_{x} / \mathrm{Al}_{2} \mathrm{O}_{3}$ [198], $\mathrm{Au} / \mathrm{La}_{2} \mathrm{O}_{3} / \mathrm{Al}_{2} \mathrm{O}_{3}$ [199], and $\mathrm{Au} / \mathrm{CeO}_{2} / \mathrm{Al}_{2} \mathrm{O}_{3}$ [200-203]. In particular, Nieuwenhuys and coworkers tested the performance of $\mathrm{Al}_{2} \mathrm{O}_{3}$-based gold catalysts in a number of reactions, and established that $\mathrm{MgO} / \mathrm{Al}_{2} \mathrm{O}_{3}$ [189], $\mathrm{BaO} / \mathrm{Al}_{2} \mathrm{O}_{3}$ [204, 205], $\mathrm{ZnO} / \mathrm{Al}_{2} \mathrm{O}_{3}$ [197], and $\mathrm{ZrO}_{x} / \mathrm{Al}_{2} \mathrm{O}_{3}$ [197] could all stabilize gold nanoparticles against thermal sintering.

Our group modified various $\mathrm{Al}_{2} \mathrm{O}_{3}$ supports (boehmite $\mathrm{AlOOH}$, amorphous $\mathrm{Al}(\mathrm{OH})_{3}$, and highly crystalline $\gamma-\mathrm{Al}_{2} \mathrm{O}_{3}$ ) by amorphous $\mathrm{TiO}_{2}$ via a surface-sol-gel method, and then loaded gold nanoparticles via deposition-precipitation [82]. The activity in $\mathrm{CO}$ oxidation was significantly enhanced after pretreating the $\mathrm{Au} / \mathrm{TiO}_{2} / \mathrm{Al}_{2} \mathrm{O}_{3}$ catalysts at high temperature. The role of the dispersed amorphous $\mathrm{TiO}_{2}$ is not to stabilize gold nanoparticles, because the gold nanoparticles on pristine $\mathrm{Al}_{2} \mathrm{O}_{3}$ supports were also small after high-temperature pretreatment. Rather, we propose that its role is to create an $\mathrm{Au}-\mathrm{TiO}_{2}$ interface which is more active than $\mathrm{Au}-\mathrm{Al}_{2} \mathrm{O}_{3}$ for $\mathrm{CO}$ oxidation.

\subsubsection{Pre-modification of carbon supports}

Although $\mathrm{Au} / \mathrm{C}$ catalysts are useful for certain liquid-phase oxidation reactions [206, 207], they are generally not active for gas-phase $\mathrm{CO}$ oxidation. Carbon surfaces are acidic, and they have low isoelectric points. In addition, carbon materials are reducing agents, and they can react with $\mathrm{Au}^{3+}$ to form large gold particles during synthesis [206]. We loaded gold onto graphite via deposition-precipitation, and found that the catalyst was not active for $\mathrm{CO}$ oxidation [80]. The XRD pattern of the spent catalyst showed sharp peaks corresponding to metallic gold, implying that the supported gold particles were large. However, the XRD results were misleading, because our TEM data showed that there were predominantly small gold nanoparticles on the support surfaces, together with a much smaller number of large gold chunks. Therefore, the fact that $\mathrm{Au} / \mathrm{C}$ catalysts are not active for $\mathrm{CO}$ oxidation cannot be solely explained by the absence of small gold nanoparticles.

To promote the catalytic activity, we first modified 
carbon supports by immersing them in aqueous $\mathrm{KMnO}_{4}$. In this case, carbon is a sacrificial reductant, and undergoes a self-limiting reaction with aqueous $\mathrm{KMnO}_{4}$ to form a decoration of $\mathrm{MnO}_{x}$ on the surface (i.e., $4 \mathrm{KMnO}_{4}+3 \mathrm{C}+2 \mathrm{H}_{2} \mathrm{O} \rightarrow 4 \mathrm{MnO}_{2}+3 \mathrm{CO}_{2}+4 \mathrm{KOH}$ ) [208]. We then loaded gold onto the $\mathrm{MnO}_{x} / \mathrm{C}$ support via deposition-precipitation [80]. The resulting $\mathrm{Au} / \mathrm{MnO}_{x} / \mathrm{C}$ catalysts were both active and stable for $\mathrm{CO}$ oxidation when the reaction temperature was below $100{ }^{\circ} \mathrm{C}$ (Fig. 8) [80]. Gold catalysts based on metal oxide-modified carbon supports include $\mathrm{Au} / \mathrm{TiO}_{2} / \mathrm{C}$ [209-211], $\mathrm{Au} / \mathrm{FeO}_{x} / \mathrm{C}$ [212], and $\mathrm{Au} / \mathrm{ZnO} / \mathrm{C}$ [213]. Although these catalysts showed improved catalytic performance, they should not be classified as "carbon-supported gold catalysts", but may be more appropriately described as "carbon-based gold catalysts". In addition, the local contact structures of these catalysts are not clear.

\subsection{Post-modification of supported catalysts}

\subsubsection{Post-modification of $\mathrm{Au} / \mathrm{TiO}_{2}$}

$\mathrm{Au} / \mathrm{TiO}_{2}$ is the most studied gold catalyst, but it often suffers from sintering of the gold nanoparticles at high temperatures. Our group loaded gold nanoparticles on $\mathrm{TiO}_{2}$, and then soaked the $\mathrm{Au} / \mathrm{TiO}_{2}$ in an aqueous $\mathrm{H}_{3} \mathrm{PO}_{4}$, followed by extensive washing [79]. The resulting $\mathrm{H}_{3} \mathrm{PO}_{4} / \mathrm{Au} / \mathrm{TiO}$ prepared under optimal conditions was still active for $\mathrm{CO}$ oxidation after

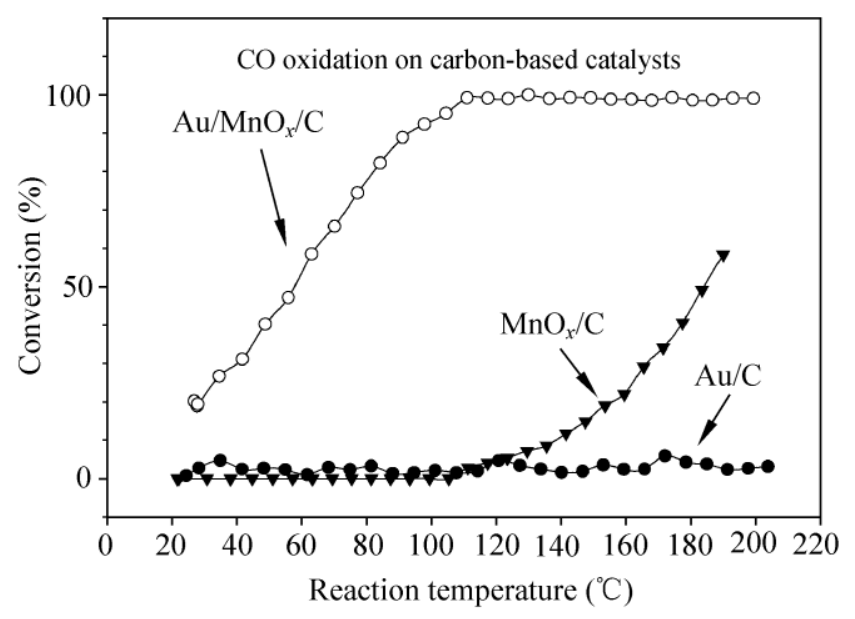

Figure 8 Conversion curves comparing the performance of an $\mathrm{Au} / \mathrm{MnO}_{x} / \mathrm{C}$ catalyst with that of $\mathrm{Au} / \mathrm{C}$, and $\mathrm{MnO}_{x} / \mathrm{C}$ catalysts for $\mathrm{CO}$ oxidation. Reproduced by permission of Elsevier from Ref. [80] high-temperature treatment indicating that the gold nanoparticles were effectively stabilized. In contrast, $\mathrm{Au} / \mathrm{TiO}_{2}$ sintered significantly after pretreatment at $500{ }^{\circ} \mathrm{C}$, and its activity in $\mathrm{CO}$ oxidation decreased dramatically. Nevertheless, the catalytic activity of $\mathrm{H}_{3} \mathrm{PO}_{4} / \mathrm{Au} / \mathrm{TiO}_{2}$, either before or after thermal treatment, was not particularly high. It is also not clear why the $\mathrm{H}_{3} \mathrm{PO}_{4}$ treatment can stabilize gold nanoparticles. It was established that the presence of an excess of phosphate species may lead to catalyst deactivation. Interestingly, Hutchings and co-workers found that the addition of small amounts of $\mathrm{NaNO}_{3}$ ( 0.00625 and $0.0125 \mathrm{wt} \% \mathrm{Na})$ to $\mathrm{Au} / \mathrm{TiO}_{2}$ led to significant enhancement in $\mathrm{CO}$ oxidation activity, whereas excess $\mathrm{NaNO}_{3}(0.0375 \mathrm{wt} \% \mathrm{Na})$ deactivated the catalyst [214].

Our group prepared $\mathrm{SiO}_{2} / \mathrm{Au} / \mathrm{TiO}_{2}$ catalysts by a solution-phase chemical grafting of $\mathrm{Si}\left(\mathrm{OCH}_{3}\right)_{4}$, $\left(\mathrm{C}_{2} \mathrm{H}_{5} \mathrm{O}\right)_{3} \mathrm{Si}\left(\mathrm{CH}_{2}\right)_{3} \mathrm{NH}_{2}$, or $\left(\left(\mathrm{CH}_{3}\right)_{3} \mathrm{CO}\right)_{3} \mathrm{SiOH}$ onto $\mathrm{Au} / \mathrm{TiO}_{2}$ [77]. The as-synthesized $\mathrm{SiO}_{2} / \mathrm{Au} / \mathrm{TiO}_{2}$ samples, containing organic fragments, were much less active than $\mathrm{Au} / \mathrm{TiO}_{2}$. But once these organic moieties were burned off, the $\mathrm{SiO}_{2} / \mathrm{Au} / \mathrm{TiO}_{2}$ samples retained small gold particle sizes and significant $\mathrm{CO}$ oxidation activity even after thermal treatment at $700{ }^{\circ} \mathrm{C}$. However, the post-modification of $\mathrm{Au} / \mathrm{TiO}_{2}$ by amorphous $\mathrm{SiO}_{2}$ did not result in more active catalysts. The role of $\mathrm{SiO}_{2}$ is limited to the mitigation of the sintering of gold nanoparticles at elevated temperatures. In later work, we modified $\mathrm{Au} / \mathrm{TiO}_{2}$ by amorphous $\mathrm{SiO}_{2}$ via a gas-phase atomic layer deposition (ALD) method (Fig. 9), and found that the catalytic activity was not particularly high although gold nanoparticles were still small after hightemperature pretreatment [84]. This difference was explained in terms of the $\mathrm{SiO}_{2}$ matrix formed via solution-phase chemical grafting being porous, whereas the $\mathrm{SiO}_{2}$ matrix fabricated via atomic layer deposition is denser. Similar procedures have also been used by others to prepare sintering-resistant $\mathrm{SiO}_{2} / \mathrm{Pt} / \mathrm{MFI}$ zeolite [215], $\mathrm{SiO}_{2} / \mathrm{Pt} / \mathrm{C}$ [216-218], and $\mathrm{SiO}_{2} / \mathrm{Pt} / \mathrm{Fe}_{2} \mathrm{O}_{3}$ [219] catalysts.

The stabilization of gold nanoparticles by coating $\mathrm{Au} / \mathrm{TiO}_{2}$ with $\mathrm{SiO}_{2}$ is understandable because the gold nanoparticles are physically encapsulated. But in some cases the loading of $\mathrm{SiO}_{2}$ was below monolayer 

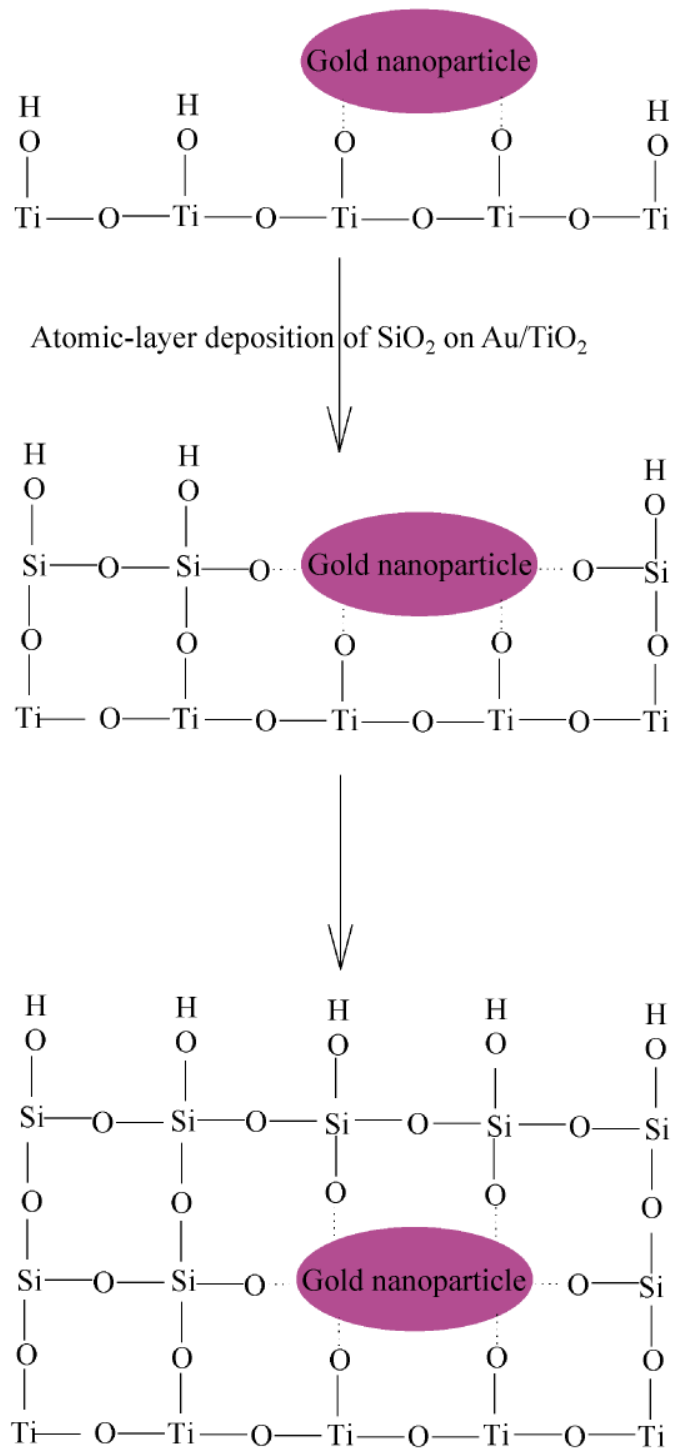

Figure 9 Schematic representation of the ALD of amorphous $\mathrm{SiO}_{2}$ onto $\mathrm{Au} / \mathrm{TiO}_{2}$. Reproduced by permission of the American Chemical Society from Ref. [84]

coverage [77]. Rashkeev and co-workers conducted a first-principles DFT study, and established that the deposition of $\mathrm{SiO}_{2}$ on a $\mathrm{TiO}_{2}$ support may cause latticemismatch instabilities and lead to the formation of strong anchoring sites for gold nanoparticles, even when the coverage of $\mathrm{SiO}_{2}$ is below monolayer [220].

\subsubsection{Post-modification of $\mathrm{Au} / \mathrm{SiO}_{2}$}

The post-modification of $\mathrm{Au} / \mathrm{SiO}_{2}$ catalysts has been rarely studied. $\mathrm{Au} / \mathrm{SiO}_{2}$ is not particularly active for $\mathrm{CO}$ oxidation, and the addition of a metal oxide modifier that creates active gold-modifier interfaces may promote the activity. Horváth and co-workers prepared $\mathrm{TiO}_{2} / \mathrm{Au} / \mathrm{SiO}_{2}$ by depositing gold colloids on an $\mathrm{SiO}_{2}$ support followed by adsorption of $\mathrm{Ti}(\mathrm{IV})$ bis(ammoniumlactato)-dihydroxide (TALH) onto the resulting $\mathrm{Au} / \mathrm{SiO}_{2}$ and a final calcination to remove the organic moieties [41]. The activity of $\mathrm{TiO}_{2} / \mathrm{Au} / \mathrm{SiO}_{2}$ in $\mathrm{CO}$ oxidation was significantly higher than that of $\mathrm{Au} / \mathrm{SiO}_{2}$, due to the presence of the $\mathrm{Au}-\mathrm{TiO}_{2}$ interface. Similarly, Guczi and co-workers deposited $\mathrm{FeO}_{x}$ layers onto $\mathrm{Au} / \mathrm{SiO}_{2} / \mathrm{Si}(100)$ by pulsed laser deposition, and found that the catalytic activity of the $\mathrm{FeO}_{x} / \mathrm{Au} / \mathrm{SiO}_{2} / \mathrm{Si}(100)$ model catalyst was higher than those of $\mathrm{Au} / \mathrm{SiO}_{2} / \mathrm{Si}(100)$ and $\mathrm{FeO}_{x} / \mathrm{SiO}_{2} / \mathrm{Si}(100)$ due to the creation of an active $\mathrm{Au}-\mathrm{FeO}_{x}$ interface [221, 222].

Our group developed $\mathrm{MnO}_{x} / \mathrm{Au} / \mathrm{SiO}_{2}$ catalysts by soaking $\mathrm{Au}(\mathrm{en})_{2} \mathrm{Cl}_{3}$-derived $\mathrm{Au} / \mathrm{SiO}_{2}$ in an aqueous $\mathrm{KMnO}_{4}$ solution followed by treatment in $\mathrm{O}_{2}-\mathrm{He}$ at 300-600 ${ }^{\circ} \mathrm{C}$ (Fig. 10) [85]. This study was motivated by previous observations that aqueous $\mathrm{KMnO}_{4}$ could partially oxidize the organic templates in as-synthesized mesoporous $\mathrm{SiO}_{2}$ to yield $\mathrm{MnO}_{x}$-containing mesoporous $\mathrm{SiO}_{2}$ upon calcination [223, 224]. In our case, the $\mathrm{KMnO}_{4}$ solution partially oxidized residual organic species on $\mathrm{Au}(\mathrm{en})_{2} \mathrm{Cl}_{3}$-derived $\mathrm{Au} / \mathrm{SiO}_{2}$, leaving behind $\mathrm{MnO}_{x}$ in close contact with gold nanoparticles on the $\mathrm{SiO}_{2}$ support. The presence of $\mathrm{MnO}_{x}$ species facilitated the removal of residual organic fragments at lower temperatures and stabilized gold nanoparticles against thermal sintering. The presence of an $\mathrm{Au}-\mathrm{MnO}_{x}$

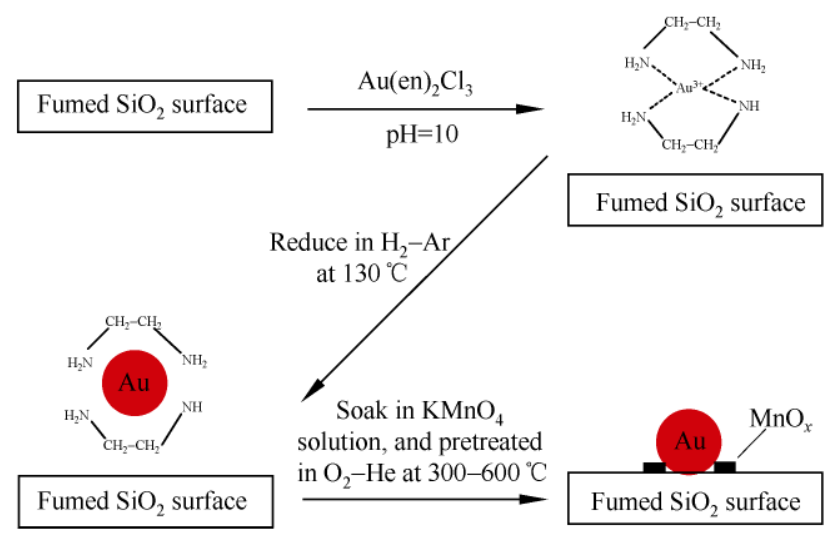

Figure 10 Schematic representation of the preparation of $\mathrm{MnO}_{x}$-loaded $\mathrm{Au} / \mathrm{SiO}_{2}$ by treating $\mathrm{Au}(\mathrm{en})_{2} \mathrm{Cl}_{3}$-derived $\mathrm{Au} / \mathrm{SiO}_{2}$ with $\mathrm{KMnO}_{4}$ solution followed by thermal activation. Reproduced by permission of the American Chemical Society from Ref. [85] 
interface is responsible for the enhanced activity in $\mathrm{CO}$ oxidation at low reaction temperatures (below $\left.-10{ }^{\circ} \mathrm{C}\right)$ [85].

Later, our group designed another catalyst by depositing dodecanethiol-protected gold nanoparticles onto a Cab-O-Sil $\mathrm{SiO}_{2}$ support followed by treating the sample with an aqueous solution of $\mathrm{KMnO}_{4}$ or $\mathrm{K}_{2} \mathrm{MnO}_{4}$ (Fig. 11) [93]. The activity of the catalyst in low-temperature $\mathrm{CO}$ oxidation was significantly improved due to the creation of active $\mathrm{Au}-\mathrm{MnO}_{x}$ interfaces [93]. One astonishing finding in that work was the formation of a composite structure composed of numerous gold nanoparticles connected by amorphous $\mathrm{MnO}_{x}$. To the best of our knowledge, such a feature had not been reported in previous publications dealing with supported gold catalysts.

\subsubsection{Post-modification of more complicated gold catalysts}

In Sections 3.3.1 and 3.3.2, respectively, we summarized the post-modification of $\mathrm{Au} / \mathrm{TiO}_{2}$ and $\mathrm{Au} / \mathrm{SiO}_{2}$ catalysts. The supports in these studies are conventional (i.e., $\mathrm{TiO}_{2}$, $\mathrm{SiO}_{2}$ ), and the modification is relatively straightforward. Some recent papers in the literature have reported the fabrication of more complicated catalysts with magnetic core-shell supports and post-installed porous shells, as summarized below.

Yin and co-workers developed novel gold catalysts by using an "encapsulation and etching" strategy (Fig. 12) [50]. In this strategy, gold nanoparticles were immobilized onto $\mathrm{SiO}_{2} @ \mathrm{Fe}_{2} \mathrm{O}_{3}$ core-shell particles to form core-satellite structures, and the composite was then coated by another layer of silica followed by surface-protected etching using aqueous $\mathrm{NaOH}$ as the etching agent. The etching process transformed

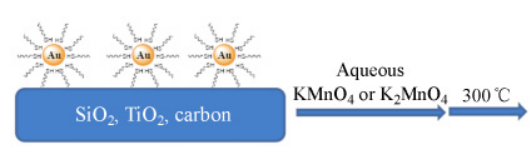

Figure 11 Formation of $\mathrm{Au}-\mathrm{MnO}_{x}$ composites and $\mathrm{MnO}_{x}$-modified gold nanoparticles by treatment of supported gold catalysts with aqueous $\mathrm{KMnO}_{4}$ or $\mathrm{K}_{2} \mathrm{MnO}_{4}$. Reproduced by permission of Springer from Ref. [93]
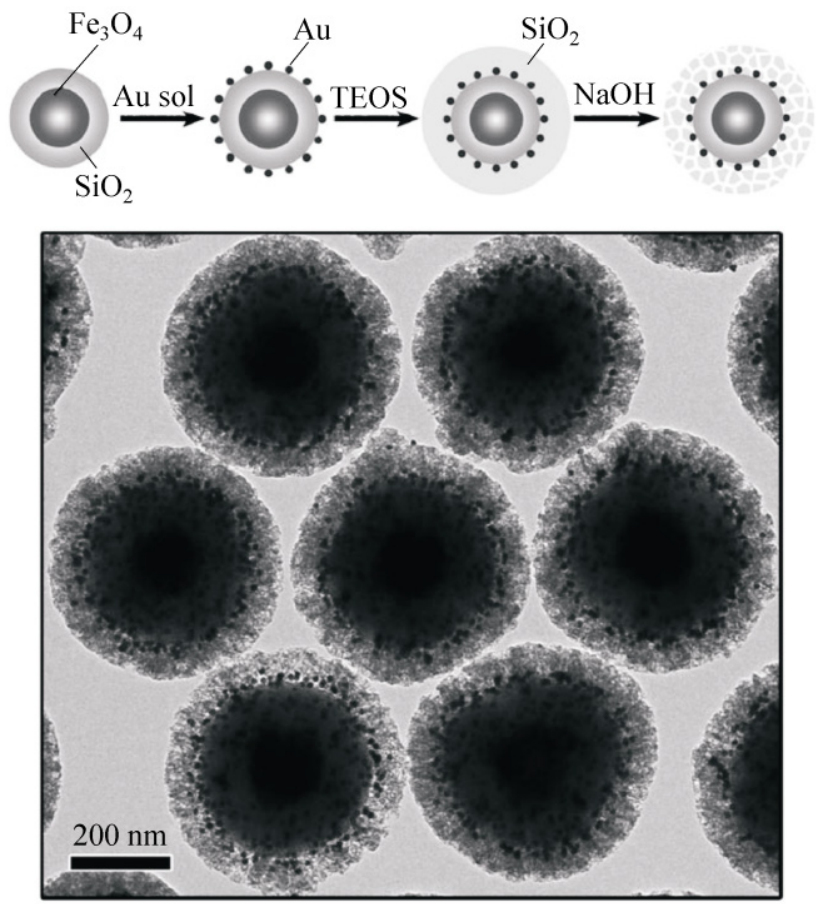

Figure 12 Schematic illustration of the synthesis procedure and a TEM image of a porous silica-protected $\mathrm{Au} / \mathrm{SiO}_{2} / \mathrm{Fe}_{3} \mathrm{O}_{4}$ composite structure. Reproduced with permission of Wiley-VCH from Ref. [50]

the dense silica coating to porous silica shells possessing mesopores, as demonstrated by $\mathrm{N}_{2}$ adsorption-desorption measurements. The resulting catalysts showed high activities in the reduction of 4-nitrophenol by $\mathrm{NaBH}_{4}$, and the activity increased with the extent of etching, i.e., with the pore size of the $\mathrm{SiO}_{2}$ shell. The catalysts showed good recyclability, whereas the detachment and agglomeration of supported gold nanoparticles was a problem for an $\mathrm{Au} / \mathrm{SiO}_{2} / \mathrm{Fe}_{3} \mathrm{O}_{4}$ catalyst. The authors proposed that the "encapsulation and etching strategy" is a versatile way of making new catalysts with various sizes, shapes, and compositions, and is superior to simply supporting metal nanoparticles in mesoporous silica, because the migration and sintering of metal nanoparticles is still possible in mesoporous silica [50].

Zhao and co-workers fabricated multifunctional mesoporous composite microspheres as a highly integrated catalyst system [60]. In their synthesis, $\mathrm{Fe}_{3} \mathrm{O}_{4} @ \mathrm{SiO}_{2}$ microspheres were modified with 3-aminopropyl triethylsilane (APTS), and gold nanoparticles prepared by citrate reduction of $\mathrm{HAuCl}_{4}$ were immobilized onto the support. The

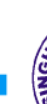

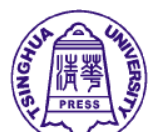

勿 Springer 
gold loading could be tuned by varying the grafting density of APTS molecules. The resulting $\mathrm{Fe}_{3} \mathrm{O}_{4} @ \mathrm{SiO}_{2}-$ $\mathrm{Au}$ microspheres were coated by mesoporous $\mathrm{SiO}_{2}$ layers using TEOS as the silica source and cetyltrimethylammonium bromide $(\mathrm{CTAB})$ as the structure-directing agent, and the CTAB surfactant was then removed by extensive acetone extraction. The resulting catalyst showed high efficiency for the reduction of 4-nitrophenol by $\mathrm{NaBH}_{4}$ and for epoxidation of styrene. Nevertheless, the gold nanoparticles prepared were as large as $\sim 12 \mathrm{~nm}$, and further improvement in these systems can be expected.

\subsection{Simultaneous dispersion of gold and an inorganic component on a support}

\subsubsection{Dispersion of $\mathrm{Au}-\mathrm{Fe}_{3} \mathrm{O}_{4}$ dumbbells on a support}

Gold nanoparticles may sinter easily on pristine supports. Our group prepared $\mathrm{Au}-\mathrm{Fe}_{3} \mathrm{O}_{4} / \mathrm{SiO}_{2}$, $\mathrm{Au}-\mathrm{Fe}_{3} \mathrm{O}_{4} / \mathrm{TiO}_{2}$, and $\mathrm{Au}-\mathrm{Fe}_{3} \mathrm{O}_{4} / \mathrm{C}$ catalysts by dispersing dumbbell-like $\mathrm{Au}-\mathrm{Fe}_{3} \mathrm{O}_{4}$ nanocomposites onto $\mathrm{SiO}_{2}, \mathrm{TiO}_{2}$, and $\mathrm{C}$ supports (Fig. 13) [87]. This process relies on the facts that the synthesis of dumbbell-like $\mathrm{Au}-\mathrm{Fe}_{3} \mathrm{O}_{4}$ is well-established [225-227] and $\mathrm{Au}-\mathrm{Fe}_{3} \mathrm{O}_{4}$ itself is active for $\mathrm{CO}$ oxidation. Because each dumbbell consists of a strongly interacting heterostructure with a gold nanoparticle at one end and $\mathrm{Fe}_{3} \mathrm{O}_{4}$ nanoparticle at the other end, the relative positions of each component can be fixed, and sintering can thus be minimized. The resulting catalysts were found to be highly active for $\mathrm{CO}$ oxidation $[57,87]$. In addition to the active $\mathrm{Au}-\mathrm{Fe}_{3} \mathrm{O}_{4}$ interface, the interface between exposed gold surfaces

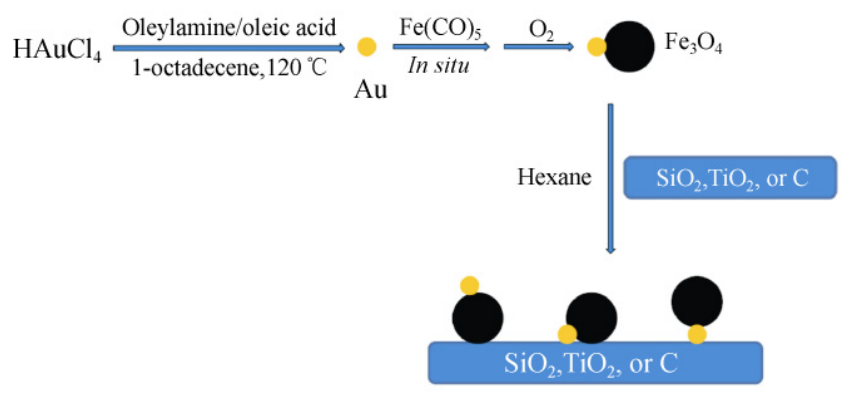

Figure 13 Synthesis of $\mathrm{Au}-\mathrm{Fe}_{3} \mathrm{O}_{4}$ dumbbell nanoparticle catalysts deposited on selected solid supports. Reproduced by permission of the Royal Society of Chemistry from Ref. [87] and the support may also contribute to the catalytic activity. Nevertheless, it is still not clear how these dumbbells interact with the support surface, i.e., whether only gold nanoparticles are in contact with the support, only the $\mathrm{Fe}_{3} \mathrm{O}_{4}$ nanoparticles are in contact with the support, or both components are in contact with the support. In later work, Zheng and co-workers found that the activity of $\mathrm{Au}$ $(6.7 \mathrm{~nm})-\mathrm{Fe}_{3} \mathrm{O}_{4} / \mathrm{TiO}_{2}$ in $\mathrm{CO}$ oxidation increased with decreasing size of the $\mathrm{Fe}_{3} \mathrm{O}_{4}$ nanoparticles [52], consistent with the previous finding that the catalytic activity of $\mathrm{Au} / \mathrm{ZrO}_{2}$ in $\mathrm{CO}$ oxidation increased when the particle size of the $\mathrm{ZrO}_{2}$ support decreased [105].

\subsubsection{In situ transformation of $\mathrm{NiAu} / \mathrm{SiO}_{2}$ into $\mathrm{Au}-\mathrm{NiO}$}

Above, we have summarized ways of fabricating gold catalysts with either simple or complex structures, and gold nanoparticles were involved in all these studies. It is interesting to tune the catalytic performance by using supported alloy catalysts [228-234]. For instance, Crooks and co-workers synthesized $\mathrm{PdAu} / \mathrm{TiO}_{2}$ using dendrimer-encapsulated alloy nanoparticles as the precursor, and found that the activities of the catalysts in $\mathrm{CO}$ oxidation followed the sequence $\mathrm{PdAu} / \mathrm{TiO}_{2}>\mathrm{Pd} / \mathrm{TiO}_{2}>\mathrm{Au} / \mathrm{TiO}_{2}$ [235]. Mou and coworkers synthesized AuAg/Al-MCM-41 catalysts via both a one-step approach [236-239] and a two step method [55], and demonstrated enhanced catalytic activity in $\mathrm{CO}$ oxidation associated with the alloyed silver. Zhang and co-workers used a similar two-step approach to prepare $\mathrm{AuAg} / \mathrm{SiO}_{2}$ [53], $\mathrm{AuAg} / \mathrm{Al}_{2} \mathrm{O}_{3}$ [53], AuCu/SBA-15 [240], and AuCu/silica gel [63] catalysts, and demonstrated their good performance in $\mathrm{CO}$ oxidation. Sun and co-workers prepared $\mathrm{AuAg} / \mathrm{SiO}_{2}$ catalysts using oleylamine-coated AuAg alloy nanoparticles as the precursor, and found that the one with an $\mathrm{Au} / \mathrm{Ag}$ ratio of 1/1 showed highest $\mathrm{CO}$ conversion [54]. In most of these studies, the oxidation state of the alloyed metal after undergoing $\mathrm{CO}$ oxidation was not studied, and the authors generally assumed that the alloy species was metallic. Furthermore, the deposition of gold and another metal on support surfaces may not be simultaneous.

Our group synthesized NiAu nanoparticles via a co-reduction method employing butyllithium as the reducing agent and trioctylphosphine as the protecting 
agent $[88,90]$. These nanoparticles were loaded onto an amorphous $\mathrm{SiO}_{2}$ support to obtain $\mathrm{NiAu} / \mathrm{SiO}_{2}$. This sample was transformed into $\mathrm{Au}-\mathrm{NiO} / \mathrm{SiO}_{2}$ after low-temperature reduction and subsequent hightemperature oxidation pretreatment (Fig. 14) [88]. Interestingly, the size of the gold nanoparticles was quite small due to the protection afforded by the surrounding $\mathrm{NiO}$, whereas $\mathrm{Au} / \mathrm{SiO}_{2}$ underwent significant sintering on calcination. The success of the new catalyst relies on the in situ transformation of a bimetallic NiAu alloy into an $\mathrm{Au}-\mathrm{NiO}$ composite structure. The presence of $\mathrm{NiO}$ in close contact with gold nanoparticles can stabilize the latter on support surfaces.

It should be mentioned that the in situ transformation of bimetallic alloys to metal-metal oxide composite structures has been found in other systems. For instance, Baiker and co-workers prepared $\mathrm{Pd} / \mathrm{ZrO}_{2}$ catalysts from an amorphous $\mathrm{Pd}-\mathrm{Zr}$ alloy [241, 242] and gold-zirconia-iron oxide and gold-silver-zirconia catalysts from amorphous $\mathrm{Au}_{5} \mathrm{FeZr}_{14}$ and $\mathrm{Au}_{5} \mathrm{AgZr}_{14}$ alloys [243]. Schaak and co-workers obtained a $\mathrm{Bi}_{2} \mathrm{O}_{3} / \mathrm{Pd}$ nanocomposite by oxidation of $\mathrm{Bi}_{2} \mathrm{Pd}$ nanocubes [244]. More recently, Albonetti and co-workers prepared $\mathrm{Au}-\mathrm{FeO}_{x} / \mathrm{TiO}_{2}$ catalysts using bimetallic carbonyl cluster salts, e.g., $\left[\mathrm{NEt}_{4}\right]_{4}\left[\mathrm{Au}_{4} \mathrm{Fe}_{4}(\mathrm{CO})_{16}\right]$ and $\left[\mathrm{NEt}_{4}\right]\left[\mathrm{AuFe}_{4}(\mathrm{CO})_{16}\right][245,246]$.

\subsubsection{Dispersion of Au@oxide core-shell structures on a support}

Great efforts have been made to design metal@oxide core-shell structures [49, 247-253]. However, only limited attention has been paid to the use of such core-shell structures [252, 254-261] or their supported versions [262-264] in the fabrication of new catalysts $[265,266]$. Some researchers have developed new

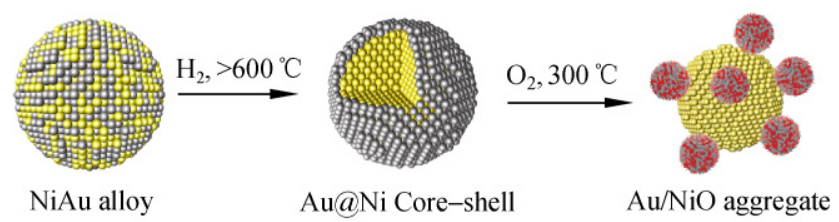

Figure 14 Schematic representation of the phase transformation from a NiAu alloy to a $\mathrm{Au} / \mathrm{NiO}$ hetero-aggregate [88]. The $\mathrm{SiO}_{2}$ support is omitted for simplicity. Reproduced by permission of Wiley-VCH from Ref. [88] catalysts featuring the strategic location of small gold nanoparticles in much bigger hollow $\mathrm{ZrO}_{2}$ or $\mathrm{SiO}_{2}$ shells to form yolk-shell structures [43, 267-271], or the entrapment of a number of gold nanoparticles in an amorphous $\mathrm{SiO}_{2}$ matrix [125]. $\mathrm{Au} @ \mathrm{TiO}_{2}$ core-shell structures were prepared and tested in photooxidation $[272,273]$, but the gold cores were too large for other catalytically interesting reactions, and the $\mathrm{TiO}_{2}$ shells were thick and rough. Zhang and co-workers prepared $\mathrm{Au} @ \mathrm{TiO}_{2}$ with gold particle sizes of 10-15 nm and $\mathrm{TiO}_{2}$ thickness of $1-3 \mathrm{~nm}$, and tested its activity in $\mathrm{CO}$ oxidation [274]. However, the CO conversion was very low when the reaction temperature was below $100{ }^{\circ} \mathrm{C}$. Xie and coworkers synthesized $\mathrm{Au} @ \mathrm{SnO}_{2}$ core-shell structures by an intermetallics-based dry-oxidation approach [46]. Gold nanoparticles with a mean size of $15 \mathrm{~nm}$ were encapsulated by a $\mathrm{SnO}_{2}$ shell having a thickness of 6-7 nm. The core-shell structured catalyst still showed $50 \%$ CO conversion when the reaction temperature was $230{ }^{\circ} \mathrm{C}$, even though the catalyst was pretreated at $850{ }^{\circ} \mathrm{C}$ prior to reaction [46]. $\mathrm{Xu}$ and co-workers synthesized bimetallic $\mathrm{Au}-\mathrm{Ni}$ nanoparticles embedded in $\mathrm{SiO}_{2}$ spheres, and demonstrated that the resulting $\mathrm{Au}-\mathrm{Ni} @ \mathrm{SiO}_{2}$ showed higher catalytic activity and better durability than monometallic $\mathrm{Au} @ \mathrm{SiO}_{2}$ or $\mathrm{Ni@SiO}$ in the hydrolysis of ammoniaborane [56]. Alivisatos and co-workers prepared $\mathrm{Au} @ \mathrm{Fe}_{2} \mathrm{O}_{3}$ core-shell structures by depositing an iron shell around gold nanoparticles stabilized by oleylamine, hexadecylamine, or dodecanethiol, followed by oxidation of the iron shell to form an $\mathrm{Fe}_{2} \mathrm{O}_{3}$ shell [251]. The magnetic properties of the resulting materials were characterized, but no catalytic data were reported.

Our group recently designed $\mathrm{Au} @ \mathrm{Fe}_{2} \mathrm{O}_{3} / \mathrm{SiO}_{2}$ catalysts by dispersing $\mathrm{Au} @ \mathrm{Fe}_{2} \mathrm{O}_{3}$ core-shell structures on a $\mathrm{SiO}_{2}$ support (Fig. 15) [95]. It was necessary to pretreat the catalysts at elevated temperatures to remove residual organic species and create pores in the $\mathrm{Fe}_{2} \mathrm{O}_{3}$ shell. However, collapse of the core-shell structure and sintering of gold nanoparticles were still observed when the catalysts were treated at $700{ }^{\circ} \mathrm{C}$. The catalytic activity in $\mathrm{CO}$ oxidation generally decreased with increasing thickness of the $\mathrm{SiO}_{2}$ shell, but was still higher than that of $\mathrm{Au} / \mathrm{Fe}_{2} \mathrm{O}_{3}$ 


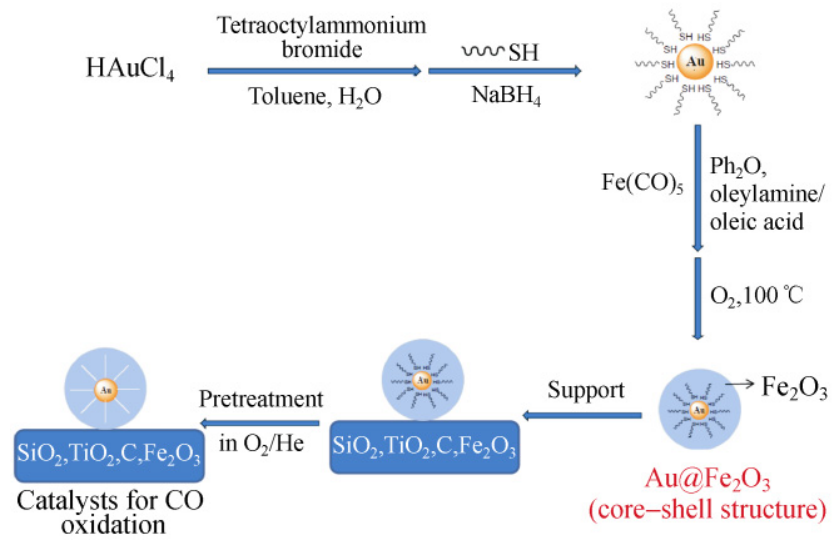

Figure 15 Preparation and catalytic reaction of supported $\mathrm{Au} @ \mathrm{Fe}_{2} \mathrm{O}_{3}$ nanoparticles. Reproduced by permission of Elsevier from Ref. [95]

or $\mathrm{Au} / \mathrm{SiO}_{2}$ with comparable gold loadings prepared by colloidal deposition. Other catalysts, such as $\mathrm{Au} @ \mathrm{Fe}_{2} \mathrm{O}_{3} / \mathrm{TiO}_{2}, \mathrm{Au} @ \mathrm{Fe}_{2} \mathrm{O}_{3} / \mathrm{C}$, and $\mathrm{Au} @ \mathrm{Fe}_{2} \mathrm{O}_{3} / \mathrm{Fe}_{2} \mathrm{O}_{3}$, were also developed in the same way. Although we used $\mathrm{CO}$ oxidation as a probe reaction for these catalysts, we believe that these catalysts may also be useful in other reactions.

\section{Concluding remarks}

In this review we have provided a survey of the development of novel supported gold catalysts from a materials perspective. Examples have been highlighted of the synthesis of novel gold catalysts with relatively simple metal-support interfaces, the pre-modification of supports before loading gold nanoparticles, the post-modification of supported gold catalysts, and the simultaneous dispersion of gold and an inorganic component on supports. Although most of the examples were taken from our own work, references to the wider literature were made when appropriate. We need to emphasize here again that most of the reviews in this field deal with new preparation methods, synthesis details, catalytic reactions, and the nature of the active sites and reaction mechanisms [18-33], with a very limited number written from a materials perspective [89]. From the references cited herein, one can see that the use of a materials perspective to develop new gold catalysts has resulted in rapid progress in recent years.
The importance of our work in relation to catalyst development lies in several points. First, we have developed new gold catalysts not previously reported, thus enriching the pool of gold catalysts. Most of our newly developed catalysts were not covered in a classic book "Catalysis by Gold" published in 2006 [28]. Second, we have improved the diversity of the morphology, built up complex metal-support interfaces, enhanced the thermal stability of gold catalysts, and added more functionality to the catalyst system. This is novel, because most of the papers in the literature have dealt with $\mathrm{Au} / \mathrm{TiO}_{2}$ with relatively simple metal-support interfaces and poor thermal stability. Third, we have established some correlations between structure and function by means of systematic characterization, although these correlations have not been summarized in detail here. Last but not least, the development of these gold catalysts has provided new opportunities for further fundamental and applied research [130, 131, 146, 186, 188, 220, 275-278]. For instance, the development of $\mathrm{Au} / \mathrm{SiO}_{2}[75,76]$ and $\mathrm{Au} / \mathrm{FePO}_{4}$ [86] catalysts makes it possible to study the nature of active sites and reaction mechanisms $[130,131,146]$, and the development of $\mathrm{Au} / \mathrm{Al}_{2} \mathrm{O}_{3} / \mathrm{TiO}_{2}$ [71] and $\mathrm{SiO}_{2} / \mathrm{Au} / \mathrm{TiO}_{2}[77,84]$ catalysts prompted the subsequent DFT studies [186, 220].

We propose several ideas for further research. First, most of the previous experiments were carried out by studying the catalysts before and after thermal treatment and reaction testing, but the details of any physical changes in the catalysts are not clear. Therefore, the sintering process should be observed by direct TEM imaging [279-281]. High-angle annular dark field scanning transmission electron microscopy (HAADF-STEM) imaging should also be helpful to obtain images with higher resolution [282-284]. Second, although we observed the phenomenon in many systems, the physical reasons for the antisintering behavior are not clear. Detailed and systematic first-principles calculations on these catalyst systems should lead to interesting results $[186,220]$. For instance, the binding energies of gold with various supports and functionalized supports should be compared. Third, considering that these modified catalysts have complex interfaces, the ways in which these interfaces may influence the nature of 
active sites and the reaction mechanisms in $\mathrm{CO}$ oxidation should be studied. These can be done by using XPS, X-ray absorption near edge structure (XANES), and FTIR measurements, and theoretical calculations can also be carried out. Finally, most of the catalysts have only been used in $\mathrm{CO}$ oxidation. This is not only because $\mathrm{CO}$ oxidation is useful in environmental protection, but also because it is a sensitive probe reaction and easy to carry out. It would be worthwhile to explore applications of these catalysts in other reactions, such as liquid-phase oxidation, hydrogenation, de- $\mathrm{NO}_{x}$ reactions, and combustions of VOCs. We think that the effort put into these aspects to date is insufficient and ample opportunities exist for future study in these directions.

\section{Acknowledgements}

Z. Ma thanks Fudan University for a start-up package and the National Science Foundation of China (No. 21007011) S. Dai thanks the Office of Basic Energy Sciences, U.S. Department of Energy for sponsorship. The Oak Ridge National Laboratory is managed by UT-Battelle, LLC for the U.S. DOE under Contract DE-AC05-00OR22725. Many colleagues working in the field of gold catalysis are acknowledged. In particular, the laboratory work of Dr. Wenfu Yan, Dr. Haoguo Zhu, Dr. Hongfeng Yin, and Dr. Shenghu Zhou made the current literature review possible.

Open Access: This article is distributed under the terms of the Creative Commons Attribution Noncommercial License which permits any noncommercial use, distribution, and reproduction in any medium, provided the original author(s) and source are credited.

\section{References}

[1] Bell, A. T. The impact of nanoscience on heterogeneous catalysis. Science 2003, 299, 1688-1691.

[2] Kung, H. H.; Kung, M. C. Heterogeneous catalysis: What lies ahead in nanotechnology. Appl. Catal. A 2003, 246, 193-196.

[3] Somorjai, G. A.; Rioux, R. M. High technology catalysts towards 100\% selectivity: Fabrication, characterization and reaction studies. Catal. Today 2005, 100, 201-215.

[4] Somorjai, G. A.; Park, J. Y. Colloid science of metal nanoparticle catalysts in $2 \mathrm{D}$ and $3 \mathrm{D}$ structures. Challenges of nucleation, growth, composition, particle shape, size control and their influence on activity and selectivity. Top. Catal. 2008, 49, 126-135.

[5] Astruc, D. Nanoparticles and Catalysis; Wiley-VCH: Weinheim, 2008.

[6] Zhu, K. K.; Wang, D. H.; Liu, J. Self-assembled materials for catalysis. Nano Res. 2009, 2, 1-29.

[7] Wang, D. S.; Xie, T.; Li, Y. D. Nanocrystals: Solutionbased synthesis and applications as nanocatalysts. Nano Res. 2009, 2, 30-46.

[8] Zaera, F. The new materials science of catalysis: Toward controlling selectivity by designing the structure of the active site. J. Phys. Chem. Lett. 2010, 1, 621-627.

[9] Valden, M.; Lai, X.; Goodman, D. W. Onset of catalytic activity of gold clusters on titania with the appearance of nonmetallic properties. Science 1998, 281, 1647-1650.

[10] Chen, M. S.; Goodman, D. W. The structure of catalytically active gold on titania. Science 2004, 306, 252-255.

[11] Pyykkö, P. Theoretical chemistry of gold. Angew. Chem. Int. Ed. 2004, 43, 4412-4456.

[12] Daniel, M. -C.; Astruc, D. Gold nanoparticles: Assembly, supramolecular chemistry, quantum-size-related properties, and applications toward biology, catalysis, and nanotechnology. Chem. Rev. 2004, 104, 293-346.

[13] Astruc, D.; Lu, F.; Aranzaes, J. R. Nanoparticles as recyclable catalysts: The frontier between homogeneous and heterogeneous catalysis. Angew. Chem. Int. Ed. 2005, 44, 7852-7872.

[14] Cuenya, B. R. Synthesis and catalytic properties of metal nanoparticles: Size, shape, support, composition, and oxidation state effects. Thin Solid Films 2010, 518, 3127-3150.

[15] Haruta, M.; Kobayashi, T.; Sano, H.; Yamada, N. Novel gold catalysts for the oxidation of carbon monoxide at a temperature far below $0{ }^{\circ} \mathrm{C}$. Chem. Lett. 1987, 405-408.

[16] Haruta, M.; Yamada, N.; Kobayashi, T.; Iijima, S. Gold catalysts prepared by coprecipitation for low-temperature oxidation of hydrogen and of carbon monoxide. J. Catal. 1989, 115, 301-309.

[17] Haruta, M.; Tsubota, S.; Kobayashi, T.; Kageyama, H.; Genet, M. J.; Delmon, B. Low-temperature oxidation of CO over gold supported on $\mathrm{TiO}_{2}, \alpha-\mathrm{Fe}_{2} \mathrm{O}_{3}$, and $\mathrm{Co}_{3} \mathrm{O}_{4}$. J. Catal. 1993, 144, 175-192.

[18] Bond, G. C.; Thompson, D. T. Catalysis by gold. Catal. Rev. -Sci. Eng. 1999, 41, 319-388.

[19] Haruta, M.; Daté, M. Advances in the catalysis of $\mathrm{Au}$ nanoparticles. Appl. Catal. A 2001, 222, 427-437.

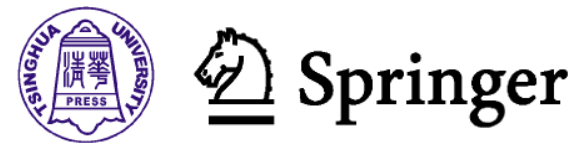


[20] Choudhary, T. V.; Goodman, D. W. Oxidation catalysis by supported gold nano-clusters. Top. Catal. 2002, 21, 25-34.

[21] Hashmi, A. S. K.; Hutchings, G. J. Gold catalysis. Angew. Chem. Int. Ed. 2006, 45, 7896-7936.

[22] Kung, M. C.; Davis, R. J.; Kung, H. H. Understanding Au-catalyzed low-temperature CO oxidation. J. Phys. Chem. C 2007, 111, 11767-11775.

[23] Carabineiro, S. A. C.; Thompson, D. T. Catalytic applications for gold nanotechnology. In Nanocatalysis; Heiz, U.; Landman, U., eds.; Springer: Berlin, 2007; pp. 377-489.

[24] Della Pina, C.; Falletta, E.; Prati, L.; Rossi, M. Selective oxidation using gold. Chem. Soc. Rev. 2008, 37, 2077-2095.

[25] Corma, A.; Garcia, H. Supported gold nanoparticles for organic reactions. Chem. Soc. Rev. 2008, 37, 2096-2126.

[26] Kung, H. H.; Kung, M. C.; Costello, C. K. Supported Au catalysts for low temperature CO oxidation. J. Catal. 2003, 216, 425-432.

[27] Fu, Q.; Saltsburg, H.; Flytzani-Stephanopoulos, M. Active nonmetallic $\mathrm{Au}$ and $\mathrm{Pt}$ species on ceria-based water-gas shift catalysts. Science 2003, 301, 935-938.

[28] Bond, G. C.; Louis, C.; Thompson, D. T. Catalysis by Gold; Imperial College Press: London, 2006.

[29] Chen, M. S.; Goodman, D. W. Structure-activity relationships in supported Au catalysts. Catal. Today 2006, 111, 22-33.

[30] Janssens, T. V. W.; Clausen, B. S.; Hvolbæk, B.; Falsig, H.; Christensen, C. H.; Bligaard, T.; Nørskov, J. K. Insights into the reactivity of supported Au nanoparticles: Combining theory and experiments. Top. Catal. 2007, 44, 15-26.

[31] Min, B. K.; Friend, C. M. Heterogeneous gold-based catalysis for green chemistry: Low-temperature $\mathrm{CO}$ oxidation and propene oxidation. Chem. Rev. 2007, 107, 2709-2724.

[32] Fierro-Gonzalez, J. C.; Gates, B. C. Catalysis by gold dispersed on supports: The importance of cationic gold. Chem. Soc. Rev. 2008, 37, 2127-2134.

[33] Gong, J. L.; Mullins, C. B. Surface science investigation of oxidative chemistry on gold. Acc. Chem. Res. 2009, 42, 1063-1073.

[34] Bamwenda, G. R.; Tsubota, S.; Nakamura, T.; Haruta, M. The influence of the preparation methods on the catalytic activity of platinum and gold supported on $\mathrm{TiO}_{2}$ for $\mathrm{CO}$ oxidation. Catal. Lett. 1997, 44, 83-87.

[35] Zanella, R.; Giorgio, S.; Henry, C. R.; Louis, C. Alternative methods for the preparation of gold nanoparticles supported on $\mathrm{TiO}_{2}$. J. Phys. Chem. B 2002, 106, 7634-7642.

[36] Wolf, A.; Schüth, F. A systematic study of the synthesis conditions for the preparation of highly active gold catalysts. Appl. Catal. A 2002, 226, 1-13.

[37] Moreau, F.; Bond, G. C.; Taylor, A. O. Gold on titania catalysts for the oxidation of carbon monoxide: Control of
$\mathrm{pH}$ during preparation with various gold contents. J. Catal. 2005, 231, 105-114.

[38] Li, W. C.; Comotti, M.; Schüth, F. Highly reproducible syntheses of active $\mathrm{Au} / \mathrm{TiO}_{2}$ catalysts for $\mathrm{CO}$ oxidation by deposition-precipitation or impregnation. J. Catal. 2006, 237, 190-196.

[39] Moreau, F.; Bond, G. C. Gold on titania catalysts, influence of some physicochemical parameters on the activity and stability for the oxidation of carbon monoxide. Appl. Catal. A 2006, 302, 110-117.

[40] Al-Sayari, S.; Carley, A. F.; Taylor, S. H.; Hutchings, G. J. $\mathrm{Au} / \mathrm{ZnO}$ and $\mathrm{Au} / \mathrm{Fe}_{2} \mathrm{O}_{3}$ catalysts for $\mathrm{CO}$ oxidation at ambient temperature: Comments on the effect of synthesis conditions on the preparation of high activity catalysts prepared by coprecipitation. Top. Catal. 2007, 44, 123-128.

[41] Horváth, A.; Beck, A.; Sárkány, A.; Stefler, G.; Varga, Z.; Geszti, O.; Tóth, L.; Guczi, L. Silica-supported Au nanoparticles decorated by $\mathrm{TiO}_{2}$ : Formation, morphology, and $\mathrm{CO}$ oxidation activity. J. Phys. Chem. B 2006, 110, 15417-15425.

[42] Glaspell, G.; Hassan, H. M. A.; Elzatahry, A.; Fuoco, L.; Radwan, N. R. E.; El-Shall, M. S. Nanocatalysis on tailored shape supports: $\mathrm{Au}$ and $\mathrm{Pd}$ nanoparticles supported on $\mathrm{MgO}$ nanocubes and $\mathrm{ZnO}$ nanobelts. J. Phys. Chem. B 2006, 110, 21387-21393.

[43] Arnal, P. M.; Comotti, M.; Schüth, F. High-temperaturestable catalysts by hollow sphere encapsulation. Angew. Chem. Int. Ed. 2006, 45, 8224-8227.

[44] Zhong, L. -S.; Hu, J. -S.; Cao, A. M.; Liu, Q.; Song, W. G.; Wan, L. -J. 3D flowerlike ceria micro/nanocomposite structure and its application for water treatment and $\mathrm{CO}$ removal. Chem. Mater. 2007, 19, 1648-1655.

[45] Zhong, Z. Y.; Ho, J.; Teo, J.; Shen, S. C.; Gedanken, A. Synthesis of porous $\alpha-\mathrm{Fe}_{2} \mathrm{O}_{3}$ nanorods and deposition of very small gold particles in the pores for catalytic oxidation of CO. Chem. Mater. 2008, 19, 4776-4782.

[46] Yu, K.; Wu, Z. C.; Zhao, Q. R.; Li, B. X.; Xie, Y. Hightemperature-stable $\mathrm{Au} @ \mathrm{SnO}_{2}$ core/shell supported catalyst for CO oxidation. J. Phys. Chem. C 2008, 112, 2244-2247.

[47] Wang, D. H.; Ma, Z.; Dai, S.; Liu, J.; Nie, Z. M.; Engelhard, M. H.; Huo, Q. S.; Wang, C. M.; Kou, R. Low-temperature synthesis of tunable mesoporous crystalline transition metal oxides and applications as Au catalyst supports. J. Phys. Chem. C 2008, 112, 13499-13509.

[48] Ge, J. P.; Huynh, T.; Hu, Y. X.; Yin, Y. D. Hierarchical magnetite/silica nanoassemblies as magnetically recoverable catalyst-supports. Nano Lett. 2008, 8, 931-934.

[49] Zhang, Q.; Zhang, T. R.; Ge, J. P.; Yin, Y. D. Permeable silica shell through surface-protected etching. Nano Lett. 2008, 8, 2867-2871. 
[50] Ge, J. P.; Zhang, Q.; Zhang, T. R.; Yin, Y. D. Core-satellite nanocomposite catalysts protected by a porous silica shell: Controllable reactivity, high stability, and magnetic recyclability. Angew. Chem. Int. Ed. 2008, 47, 8924-8928.

[51] Zhou, Z.; Kooi, S.; Flytzani-Stephanopoulos, M.; Saltsburg, $\mathrm{H}$. The role of the interface in $\mathrm{CO}$ oxidation on $\mathrm{Au} / \mathrm{CeO}_{2}$ multilayer nanotowers. Adv. Funct. Mater. 2008, 18, 2801-2807.

[52] Wu, B. H.; Zhang, H.; Chen, C.; Lin, S. C.; Zheng, N. F. Interfacial activation of catalytically inert $\mathrm{Au}(6.7 \mathrm{~nm})$ $-\mathrm{Fe}_{3} \mathrm{O}_{4}$ dumbbell nanoparticles for $\mathrm{CO}$ oxidation. Nano Res. 2009, 2, 975-983.

[53] Liu, X. Y.; Wang, A. Q.; Yang, X. F.; Zhang, T.; Mou, C. -Y.; Su, D. -S.; Li, J. Synthesis of thermally stable and highly active bimetallic $\mathrm{Au}-\mathrm{Ag}$ nanoparticles on inert supports. Chem. Mater. 2009, 21, 410-418.

[54] Wang, C.; Yin, H. F.; Chan, R.; Peng, S.; Dai, S.; Sun, S. H. One-pot synthesis of oleylamine coated AuAg alloy NPs and their catalysis for CO oxidation. Chem. Mater. 2009, 21, 433-435.

[55] Yen, C. -W.; Lin, M. -L.; Wang, A. Q.; Chen, S. -A.; Chen, J. -M.; Mou, C. -Y. $\mathrm{CO}$ oxidation catalyzed by $\mathrm{Au}-\mathrm{Ag}$ bimetallic nanoparticles supported in mesoporous silica. $J$. Phys. Chem. C 2009, 41, 17831-17839.

[56] Jiang, H. -L.; Umegaki, T.; Akita, T.; Zhang, X. -B.; Haruta, M.; Xu, Q. Bimetallic $\mathrm{Au}-\mathrm{Ni}$ nanoparticles embedded in $\mathrm{SiO}_{2}$ nanospheres: Synergetic catalysis in hydrolytic dehydrogenation of ammonia borane. Chem. Eur. J. 2010, 16, 3132-3137.

[57] Wang, C.; Yin, H. F.; Dai, S.; Sun, S. H. A general approach to noble metal-metal oxide dumbbell nanoparticles and their catalytic application for $\mathrm{CO}$ oxidation. Chem. Mater. 2010, 22, 3277-3282.

[58] Cao, C. -Y.; Cui, Z. -M.; Chen, C. -Q.; Song, W. -G.; Cai, W. Ceria hollow nanospheres produced by a template-free microwave-assisted hydrothermal method for heavy metal ion removal and catalysis. J. Phys. Chem. C 2010, 114, 9865-9870.

[59] Laursen, A.; Højholt, K. T.; Lundegaard, L. F.; Simonsen, S B.; Helveg, S.; Schüth, F.; Paul, M.; Grunwaldt, J. -D.; Kegnæs, S.; Christensen, C. H.; Egeblad, K. Substrate size-selective catalysis with zeolite-encapsulated gold nanoparticles. Angew. Chem. Int. Ed. 2010, 49, 3504-3507.

[60] Deng, Y. H.; Cai, Y.; Sun, Z. K.; Liu, J.; Liu, C.; Wei, J.; Li, W.; Liu, C.; Wang, Y.; Zhao, D. Y. Multifunctional mesoporous composite microspheres with well-designed nanostructure: A highly integrated catalyst system. J. Am. Chem. Soc. 2010, 132, 8466-8473.

[61] Liu, J.; Qiao, S. Z.; Hartono, S. B.; Lu, G. Q. Monodisperse yolk-shell nanoparticles with a hierarchical porous structure for delivery vehicles and nanoreactors. Angew. Chem. Int. Ed. 2010, 49, 4981-4985.

[62] Cargnello, M.; Gentilini, C.; Montini, T.; Fonda, E.; Mehraeen, S.; Chi, M. F.; Herrera-Collado, M.; Browning, N. D.; Polizzi, S.; Pasquato, L.; Fornasiero, P. Active and stable embedded $\mathrm{Au} @ \mathrm{CeO}_{2}$ catalysts for preferential oxidation of CO. Chem. Mater. 2010, 22, 4335-4345.

[63] Liu, X. Y.; Wang, A. Q.; Zhang, T.; Su, D. -S.; Mou, C. -Y. $\mathrm{Au}-\mathrm{Cu}$ alloy nanoparticles supported on silica gel as catalyst for $\mathrm{CO}$ oxidation: Effects of $\mathrm{Au} / \mathrm{Cu}$ ratios. Catal. Today 2010, in press, DOI: 10.1016/j.cattod.2010.1005.1019.

[64] Zhu, H. G.; Lee, B.; Dai, S.; Overbury, S. H. Coassembly synthesis of ordered mesoporous silica materials containing Au nanoparticles. Langmuir 2003, 19, 3974-3980.

[65] Yan, W. F.; Chen, B.; Mahurin, S. M.; Dai, S.; Overbury, S. H. Brookite-supported highly stable gold catalytic system for CO oxidation. Chem. Commun. 2004, 1918-1919.

[66] Yan, W. F.; Chen, B.; Mahurin, S. M.; Hagaman, E. W.; Dai, S.; Overbury, S. H. Surface sol-gel modification of mesoporous silica materials with $\mathrm{TiO}_{2}$ for the assembly of ultrasmall gold nanoparticles. J. Phys. Chem. B 2004, 108, 2793-2796.

[67] Zhu, H. G.; Pan, Z. W.; Chen, B.; Lee, B.; Mahurin, S. M.; Overbury, S. H.; Dai, S. Synthesis of ordered mixed titania and silica mesostructured monoliths for gold catalysts. $J$. Phys. Chem. B 2004, 108, 20038-20044.

[68] Lee, B.; Zhu, H. G.; Zhang, Z. T.; Overbury, S. H.; Dai, S. Preparation of bicontinuous mesoporous silica and organosilica materials containing gold nanoparticles by co-synthesis method. Micropor. Mesopor. Mater. 2004, 70, 71-80.

[69] Yan, W. F.; Petkov, V.; Mahurin, S. M.; Overbury, S. H.; Dai, S. Powder XRD analysis and catalysis characterization of ultra-small gold nanoparticles deposited on titaniamodified SBA-15. Catal. Commun. 2005, 6, 404-408.

[70] Yan, W. F.; Chen, B.; Mahurin, S. M.; Schwartz, V.; Mullins, D. R.; Lupini, A. R.; Pennycook, S. J.; Dai, S.; Overbury, S. H. Preparation and comparison of supported gold nanocatalysts on anatase, brookite, rutile, and P25 polymorphs of $\mathrm{TiO}_{2}$ for catalytic oxidation of CO. J. Phys. Chem. B 2005, 109, 10676-10685.

[71] Yan, W. F.; Mahurin, S. M.; Pan, Z. W.; Overbury, S. H.; Dai, S. Ultrastable Au nanocatalyst supported on surfacemodified $\mathrm{TiO}_{2}$ nanocrystals. J. Am. Chem. Soc. 2005, 127, 10480-10481.

[72] Yan, W. F.; Mahurin, S. M.; Chen, B.; Overbury, S. H.; Dai, S. Effect of supporting surface layers on catalytic activities 
of gold nanoparticles in $\mathrm{CO}$ oxidation. J. Phys. Chem. B 2005, 109, 15489-15496.

[73] Yan, W. F.; Brown, S.; Pan, Z. W.; Mahurin, S. M.; Overbury, S. H.; Dai, S. Ultrastable gold nanocatalyst supported by nanosized non-oxide substrate. Angew. Chem. Int. Ed. 2006, 45, 3614-3618.

[74] Yan, W. F.; Mahurin, S. M.; Overbury, S. H.; Dai, S. Nanoengineering catalyst supports via layer-by-layer surface functionalization. Top. Catal. 2006, 39, 199-212.

[75] Zhu, H. G.; Liang, C. D.; Yan, W. F.; Overbury, S. H.; Dai, $\mathrm{S}$. Preparation of highly active silica-supported Au catalysts for $\mathrm{CO}$ oxidation by a solution-based technique. J. Phys. Chem. B 2006, 110, 10842-10848.

[76] Zhu, H. G.; Ma, Z.; Clark, J. C.; Pan, Z. W.; Overbury, S. H.; Dai, S. Low-temperature $\mathrm{CO}$ oxidation on $\mathrm{Au} /$ fumed $\mathrm{SiO}_{2}$-based catalysts prepared from $\mathrm{Au}(\mathrm{en})_{2} \mathrm{Cl}_{3}$ precursor. Appl. Catal. A 2007, 326, 89-99.

[77] Zhu, H. G.; Ma, Z.; Overbury, S. H.; Dai, S. Rational design of gold catalysts with enhanced thermal stability: Post modification of $\mathrm{Au} / \mathrm{TiO}_{2}$ by amorphous $\mathrm{SiO}_{2}$ decoration. Catal. Lett. 2007, 116, 128-135.

[78] Ma, Z.; Overbury, S. H.; Dai, S. Au/ $\mathrm{M}_{x} \mathrm{O}_{y} / \mathrm{TiO}_{2}$ catalysts for $\mathrm{CO}$ oxidation: Promotional effect of main-group, transition, and rare-earth metal oxide additives. J. Mol. Catal. A 2007, 273, 186-197.

[79] Ma, Z.; Brown, S.; Overbury, S. H.; Dai, S. Au/PO $4{ }^{3-} / \mathrm{TiO}_{2}$ and $\mathrm{PO}_{4}{ }^{3-} / \mathrm{Au} / \mathrm{TiO}_{2}$ catalysts for $\mathrm{CO}$ Oxidation: Effect of synthesis details on catalytic performance. Appl. Catal. A 2007, 327, 226-237.

[80] Ma, Z.; Liang, C. D.; Overbury, S. H.; Dai, S. Gold nanoparticles on electroless-deposition-derived $\mathrm{MnO}_{x} / \mathrm{C}$ : Synthesis, characterization, and catalytic $\mathrm{CO}$ oxidation. $J$. Catal. 2007, 252, 119-126.

[81] Yan, W. F.; Chen, B.; Mahurin, S. M.; Overbury, S. H.; Dai, S. Gold supported on microporous aluminophosphate $\mathrm{AlPO}_{4}-\mathrm{H} 1$ for selective oxidation of $\mathrm{CO}$ in a $\mathrm{H}_{2}$-rich stream. Stud. Surf. Sci. Catal. 2007, 170, 1065-1071.

[82] Yan, W. F.; Ma, Z.; Mahurin, S. M.; Jiao, J.; Hagaman, E. W.; Overbury, S. H.; Dai, S. Novel Au/ $/ \mathrm{TiO}_{2} / \mathrm{Al}_{2} \mathrm{O}_{3} \cdot x \mathrm{H}_{2} \mathrm{O}$ catalysts for CO oxidation. Catal. Lett. 2008, 121, 209-218.

[83] Ma, Z.; Zhu, H. G.; Yan, W. F.; Overbury, S. H.; Dai, S. Functionalized mesoporous materials for gold catalysis. In Nanoporous Materials: Proceedings of the 5th International Symposium; Sayari, A.; Jaroniec, M., eds.; World Scientific Publishing, Singapore, 2008; pp. 529-542.

[84] Ma, Z.; Brown, S.; Howe, J. Y.; Overbury, S. H.; Dai, S. Surface modification of $\mathrm{Au} / \mathrm{TiO}_{2}$ catalysts by $\mathrm{SiO}_{2}$ via atomic layer deposition. J. Phys. Chem. C 2008, 112, 9448-9457.
[85] Yin, H. F.; Ma, Z.; Overbury, S. H.; Dai, S. Promotion of $\mathrm{Au}(\mathrm{en})_{2} \mathrm{Cl}_{3}$-derived $\mathrm{Au} /$ fumed $\mathrm{SiO}_{2}$ by treatment with $\mathrm{KMnO}_{4}$. J. Phys. Chem. C 2008, 112, 8349-8358.

[86] Ma, Z.; Yin, H. F.; Overbury, S. H.; Dai, S. Metal phosphates as a new class of supports for gold nanocatalysts. Catal. Lett. 2008, 126, 20-30.

[87] Yin, H. F.; Wang, C.; Zhu, H. G.; Overbury, S. H.; Sun, S. H.; Dai, S. Colloidal deposition synthesis of supported gold nanocatalysts based on $\mathrm{Au}-\mathrm{Fe}_{3} \mathrm{O}_{4}$ dumbbell nanoparticles. Chem. Commun. 2008, 4357-4359.

[88] Zhou, S. H.; Yin, H. F.; Schwartz, V.; Wu, Z. L.; Mullins, D. R.; Eichhorn, B.; Overbury, S. H.; Dai, S. In situ phase separation of NiAu alloy nanoparticles for preparing highly active $\mathrm{Au} / \mathrm{NiO} \mathrm{CO}$ oxidation catalysts. Chem. Phys. Chem. 2008, 9, 2475-2479.

[89] Ma, Z.; Overbury, S. H.; Dai, S. Gold nanoparticles as chemical catalysts. In Nanomaterials: Inorganic and Bioinorganic Perspectives; Lukehart, C. M.; Scott, R. A. eds.; John Wiley \& Sons, Chichester, 2009; pp. 247-266.

[90] Zhou, S. H.; Ma, Z.; Yin, H. F.; Wu, Z. L.; Eichhorn, B.; Overbury, S. H.; Dai, S. Low-temperature solution-phase synthesis of NiAu alloy nanoparticles via butyllithium reduction: Influence of synthesis details and application as the precursor to active $\mathrm{Au}-\mathrm{NiO} / \mathrm{SiO}_{2}$ catalysts through proper pretreatment. J. Phys. Chem. C 2009, 113, 5758-5765.

[91] Lee, B.; Ma, Z.; Zhang, Z.; Park, C.; Dai, S. Influences of synthesis conditions and mesoporous structures on the gold nanoparticles supported on mesoporous silica hosts. Micropor. Mesopor. Mater. 2009, 122, 160-167.

[92] Ma, Z.; Yin, H. F.; Dai, S. Performance of $\mathrm{Au} / \mathrm{M}_{x} \mathrm{O}_{y} / \mathrm{TiO}_{2}$ catalysts in water-gas shift reaction. Catal. Lett. 2010, 136, 83-91.

[93] Yin, H. F.; Ma, Z.; Chi, M. F.; Dai, S. Activation of dodecanethiol-capped gold catalysts for $\mathrm{CO}$ oxidation by treatment with $\mathrm{KMnO}_{4}$ or $\mathrm{K}_{2} \mathrm{MnO}_{4}$. Catal. Lett. 2010, 136, 209-221.

[94] Ma, Z.; Yin, H. F.; Dai, S. Influence of preparation methods on the performance of metal phosphate-supported gold catalysts in CO oxidation. Catal. Lett. 2010, 40-45.

[95] Yin, H. F.; Ma, Z.; Chi, M. F.; Dai, S. Heterostructured catalysts prepared by dispersing $\mathrm{Au} @ \mathrm{Fe}_{2} \mathrm{O}_{3}$ core-shell structures on supports and their performance in $\mathrm{CO}$ oxidation. Catal. Today 2010, in press, DOI: 10.1016/ $\mathrm{j} /$ cattod.2010.1005.1013.

[96] Bokhimi, X.; Zanella, R. Crystallite size and morphology of the phases in $\mathrm{Au} / \mathrm{TiO}_{2}$ and $\mathrm{Au} / \mathrm{Ce}-\mathrm{TiO}_{2}$ catalysts. J. Phys. Chem. C 2007, 111, 2525-2532.

[97] Comotti, M.; Weidenthaler, C.; Li, W. -C.; Schüth, F. Comparison of gold supported catalysts obtained by using different allotropic forms of titanium dioxide. Top. Catal. 
2007, 44, 275-284.

[98] Su, F. -Z.; Chen, M.; Wang, L. -C.; Huang, X. -S.; Liu, Y. -M.; Cao, Y.; He, H. Y.; Fan, K. -N. Aerobic oxidation of alcohols catalyzed by gold nanoparticles supported on gallia polymorphs. Chem. Commun. 2008, 1027-1032.

[99] Huang, J.; Dai, W. L.; Fan, K. N. Support effect of $\mathrm{Au} / \mathrm{FeO}_{x}$ catalysts in the oxidative dehydrogenation of $\alpha, \gamma$-diols to lactones. J. Catal. 2008, 112, 16110-16117.

[100] Huang, J.; Dai, W. L.; Fan, K. N. Remarkable support crystal phase effect in $\mathrm{Au} / \mathrm{FeO}_{x}$ catalyzed oxidation of 1,4-butanediol to $\gamma$-butyrolactone. J. Catal. 2009, 266, 228-235.

[101] Pietron, J. J.; Stroud, R. M.; Rolison, D. R. Using three dimensions in catalytic mesoporous nanoarchitectures. Nano Lett. 2002, 2, 545-549.

[102] Rolison, D. R. Catalytic nanoarchitectures-The importance of nothing and the unimportance of periodicity. Science 2003, 299, 1698-1701.

[103] Carrettin, S.; Concepción, P.; Corma, A.; Nieto, J. M. L.; Puntes, V. F. Nanocrystalline $\mathrm{CeO}_{2}$ increases the activity of $\mathrm{Au}$ for $\mathrm{CO}$ oxidation by two orders of magnitude. Angew. Chem. Int. Ed. 2004, 43, 2538-2540.

[104] Guzman, J.; Corma, A. Nanocrystalline and mesostructured $\mathrm{Y}_{2} \mathrm{O}_{3}$ as supports for gold catalysts. Chem. Commun. 2005, 743-745.

[105] Zhang, X.; Wang, H.; Xu, B. Q. Remarkable nanosize effect of zirconia in $\mathrm{Au} / \mathrm{ZrO}_{2}$ catalyst for $\mathrm{CO}$ oxidation. $J$. Phys. Chem. B 2005, 109, 9678-9683.

[106] Bokhimi, X.; Zanella, R.; Morales, A. Au/rutile catalysts: Effect of support dimensions on the gold crystallite size and the catalytic activity for $\mathrm{CO}$ oxidation. J. Phys. Chem. C 2007, 111, 15210-15216.

[107] Li, J.; Ta, N.; Song, W.; Zhan, E. S.; Shen, W. J. Au/ZrO catalysts for low-temperature water gas shift reaction: Influence of particle sizes. Gold Bull. 2009, 42, 48-60.

[108] Wang, G. -H.; Li, W. -C.; Jia, K. -M.; Spliethoff, B.; Schüth, F.; Lu, A. -H. Shape and size controlled $\alpha-\mathrm{Fe}_{2} \mathrm{O}_{3}$ nanoparticles as supports for gold-catalysts: Synthesis and influence of support shape and size on catalytic performance. Appl. Catal. A 2009, 364, 42-47.

[109] Han, Y. -F.; Zhong, Z. Y.; Ramesh, K.; Chen, F.; Chen, L. Effects of different types of $\gamma-\mathrm{Al}_{2} \mathrm{O}_{3}$ on the activity of gold nanoparticles for $\mathrm{CO}$ oxidation at low-temperatures. $J$. Phys. Chem. C 2007, 111, 3163-3170.

[110] Si, R.; Flytzani-Stephanopoulos, M. Shape and crystalplane effects of nanoscale ceria on the activity of $\mathrm{Au}-\mathrm{CeO}_{2}$ catalysts for the water-gas shift reaction. Angew. Chem. Int. Ed. 2008, 47, 2884-2887.

[111] Wang, L. C.; Liu, Y. M.; Chen, M.; Cao, Y.; He, H. -Y.;
Fan, K. -N. $\mathrm{MnO}_{2}$ nanorod supported gold nanoparticles with enhanced activity for solvent-free aerobic alcohol oxidation. J. Phys. Chem. C 2008, 112, 1027-1032.

[112] Yi, G. Q.; Xu, Z. N.; Guo, G. C.; Tanaka, K.; Yuan, Y. Z. Morphology effects of nanocrystalline $\mathrm{CeO}_{2}$ on the preferential $\mathrm{CO}$ oxidation in $\mathrm{H}_{2}$-rich gas over $\mathrm{Au} / \mathrm{CeO}_{2}$ catalyst. Chem. Phys. Lett. 2009, 479, 128-132.

[113] Huang, X. -S.; Sun, H.; Wang, L. -C.; Liu, Y. -M.; Fan, K. -N.; Cao, Y. Morphology effects of nanoscale ceria on the activity of $\mathrm{Au} / \mathrm{CeO}_{2}$ catalysts for low-temperature $\mathrm{CO}$ oxidation. Appl. Catal. B 2009, 90, 224-232.

[114] Yi, G. Q.; Yang, H. W.; Li, B. D.; Lin, H. Q.; Tanaka, K.; Yuan, Y. Z. Preferential $\mathrm{CO}$ oxidation in $\mathrm{a}_{2}$-rich gas by $\mathrm{Au} / \mathrm{CeO}_{2}$ catalysts: Nanoscale $\mathrm{CeO}_{2}$ shape effect and mechanism aspect. Catal. Today 2010, in press, DOI: 10.1016/j.cattod.2010.1001.1049.

[115] Lin, S. D.; Bollinger, M.; Vannice, M. A. Low-temperature $\mathrm{CO}$ oxidation over $\mathrm{Au} / \mathrm{TiO}_{2}$ and $\mathrm{Au} / \mathrm{SiO}_{2}$ catalysts. Catal. Lett. 1993, 17, 245-262.

[116] Overbury, S. H.; Ortiz-Soto, L.; Zhu, H. G.; Lee, B.; Amiridis, M. D.; Dai, S. Comparison of $\mathrm{Au}$ catalysts supported on mesoporous titania and silica: Investigation of Au particle size effects and metal-support interactions. Catal. Lett. 2004, 95, 99-106.

[117] Schubert, M. M.; Hackenberg, S.; van Veen, A. C.; Muhler, M.; Plzak, V.; Behm, R. J. CO oxidation over supported gold catalysts-"inert" and "active" support materials and their role for the oxygen supply during reaction. J. Catal. 2001, 197, 113-122.

[118] Lee, S. -J.; Gavriilidis, A. Supported Au catalysts for low-temperature $\mathrm{CO}$ oxidation prepared by impregnation. J. Catal. 2002, 206, 305-313.

[119] Wen, L.; Fu, J. -K.; Gu, P. -Y.; Yao, B. -X.; Lin, Z. -H.; Zhou, J. -Z. Monodispersed gold nanoparticles supported on $\gamma-\mathrm{Al}_{2} \mathrm{O}_{3}$ for enhancement of low-temperature catalytic oxidation of CO. Appl. Catal. B 2008, 79, 402-409.

[120] Okumura, M.; Tsubota, S.; Iwamoto, M.; Haruta, M. Chemical vapor deposition of gold nanoparticles on MCM-41 and their catalytic activities for the lowtemperature oxidation of $\mathrm{CO}$ and of $\mathrm{H}_{2}$. Chem. Lett. 1998, 315-316.

[121] Okumura, M.; Nakamura, S.; Tsubota, S.; Nakamura, T.; Azuma, M.; Haruta, M. Chemical vapor deposition of gold on $\mathrm{Al}_{2} \mathrm{O}_{3}, \mathrm{SiO}_{2}$, and $\mathrm{TiO}_{2}$ for the oxidation of $\mathrm{CO}$ and of $\mathrm{H}_{2}$. Catal. Lett. 1998, 51, 53-58.

[122] Okumura, M.; Tsubota, S.; Haruta, M. Preparation of supported gold catalysts by gas-phase grafting of gold acethylacetonate for low-temperature oxidation of $\mathrm{CO}$ and of $\mathrm{H}_{2}$. J. Mol. Catal. A 2003, 199, 73-84. 
[123] Yang, C. -M.; Kalwei, M.; Schüth, F.; Chao, K. -J. Gold nanoparticles in SBA-15 showing catalytic activity in $\mathrm{CO}$ oxidation. Appl. Catal. A 2003, 254, 289-296.

[124] Chi, Y. -S.; Lin, H. -P.; Mou, C. -Y. CO oxidation over gold nanocatalyst confined in mesoporous silica. Appl. Catal. A 2005, 284, 199-206.

[125] Budroni, G., Corma, A. Gold-organic-inorganic highsurface-area materials as precursors of highly active catalysts. Angew. Chem. Int. Ed. 2006, 45, 3328-3331.

[126] Guillemot, D.; Polisset-Thfoin, M.; Fraissard, J. Preparation of nanometeric gold particles on NaHY. Catal. Lett. 1996, 41, 143-148.

[127] Bulushev, D. A.; Yuranov, I.; Suvorova, E. I.; Buffat, P. A.; Kiwi-Minsker, L. Highly dispersed gold on activated carbon fibers for low-temperature CO oxidation. J. Catal. 2004, 224, 8-17.

[128] Zhu, L. H.; Letaief, S.; Liu, Y.; Gervais, F.; Detellier, C. Clay-mineral-supported gold nanoparticles. Appl. Clay. Sci. 2009, 43, 439-446.

[129] Zanella, R.; Sandoval, A.; Santiago, P.; Basiuk, V. A.; Saniger, J. M. New preparation method of gold nanoparticles on $\mathrm{SiO}_{2}$. J. Phys. Chem. B 2006, 110, 8559-8565.

[130] Wu, Z. L.; Zhou, S. H.; Zhu, H. G.; Dai, S.; Overbury, S. $\mathrm{H}$. Oxygen-assisted reduction of $\mathrm{Au}$ species on $\mathrm{Au} / \mathrm{SiO}_{2}$ catalyst in room temperature $\mathrm{CO}$ oxidation. Chem. Commun. 2008, 3308-3310.

[131] Wu, Z. L.; Zhou, S. H.; Zhu, H. G.; Dai, S.; Overbury, S. H. DRIFTS-QMS study of room temperature $\mathrm{CO}$ oxidation on $\mathrm{Au} / \mathrm{SiO}_{2}$ catalyst: Nature and role of different Au species. J. Phys. Chem. C 2009, 113, 3726-3734.

[132] Yin, H. F.; Ma, Z.; Zhu, H. G.; Chi, M. F.; Dai, S. Evidence for and mitigation of the encapsulation of gold nanoparticles within $\mathrm{SiO}_{2}$ matrix upon calcining $\mathrm{Au} / \mathrm{SiO}_{2}$ catalysts at high temperatures: implication to catalyst deactivation. Appl. Catal. A 2010, 386, 147-156.

[133] Venugopal, A.; Scurrell, M. S. Hydroxyapatite as a novel support for gold and ruthenium catalysts: Behaviour in the water gas shift reaction. Appl. Catal. A 2003, 245, 137-147.

[134] Lian, H. L.; Jia, M. J.; Pan, W. C.; Li, Y.; Zhang, W. X.; Jiang, D. Z. Gold-base catalysts supported on carbonate for low-temperature CO oxidation. Catal. Commun. 2005, $6,47-51$.

[135] Phonthammachai, N.; Zhong, Z. Y.; Guo, J.; Han, Y. F.; White, T. J. Synthesis of high performance hydroxyapatitegold catalysts for CO oxidation. Gold Bull. 2008, 41, $42-50$.

[136] Han, Y. -F.; Phonthammachai, N.; Ramesh, K.; Zhong, Z. Y.; White, T. Removing organic compounds from aqueous medium via wet peroxidation by gold catalysts. Ind. Eng. Chem. Res. 2008, 42, 908-912.

[137] Liu, J. F.; Chen, W.; Liu, X. W.; Zhou, K. B.; Li, Y. D. $\mathrm{Au} / \mathrm{LaVO}_{4}$ nanocomposite: Preparation, characterization, and catalytic activity for CO oxidation. Nano Res. 2008, 1 , 46-55.

[138] Sun, H.; Su, F. -Z.; Ni, J.; Cao, Y.; He, H. Y.; Fan, K. N. Gold supported on hydroxyapatite as a versatile multifunctional catalyst for the direct tandem synthesis of imines and oximes. Angew. Chem. Int. Ed. 2009, 48, 4390-4393.

[139] Domínguez, M. I.; Romero-Sarria, F.; Centeno, M. A.; Odriozola, J. A. Gold/hydroxyapatite catalysts: Synthesis, characterization and catalytic activity to $\mathrm{CO}$ oxidation. Appl. Catal. B 2009, 87, 245-251.

[140] Karimi, B.; Esfahani, F. K. Gold nanoparticles supported on $\mathrm{Cs}_{2} \mathrm{CO}_{3}$ as recyclable catalyst system for selective aerobic oxidation of alcohols at room temperature. Chem. Commun. 2009, 5555-5557.

[141] Mitsudome, T.; Noujima, A.; Mizugaki, T.; Jitsukawa, K.; Kaneda, K. Efficient aerobic oxidation of alcohols using a hydrotalcite-supported gold nanoparticle catalyst. Adv. Synth. Catal. 2009, 351, 1890-1896.

[142] Park, Y.; Lee, B.; Kim, C.; Kim, J.; Nam, S.; Oh, Y.; Park, B. Modification of gold catalysis with aluminum phosphate for oxygen-reduction reaction. J. Phys. Chem. C 2010, 114, 3688-3692.

[143] Liu, Y. M.; Tsunoyama, H.; Akita, T.; Tsukuda, T. Efficient and selective epoxidation of styrene with TBHP catalyzed by $\mathrm{Au}_{25}$ clusters on hydroxyapatite. Chem. Commun. 2010, 46, 550-552.

[144] Mitsudome, T.; Noujima, A.; Mikami, Y.; Mizugaki, T.; Jitsukawa, K.; Kaneda, K. Supported gold and silver nanoparticles for catalytic deoxygenation of epoxide into alkenes. Angew. Chem. Int. Ed. 2010, 49, 5545-5548.

[145] Tanabe, K.; Misono, M.; Ono, Y.; Hattori, H. New Solid Acids and Bases; Elsevier: Amsterdam, 1989.

[146] Li, M. J.; Wu, Z. L.; Ma, Z.; Schwartz, V.; Mullins, D. R.; Dai, S.; Overbury, S. H. CO oxidation on $\mathrm{Au} / \mathrm{FePO}_{4}$ catalyst: Reaction pathways and nature of $\mathrm{Au}$ sites. $J$. Catal. 2009, 266, 98-105.

[147] Guzman, J.; Carrettin, S.; Corma, A. Spectroscopic evidence for the supply of reactive oxygen during $\mathrm{CO}$ oxidation catalyzed by gold supported on nanocrystalline $\mathrm{CeO}_{2}$. J. Am. Chem. Soc. 2005, 127, 3286-3287.

[148] Guzman, J.; Carrettin, S.; Fierro-Gonzalez, J. C.; Hao, Y. L.; Gates, B. C.; Corma, A. CO oxidation catalyzed by supported gold: Cooperation between gold and nanocrystalline rare-earth supports forms reactive surface superoxide and 
peroxide species. Angew. Chem. Int. Ed. 2005, 44, 4778-4781.

[149] Ma, Z.; Zaera, F. Heterogeneous Catalysis by Metals. In Encyclopedia of Inorganic Chemistry (Second Edition); King, R. B., ed.; John Wiley \& Sons: Chichester, 2005; pp. 1768-1784.

[150] Bore, M. T.; Mokhonoana, M. P.; Ward, T. L.; Coville, N. J.; Datye, A. K. Synthesis and reactivity of gold nanoparticles supported on transition metal doped mesoporous silica. Micropor. Mesopor. Mater. 2006, 95, 118-125.

[151] Nijhuis, T. A.; Huizinga, B. J.; Makkee, M.; Moulijn, J. A. Direct epoxidation of propene using gold dispersed on TS-1 and other titanium-containing supports. Ind. Eng. Chem. Res. 1999, 38, 884-891.

[152] Stangland, E. E.; Stavens, K. B.; Andres, R. P.; Delgass, W. N. Characterization of gold-titania catalysts via oxidation of propylene to propylene oxide. J. Catal. 2000, 191, 332-347.

[153] Qi, C. X.; Akita, T.; Okumura, M.; Haruta, M. Epoxidation of propylene over gold catalysts supported on non-porous silica. Appl. Catal. A 2001, 218, 81-89.

[154] Tai, Y.; Murakami, J.; Tajiri, K.; Ohashi, F.; Daté, M.; Tsubota, S. Oxidation of carbon monoxide on $\mathrm{Au}$ nanoparticles in titania and titania-coated silica aerogels. Appl. Catal. A 2004, 268, 183-187.

[155] Venezia, A. M.; Liotta, F. L.; Pantaleo, G.; Beck, A.; Horvath, A.; Geszti, O.; Kocsonya, A.; Guczi, L. Effect of $\mathrm{Ti}(\mathrm{IV})$ loading on $\mathrm{CO}$ oxidation activity of gold on $\mathrm{TiO}_{2}$ doped amorphous silica. Appl. Catal. A 2006, 310, 114-121.

[156] Bandyopadhyay, M.; Korsak, O.; van den Berg, M. W. E.; Grunert, W.; Birkner, A.; Li, W.; Schüth, F.; Gies, H. Gold nano-particles stabilized in mesoporous MCM-48 as active CO-oxidation catalyst. Micropor. Mesopor. Mater. 2006, 89, 158-163.

[157] Xu, L. -X.; He, C. -H.; Zhu, M. -Q.; Wu, K. -J.; Lai, Y. -L. Silica-supported gold catalyst modified by doping with titania for cyclohexane oxidation. Catal. Lett. 2007, 118, 248-253.

[158] Ruszel, M.; Grzybowska, B.; Łaniecki, M.; Wójtowski, M. $\mathrm{Au} / \mathrm{Ti}-\mathrm{SBA}-15$ catalysts in $\mathrm{CO}$ and preferential (PROX) CO oxidation. Catal. Commun. 2007, 8, 1284-1286.

[159] Beck, A.; Horváth, A.; Stefler, G.; Katona, R.; Geszti, O.; Tolnai, G.; Liotta, L. F.; Guczi, L. Formation and structure of $\mathrm{Au} / \mathrm{TiO}_{2}$ and $\mathrm{Au} / \mathrm{CeO}_{2}$ nanostructures in mesoporous SBA-15. Catal. Today 2008, 139, 180-187.

[160] Tai, Y.; Tajiri, K. Preparation, thermal stability, and CO oxidation activity of highly loaded Au/titania-coated silica aerogel catalysts. Appl. Catal. A 2008, 342, 113-118.

[161] Tai, Y.; Yamaguchi, W.; Tajiri, K.; Kageyama, H. Structures and $\mathrm{CO}$ oxidation activities of size-selected $\mathrm{Au}$ nanoparticles in mesoporous titania-coated silica aerogels. Appl. Catal. A 2009, 364, 143-149.

[162] Beck, A.; Horváth, A.; Stefler, G.; Scurrel, M. S.; Guczi, L. Role of preparation techniques in the activity of $\mathrm{Au} / \mathrm{TiO}_{2}$ nanostructures stabilised on $\mathrm{SiO}_{2}: \mathrm{CO}$ and preferential $\mathrm{CO}$ oxidation. Top. Catal. 2009, 52, 912-919.

[163] Narkhede, V. S.; De Toni, A.; Narkhede, V. V.; Guraya, M.; Niemantsverdriet, J. W.; van den Berg, M. W. E.; Grünert, W.; Gies, H. Au/ $/ \mathrm{TiO}_{2}$ catalysts encapsulated in the mesopores of siliceous MCM-48-Reproducible synthesis, structural characterization and activity for $\mathrm{CO}$ oxidation. Micropor. Mesopor. Mater. 2009, 118, 52-60.

[164] Lim, S. H.; Phonthammachai, N.; Zhong, Z. Y.; Teo, J.; White, T. J. Robust gold-decorated silica-titania pebbles for low-temperature $\mathrm{CO}$ catalytic oxidation. Langmuir 2009, 25, 9480-9486.

[165] Peza-Ledesma, C. L.; Escamilla-Perea, L.; Nava, R.; Pawelec, B.; Fierro, J. L. G. Supported gold catalysts in SBA-15 modified with $\mathrm{TiO}_{2}$ for oxidation of carbon monoxide. Appl. Catal. A 2010, 375, 37-48.

[166] Moreau, F.; Bond, G. C. CO oxidation activity of gold catalysts supported on various oxides and their improvement by inclusion of an iron component. Catal. Today 2006, 114, 362-368.

[167] Xu, H. Y.; Chu, W.; Luo, J. J.; Liu, M. New Au/FeO $/ \mathrm{SiO}_{2}$ catalysts using deposition-precipitation for low-temperature carbon monoxide oxidation. Catal. Commun. 2010, 11, 812-815.

[168] Dekkers, M. A. P.; Lippits, M. J.; Nieuwenhuys, B. E., Supported gold $/ \mathrm{MO}_{x}$ catalysts for $\mathrm{NO} / \mathrm{H}_{2}$ and $\mathrm{CO} / \mathrm{O}_{2}$ reactions. Catal. Today 1999, 54, 381-390.

[169] Xu, X. Y.; Li, J. J.; Hao, Z. P.; Zhao, W.; Hu, C. Characterization and catalytic performance of Co/SBA-15 supported gold catalysts for CO oxidation. Mater. Res. Bull. 2006, 41, 406-413.

[170] Qian, K.; Huang, W. X.; Jiang, Z. Q.; Sun, H. X. Anchoring highly active gold nanoparticles on $\mathrm{SiO}_{2}$ by $\mathrm{CoO}_{x}$ additive. J. Catal. 2007, 248, 137-141.

[171] Qian, K.; Fang, J.; Huang, W. X.; He, B.; Jiang, Z. Q.; Ma, Y. S.; Wei, S. Q. Understanding the deposition-precipitation process for the preparation of supported Au catalysts. $J$. Mol. Catal. A 2010, 320, 97-105.

[172] Qian, K.; Huang, W. X.; Fang, J.; Lv, S. S.; He, B.; Jiang, Z. Q.; Wei, S. Q. Low-temperature CO oxidation over $\mathrm{Au} / \mathrm{ZnO} / \mathrm{SiO}_{2}$ catalysts: Some mechanism insights. $J$. Catal. 2008, 255, 269-278. 
[173] Qian, K.; Lv, S. S.; Xiao, X. Y.; Sun, H. X.; Lu, J. Q.; Luo, M. F.; Huang, W. X. Influence of $\mathrm{CeO}_{2}$ nicrostructures on the structure and activity of $\mathrm{Au} / \mathrm{CeO}_{2} / \mathrm{SiO}_{2}$ catalysts in $\mathrm{CO}$ oxidation. J. Mol. Catal. A 2009, 306, 40-47.

[174] Hernandez, J. A.; Gómez, S.; Pawelec, B.; Zepeda, T. A. $\mathrm{CO}$ oxidation on Au nanoparticles supported on wormhole HMS material: Effect of support modification with $\mathrm{CeO}_{2}$. Appl. Catal. B 2009, 89, 128-136.

[175] Escamilla-Perea, L.; Nava, R.; Pawelec, B.; Rosmaninho, M. G.; Peza-Ledesma, C. L.; Fierro, J. L. G. SBA-15supported gold nanoparticles decorated by $\mathrm{CeO}_{2}$ : Structural characteristics and $\mathrm{CO}$ oxidation activity. Appl. Catal. A 2010, 381, 42-53.

[176] Veith, G. M.; Lupini, A. R.; Rashkeev, S.; Pennycook, S. J.; Mullins, D. R.; Schwartz, V.; Bridges, C. A.; Dudney, N. J. Thermal stability and catalytic activity of gold nanoparticles supported on silica. J. Catal. 2009, 262, 92-101.

[177] Chang, L. -H.; Chen, Y. -W.; Sasirekha, N. Preferential oxidation of carbon monoxide in hydrogen stream over $\mathrm{Au} / \mathrm{MgO}_{x}-\mathrm{TiO}_{2}$ catalysts. Ind. Eng. Chem. Res. 2008, 47, 4098-4105.

[178] Chang, L. -H.; Sasirekha, N.; Chen, Y. -W.; Au/ $\mathrm{MnO}_{2}-$ $\mathrm{TiO}_{2}$ catalyst for preferential oxidation of carbon monoxide in hydrogen stream. Catal. Commun. 2007, 8, 1702-1710.

[179] Shou, M.; Takekawa, H.; Ju, D. -Y.; Hagiwara, T.; Lu, D. -L.; Tanaka, K. Activation of a $\mathrm{Au} / \mathrm{TiO}_{2}$ catalyst by loading a large amount of Fe-oxide: Oxidation of $\mathrm{CO}$ enhanced by $\mathrm{H}_{2}$ and $\mathrm{H}_{2} \mathrm{O}$. Catal. Lett. 2006, 108, 119-124.

[180] Chang, F. -W.; Yu, H. -Y.; Roselin, L. S.; Yang, H. -C.; Ou, T. -C. Hydrogen production by partial oxidation of methanol over gold catalysts supported on $\mathrm{TiO}_{2}-\mathrm{MO}_{x}(\mathrm{M}$ = Fe, Co, Zn) composite oxides. Appl. Catal. A 2006, 302, 157-167.

[181] Sangeetha, P.; Zhao, B.; Chen, Y. -W. Au/CuO $-\mathrm{TiO}_{2}$ catalysts for preferential oxidation of $\mathrm{CO}$ in hydrogen stream. Ind. Eng. Chem. Res. 2010, 49, 2096-2102.

[182] Mallick, K.; Scurrell, M. S. CO oxidation over gold nanoparticles supported on $\mathrm{TiO}_{2}$ and $\mathrm{TiO}_{2}-\mathrm{ZnO}$ : Catalytic activity effects due to surface modification of $\mathrm{TiO}_{2}$ with ZnO. Appl. Catal. A 2003, 253, 527-536.

[183] Sangeetha, P.; Chen, Y. -W. Preferential oxidation of CO in $\mathrm{H}_{2}$ stream on $\mathrm{Au} / \mathrm{CeO}_{2}-\mathrm{TiO}_{2}$ catalysts. Int. J. Hydrogen Energ. 2009, 34, 7342-7347.

[184] Park, J. B.; Graciani, J.; Evans, J.; Stacchiola, D.; Ma, S. G.; Liu, P.; Nambu, A.; Sanz, J. F.; Hrbek, J.; Rodrigues, J. A. High catalytic activity of $\mathrm{Au} / \mathrm{CeO}_{x} / \mathrm{TiO}_{2}(110)$ controlled by the nature of the mixed-metal oxide at the nanometer level. Proc. Natl. Acad. Sci. USA 2009, 106, 4975-4980.

[185] Xie, Y. C.; Tang, Y. Q. Spontaneous monolayer dispersion of oxides and salts. Adv. Catal. 1990, 37, 1-43.

[186] Wang, C. -M.; Fan, K. -N.; Liu, Z. -P. Insight into the synergetic effect in ternary gold-based catalysts: Ultrastability and high activity of $\mathrm{Au}$ on alumina modified titania. $J$. Phys. Chem. C 2007, 111, 13539-13546.

[187] Shang, C.; Liu, Z. -P. Is transition metal oxide a must? Moisture-assisted oxygen activation in $\mathrm{CO}$ oxidation on gold/ $\gamma$-alumina. J. Phys. Chem. C 2010, in press, DOI: $10.1021 / j p 102477 \mathrm{~g}$.

[188] Hagaman, E. W.; Jiao, J.; Chen, B. H.; Ma, Z.; Yin, H. F. L.; Dai, S. Surface alumina species on modified titanium oxide. A solid-state ${ }^{27} \mathrm{Al}$ MAS and 3QMAS NMR investigation of catalyst supports. Solid State NMR 2010, $37,82-90$.

[189] Grisel, R. J. H.; Nieuwenhuys, B. E. Selective oxidation of CO over supported Au catalysts. J. Catal. 2001, 199, 48-59.

[190] Szabó, E. G.; Hegedűs, M.; Szegedi, Á.; Sajó, I.; Margitfalvi, J. L. CO oxidation over $\mathrm{Au} / \mathrm{Al}_{2} \mathrm{O}_{3}$ catalysts modified by $\mathrm{MgO}$. React. Kinet. Catal. Lett. 2005, 86, 339-345.

[191] Szabó, E. G.; Hegedűs, M.; Lónyi, F.; Szegedi, Á.; Datye, A. K.; Margitfalvi, J. L. Preparation, characterization and activity of $\mathrm{Au} / \mathrm{Al}_{2} \mathrm{O}_{3}$ modified by $\mathrm{MgO}$. Catal. Commun. 2009, 10, 889-893.

[192] Grisel, R. J. H.; Nieuwenhuys, B. E. A comparative study of the oxidation of $\mathrm{CO}$ and $\mathrm{CH}_{4}$ over $\mathrm{Au} / \mathrm{MO}_{x} / \mathrm{Al}_{2} \mathrm{O}_{3}$ catalysts. Catal. Today 2001, 64, 69-81.

[193] Wang, D. H.; Hao, Z. P.; Cheng, D. Y.; Shi, X. C.; Hu, C. Influence of pretreatment conditions on low-temperature $\mathrm{CO}$ oxidation over $\mathrm{Au} / \mathrm{MO}_{x} / \mathrm{Al}_{2} \mathrm{O}_{3}$ catalysts. J. Mol. Catal. A 2003, 200, 229-238.

[194] Szabó, E. G.; Hegedűs, M.; Margitfalvi, J. L. The role of the nano-environment of supported gold catalysts in the activity control. Modification of $\mathrm{Au} / \mathrm{Al}_{2} \mathrm{O}_{3}$ catalysts by redox-type metal oxides. React. Kinet. Catal. Lett. 2008, 93, 119-125.

[195] Wang, D. H.; Hao, Z. P.; Cheng, D. Y.; Shi, X. C. Influence of the calcination temperature on the $\mathrm{Au} / \mathrm{FeO}_{x} / \mathrm{Al}_{2} \mathrm{O}_{3}$ catalyst. J. Chem. Technol. Biotechnol. 2006, 1246-1251.

[196] Wang, F.; Lu, G. X. Control reaction path of CO oxidation by regulating the oxidation state of Au species. Catal. Lett. 2010, 134, 72-77.

[197] Gluhoi, A. C.; Nieuwenhuys, B. E. Catalytic oxidation of 
saturated hydrocarbons on multicomponent $\mathrm{Au} / \mathrm{Al}_{2} \mathrm{O}_{3}$ catalysts: Effect of various promoters. Catal. Today 2007, 119, 305-310.

[198] Somodi, F.; Borbáth, I.; Hegedűs, M.; Lázár, K.; Sajó, I.; Geszti, O.; Rojas, S.; Fierro, J. L. G.; Margitfalvi, J. L. Promoting effect of tin oxides on alumina-supported gold catalysts used in CO oxidation. Appl. Surf. Sci. 2009, 256, 726-736.

[199] Hereijgers, B. P. C.; Weckhuysen, B. M. Selective oxidation of methanol to hydrogen over gold catalysts promoted by alkaline-earth-metal and lanthanum oxides. Chem. Suc. Chem. 2009, 2, 743-748.

[200] Centeno, M. A.; Paulis, M.; Montes, M.; Odriozola, J. A. Catalytic combustion of volatile organic compounds on $\mathrm{Au} / \mathrm{CeO}_{2} / \mathrm{Al}_{2} \mathrm{O}_{3}$ and $\mathrm{Au} / \mathrm{Al}_{2} \mathrm{O}_{3}$ catalysts. Appl. Catal. $A$ 2002, 234, 65-78.

[201] Centeno, M. A.; Portales, C.; Carrizosa, I.; Odriozola, J. A. Gold supported $\mathrm{CeO}_{2} / \mathrm{Al}_{2} \mathrm{O}_{3}$ catalysts for $\mathrm{CO}$ oxidation: Influence of the ceria phase. Catal. Lett. 2005, 102, 289-297.

[202] Lakshmanan, P.; Delannoy, L.; Richard, V.; Méthivier, C.; Potvin, C.; Louis, C. Total oxidation of propene over $\mathrm{Au} / x \mathrm{CeO}_{2}-\mathrm{Al}_{2} \mathrm{O}_{3}$ catalysts: Influence of the $\mathrm{CeO}_{2}$ loading and the activation treatment. Appl. Catal. B 2010, 96, 117-125.

[203] Yuan, Q.; Duan, H. -H.; Li, L. -L.; Li, Z. -X.; Duan, W. -T.; Zhang, L. -S.; Song, W. -G.; Yan, C. -H. Homogeneously dispersed ceria nanocatalyst stabilized with ordered mesoporous alumina. Angew. Chem. Int. Ed. 2010, 22, 1475-1478.

[204] Gluhoi, A. C.; Tang, X.; Marginean, P.; Nieuwenhuys, B. E. Characterization and catalytic activity of unpromoted and alkali (earth)-promoted $\mathrm{Au} / \mathrm{Al}_{2} \mathrm{O}_{3}$ catalysts for lowtemperature CO oxidation. Top. Catal. 2006, 39, 101-110.

[205] Gluhoi, A. C.; Nieuwenhuys, B. E. Structural and chemical promoter effects of alkali (earth) and cerium oxides in $\mathrm{CO}$ oxidation on supported gold. Catal. Today 2007, 122, 226-232.

[206] Prati, L.; Martra, G. New gold catalysts for liquid phase oxidation. Gold Bull. 1999, 32, 96-101.

[207] Ketchie, W. C.; Fang, Y. -L.; Wong, M. S.; Murayama, M.; Davis, R. J. Influence of gold particle size on the aqueous-phase oxidation of carbon monoxide and glycerol. J. Catal. 2007, 250, 95-102.

[208] Huang, X. K.; Yue, H. J.; Attia, A.; Yang, Y. Preparation and properties of manganese oxide/carbon composites by reduction of potassium permanganate with acetylene black. J. Electrochem. Soc. 2007, 154, A26-A33.

[209] Hammer, N.; Kvande, I.; Chen, D.; Rønning, M. Au-TiO catalysts stabilised by carbon nanofibres. Catal. Today 2007, 122, 365-369.

[210] Hammer, N.; Kvande, I.; Xu, X.; Gunnarsson, V.; Totdal, B.; Chen, D.; Rønning, M. Au- $\mathrm{TiO}_{2}$ catalysts on carbon nanofibres prepared by deposition-precipitation and from colloid solutions. Catal. Today 2007, 123, 245-256.

[211] George, P. P.; Gedanken, A.; Perkas, N.; Zhong, Z. Y. Selective oxidation of $\mathrm{CO}$ in the presence of air over gold-based catalysts $\mathrm{Au} / \mathrm{TiO}_{2} / \mathrm{C}$ (sonochemistry) and $\mathrm{Au} / \mathrm{TiO}_{2} / \mathrm{C}$ (microwave). Ultrason. Sonochem. 2007, 15, 539-547.

[212] Bulushev, D. A.; Kiwi-Minsker, L.; Yuranov, I.; Suvorova, E. I.; Buffat, P. A.; Renken, A. Structured $\mathrm{Au} / \mathrm{FeO}_{x} / \mathrm{C}$ catalysts for low-temperature $\mathrm{CO}$ oxidation. J. Catal. 2002, 210, 149-159.

[213] Khanderi, J.; Hoffmann, R. C.; Engstler, J.; Schneider, J. J.; Arras, J.; Claus, P.; Cherkashinin, G. Binary Au/MWCNT and ternary $\mathrm{Au} / \mathrm{ZnO} / \mathrm{MWCNT}$ nanocomposites: Synthesis, characterization and catalytic performance. Chem. Eur. J. 2010, 16, 2300-2308.

[214] Solsona, B.; Conte, M.; Cong, Y.; Carley, A.; Hutchings, G. Unexpected promotion of $\mathrm{Au} / \mathrm{TiO}_{2}$ by nitrate for $\mathrm{CO}$ oxidation. Chem. Commun. 2005, 2351-2353.

[215] Kanazawa, T. Suppression of Pt sintering on MFI zeolite by modification with tetramethoxysilane. Catal. Lett. 2006, 108, 45-47.

[216] Takenaka, S.; Matsumori, H.; Nakagawa, K.; Matsune, H.; Tanabe, E.; Kishida, M. Improvement in the durability of Pt electrocatalysts by coverage with silica layers. J. Phys. Chem. C 2007, 111, 15133-15136.

[217] Takenaka, S.; Arike, T.; Matsune, H.; Tanabe, E.; Kishida, M. Preparation of carbon nanotube-supported metal nanoparticles coated with silica layers. J. Catal. 2008, 257, 345-355.

[218] Nakagawa, K.; Tanimoto, Y.; Okayama, T.; Sotowa, K. -I.; Sugiyama, S.; Takenaka, S.; Kishida, M. Sintering resistance and catalytic activity of platinum nanoparticles covered with a microporous silica layer using methyltriethoxysilane. Catal. Lett. 2010, 136, 71-76.

[219] Zhang, P.; Chi, M. F.; Sharma, S.; McFarland, E. W. Silica encapsulated heterostructure catalyst of Pt nanoclusters on hematite nanocubes: synthesis and reactivity. J. Mater. Chem. 2010, 20, 2013-2017.

[220] Rashkeev, S. N.; Dai, S.; Overbury, S. H. Modification of $\mathrm{Au} / \mathrm{TiO}_{2}$ nanosystems by $\mathrm{SiO}_{2}$ monolayers: Toward the control of the catalyst activity and stability. J. Phys. Chem. C 2010, 114, 2996-3002.

[221] Guczi, L.; Frey, K.; Beck, A.; Petõ, B.; Daróczi, C. S.; Kruse, N.; Chenakin, S. Iron oxide overlayers on 
$\mathrm{Au} / \mathrm{SiO}_{2} / \mathrm{Si}(100)$ : Promoting effect of $\mathrm{Au}$ on the catalytic activity of iron oxide in $\mathrm{CO}$ oxidation. Appl. Catal. A 2005, 291, 116-125.

[222] Guczi, L.; Pászti, Z.; Frey, K.; Beck, A.; Pető, G.; Daróczy, C. S. Modeling gold/iron oxide interface system. Top. Catal. 2006, 39, 137-143.

[223] Dong, X. P.; Shen, W. H.; Zhu, Y. F.; Xiong, L. M.; Gu, J. L.; Shi, J. L. Investigation on Mn-loaded mesoporous silica MCM-41 prepared via reducing $\mathrm{KMnO}_{4}$ with in situ surfactant. Micropor. Mesopor. Mater. 2005, 81, 235-240.

[224] Dong, X. P.; Shen, W. H.; Zhu, Y. F.; Xiong, L. M.; Shi, J. L. Facile synthesis of manganese-loaded mesoporous silica materials by direct reaction between $\mathrm{KMnO}_{4}$ and an in-situ surfactant template. Adv. Funct. Mater. 2005, 15, 955-960.

[225] Yu, H.; Chen, M.; Rice, P. M.; Wang, S. X.; White, R. L.; Sun, S. H. Dumbbell-like bifunctional $\mathrm{Au}-\mathrm{Fe}_{3} \mathrm{O}_{4}$ nanoparticles. Nano Lett. 2005, 5, 379-382.

[226] Wang, C.; Xu, C. J.; Zeng, H.; Sun, S. H. Recent progress in synthesis and applications of dumbbell-like nanoparticles. Adv. Mater. 2009, 21, 3045-3052.

[227] Lee, Y.; Garcia, M. A.; Huls, N. A. F.; Sun, S. H. Synthetic tuning of the catalytic properties of $\mathrm{Au}-\mathrm{Fe}_{3} \mathrm{O}_{4}$. Angew. Chem. Int. Ed. 2010, 49, 1271-1274.

[228] Enache, D. I.; Edwards, J. K.; Landon, P.; Solsona-Espriu, B.; Carley, A. F.; Herzing, A. A.; Watanabe, M.; Kiely, C. J.; Knight, D. W.; Hutchings, G. J. Solvent-free oxidation of primary alcohols to aldehydes using $\mathrm{Au}-\mathrm{Pd} / \mathrm{TiO}_{2}$ catalysts. Science 2006, 311, 362-365.

[229] Bracey, C. L.; Ellis, P. R.; Hutchings, G. J. Application of copper-gold alloys in catalysis: Current status and future perspectives. Chem. Soc. Rev. 2009, 38, 2231-2243.

[230] Keane, M. A.; Gómez-Quero, S.; Cárdenas-Lizana, F.; Shen, W. Q. Alumina-supported Ni-Au: Surface synergistic effects in catalytic hydrodechlorination. Chem. Cat. Chem. 2009, 1, 270-278.

[231] Wong, M. S.; Alvarez, P. J. J.; Fang, Y. -L.; Akçin, N.; Nutt, M. O.; Miller, J. T.; Heck, K. N. Cleaner water using bimetallic nanoparticle catalysts. J. Chem. Technol. Biotechnol. 2009, 84, 158-166.

[232] Chen, Y. T.; Lim, H. M.; Tang, Q. H.; Gao, Y. T.; Sun, T.; Yan, Q. Y.; Yang, Y. H. Solvent-free aerobic oxidation of benzyl alcohol over Pd monometallic and $\mathrm{Au}-\mathrm{Pd}$ bimetallic catalysts supported on SBA-16 mesoporous molecular sieves. Appl. Catal. A 2010, 380, 55-65.

[233] Ye, Q.; Wang, J.; Zhao, J. S.; Yan, L. N.; Cheng, S. Y.; Kang, T. F.; Dai, H. X. Pt or Pd-doped $\mathrm{Au} / \mathrm{SnO}_{2}$ catalysts: High activity for low-temperature $\mathrm{CO}$ oxidation. Catal. Lett. 2010, 138, 56-61.
[234] Yu, Q. Q.; Chen, W.; Li, Y.; Jin, M. S.; Suo, Z. H. The action of $\mathrm{Pt}$ in bimetallic $\mathrm{Au}-\mathrm{Pt} / \mathrm{CeO}_{2}$ catalyst for water-gas shift reaction. Catal Today 2010, in press, DOI: 10.1016/j.cattod.2010.1004.1005.

[235] Scott, R. W. J.; Sivadinarayana, C.; Wilson, O. M.; Yan, Z.; Goodman, D. W.; Crooks, R. M. Titania-supported $\mathrm{PdAu}$ bimetallic catalysts prepared from dendrimerencapsulated nanoparticle precursors. J. Am. Chem. Soc. 2005, 127, 1380-1381.

[236] Liu, J. -H.; Wang, A. -Q.; Chi, Y. -S.; Lin, H. -P.; Mou, C. -Y. Synergistic effect in an $\mathrm{Au}-\mathrm{Ag}$ alloy nanocatalyst: $\mathrm{CO}$ oxidation. J. Phys. Chem. B 2005, 109, 40-43.

[237] Wang, A. -Q.; Liu, J. -H.; Lin, S. D.; Lin, T. -S.; Mou, C. -Y. A novel efficient $\mathrm{Au}-\mathrm{Ag}$ alloy catalyst system: Preparation, activity, and characterization. J. Catal. 2005, 233, 186-197.

[238] Wang, A. Q.; Chang, C. M.; Mou, C. Y. Evolution of catalytic activity of $\mathrm{Au}-\mathrm{Ag}$ bimetallic nanoparticles on mesoporous support for $\mathrm{CO}$ oxidation. J. Phys. Chem. B 2005, 109, 18860-18867.

[239] Wang, A. Q.; Hsieh, Y. -P.; Chen, Y. -F.; Mou, C. -Y. $\mathrm{Au}-\mathrm{Ag}$ alloy nanoparticle as catalyst for $\mathrm{CO}$ oxidation: Effect of $\mathrm{Si} / \mathrm{Al}$ ratio of mesoporous support. J. Catal. 2006, 237, 197-206.

[240] Liu, X. Y.; Wang, A. Q.; Wang, X. D.; Mou, C. Y.; Zhang, T. $\mathrm{Au}-\mathrm{Cu}$ alloy nanoparticles confined in SBA-15 as a highly efficient catalyst for $\mathrm{CO}$ oxidation. Chem. Commun. 2008, 3187-3189.

[241] Baiker, A.; Gasser, D.; Lenzner, J.; Reller, A.; Schlögl, R. Oxidation of carbon monoxide over palladium on zirconia prepared from amorphous $\mathrm{Pd}-\mathrm{Zr}$ alloy. 1. Bulk structural, morphological, and catalytic properties of catalyst. $J$. Catal. 1990, 126, 555-571.

[242] Schlögl, R.; Loose, G.; Wesemann, M.; Baiker, A. Oxidation of carbon monoxide over palladium on zirconia prepared from amorphous $\mathrm{Pd}-\mathrm{Zr}$ alloy. 2. The nature of the active surface. J. Catal. 1992, 137, 139-157.

[243] Baiker, A.; Maciejewski, M.; Tagliaferri, S.; Hug, P. Carbon monoxide oxidation over catalysts prepared by in situ activation of amorphous gold-silver-zirconium and gold-iron-zirconium alloys. J. Catal. 1995, 151, 407-419.

[244] Dawood, F.; Leonard, B. M.; Schaak, R. E. Oxidative transformation of intermetallic nanoparticles: An alternative pathway to metal/oxide nanocomposites, textured ceramics, and nanocrystalline multimetal oxides. Chem. Mater. 2007, $19,4545-4550$.

[245] Albonetti, S.; Bonelli, R.; Mengou, J. E.; Femoni, C.; Tiozzo, C.; Zacchini, S.; Trifirò, F. Gold/iron carbonyl clusters as precursors for $\mathrm{TiO}_{2}$ supported catalysts. Catal. 
Today 2008, 137, 483-488.

[246] Albonetti, S.; Bonelli, R.; Delaigle, R.; Femoni, C.; Gaigneaux, E. M.; Morandi, V.; Ortolani, L.; Tiozzo, C.; Zacchini, S.; Trifirò, F. Catalytic combustion of toluene over cluster-derived gold/iron catalysts. Appl. Catal. A 2010, 372, 138-146.

[247] Liz-Marzan, L. M.; Giersig, M.; Mulvaney, P. Synthesis of nanosized gold-silica core-shell particles. Langmuir 1996, $12,4329-4335$.

[248] Liz-Marzan, L. M.; Mulvaney, P. The assembly of coated nanocrystals. J. Phys. Chem. B 2003, 107, 7312-7326.

[249] Botella, P.; Corma, A.; Navarro, M. T. Single gold nanoparticles encapsulated in monodispersed regular spheres of mesostructured silica produced by pseudomorphic transformation. Chem. Mater. 2007, 19, 1979-1983.

[250] Casavola, M.; Buonsanti, R.; Caputo, G.; Cozzoli, P. D. Colloidal strategies for preparing oxide-based hybride nanocrystals. Eur. J. Inorg. Chem. 2008, 837-854.

[251] Shevchenko, E. V.; Bodnarchuk, M. I.; Kovalenko, M. V.; Talapin, D. V.; Smith, R. K.; Aloni, S.; Heiss, W.; Alivisatos, A. P. Gold/iron oxide core-hollow shell nanoparticles. Adv. Mater. 2008, 20, 4323-4329.

[252] Joo, S. H.; Park, J. Y.; Tsung, C. -K.; Yamada, Y.; Yang, P. D.; Somorjai, G. A. Thermally stable Pt/mesoporous silica core-shell nanocatalysts for high-temperature reactions. Nat. Mater. 2009, 8, 126-131.

[253] Liu, S. H.; Han, M. Y. Silica-coated metal nanoparticles. Chem. Asian J. 2010, 5, 36-45.

[254] Ikeda, M.; Tago, T.; Kishida, M.; Wakabayashi, K. Thermal stability of an $\mathrm{SiO}_{2}$-coated $\mathrm{Rh}$ catalyst and catalytic activity in NO reduction by CO. Chem. Commun. 2001, 2512-2513.

[255] Yin, Y. D.; Rioux, R. M.; Erdonmez, C. K.; Hughes, S.; Somorjai, G. A.; Alivisatos, A. P. Formation of hollow nanocrystals through the nanoscale Kirkendall effect. Science 2004, 304, 711-714.

[256] Takenaka, S.; Hori, K.; Matsune, H.; Kishida, M. Control of selectivity based on the diffusion rates of the reactants in the oxidation of mixed hydrocarbons with molecular oxygen over silica-coated Pt catalysts. Chem. Lett. 2005, 34, 1594-1595.

[257] Yeung, C. M. Y.; Yu, K. M. K.; Fu, Q. J.; Thompsett, D.; Petch, M. I.; Tsang, S. C. Engineering Pt in ceria for a maximum metal-support interaction in catalysis. J. Am. Chem. Soc. 2005, 127, 18010-18011.

[258] Yeung, C. M. Y.; Meunier, F.; Burch, R.; Thompsett, D.; Tsang, S. C. Comparison of new microemulsion prepared "Pt-in-Ceria" catalyst with conventional "Pt-on-Ceria" catalyst for water-gas shift reaction. J. Phys. Chem. B
2006, 110, 8540-8543.

[259] Takenaka, S.; Umebayashi, H.; Tanabe, E.; Matsune, H.; Kishida, M. Specific performance of silica-coated $\mathrm{Ni}$ catalysts for the partial oxidation of methane to synthesis gas. J. Catal. 2007, 245, 392-400.

[260] Park, J. N.; Forman, A. J.; Tang, W.; Cheng, J. H.; Hu, Y. -S.; Lin, H. F.; McFarland, E. W. Highly active and sinter-resistant Pd nanoparticle catalysts encapsulated in silica. Small 2008, 4, 1694-1697.

[261] Yao, L. H.; Li, Y. X.; Zhao, J.; Ji, W. J.; Au, C. T. Core-shell structured nanoparticles $\left(\mathrm{M} @ \mathrm{SiO}_{2}, \mathrm{Al}_{2} \mathrm{O}_{3}, \mathrm{MgO}\right.$; $\mathrm{M}=\mathrm{Fe}, \mathrm{Co}, \mathrm{Ni}, \mathrm{Ru}$ ) and their application in $\mathrm{CO}_{x}$-free $\mathrm{H}_{2}$ production via $\mathrm{NH}_{3}$ decomposition. Catal. Today, in press, DOI: 10.1016/j.cattod.2010.1005.1009.

[262] Yu, K. M. K.; Yeung, C. M. Y.; Thompsett, D.; Tsang, S. C. Aerogel-coated metal nanoparticle colloids as novel entities for the synthesis of defined supported metal catalysts. J. Phys. Chem. B 2003, 107, 4515-4526.

[263] Yu, K. M. K.; Thompsett, D.; Tsang, S. C. Ultra-thin porous silica coated silver-platinum alloy nano-particle as a new catalyst precursor. Chem. Commun. 2003, 1522-1523.

[264] Kong, T. S. A.; Yu, K. M. K.; Tsang, S. C. Silica coated noble metal nanoparticle hydrosols as supported catalyst precursors. J. Nanosci. Nanotechnol. 2006, 6, 1167-1172.

[265] Ma, Z.; Dai, S. Materials design of advanced performance metal catalysts. Mater. Technol. 2008, 21, 81-87.

[266] De Rogatis, L.; Cargnello, M.; Gombac, V.; Lorenzut, B.; Montini, T.; Fornasiero, P. Embedded phases: A way to active and stable catalysts. Chem. Sus. Chem. 2010, 3, $24-42$.

[267] Lee, J.; Park, J. C.; Bang, J. U.; Song, H. Precise tuning of porisity and surface functionality in $\mathrm{Au} @ \mathrm{SiO}_{2}$ nanoreactors for high activity efficiency. Chem. Mater. 2008, 20, 58395844.

[268] Lee, J.; Park, J. C.; Song, H. A nanoreactor framework of a Au@ $\mathrm{SiO}_{2}$ yolk/shell structure for catalytic reduction of p-nitrophenol. Adv. Mater. 2008, 20, 1523-1528.

[269] Huang, X. Q.; Guo, C. Y.; Zuo, J. Q.; Zheng, N. F.; Stucky, G. D. An assembly route to inorganic catalytic nanoreactors containing sub-10-nm gold nanoparticles with antiaggregation properties. Small 2009, 5, 361-365.

[270] Güttel, R.; Paul, M.; Schüth, F. Ex-post size control of high-temperature-stable yolk-shell $\mathrm{Au} @ \mathrm{ZrO}_{2}$ catalysts. Chem. Commun. 2010, 46, 895-897.

[271] Chen, Y.; Chen, H. R.; Guo, L. M.; He, Q. J.; Chen, F.; Zhou, J.; Feng, J. W.; Shi, J. L. Hollow/rattle-type mesoporous nanostructures by a structural difference-based selective etching strategy. ACS Nano 2010, 4, 529-539.

[272] Li, J.; Zeng, H. C. Size tuning, functionalization, and 
reactivation of $\mathrm{Au}$ in $\mathrm{TiO}_{2}$ nanoreactors. Angew. Chem. Int Ed. 2005, 44, 4342-4345.

[273] Wu, X. -F.; Song, H. -Y.; Yoon, J. -M.; Yu, Y. -T.; Chen, Y. -F. Synthesis of core-shell $\mathrm{Au} @ \mathrm{TiO}_{2}$ nanoparticles with truncated wedge-shaped morphologies and their photocatalytic properties. Langmuir 2009, 25, 6438-6447.

[274] Chen, Y. L.; Zhu, B. L.; Yao, M. Y.; Wang, S. R.; Zhang, S. M. The preparation and characterization of $\mathrm{Au} @ \mathrm{TiO}_{2}$ nanoparticles and their catalytic activity for $\mathrm{CO}$ oxidation. Catal. Commun. 2010, 11, 1003-1007.

[275] Hagaman, E. W.; Zhu, H. G.; Overbury, S. H.; Dai, S. ${ }^{13} \mathrm{C}$ NMR characterization of the organic constituents in ligandmodified hexagonal mesoporous silicas: Media for the synthesis of small, uniform-size gold nanoparticles. Langmuir 2004, 20, 9577-9584.

[276] Schwartz, V.; Mullins, D. R.; Yan, W. F.; Chen, B.; Dai, S.; Overbury, S. H. XAS study of Au supported on $\mathrm{TiO}_{2}$ : Influence of oxidation state and particle size on catalytic activity. J. Phys. Chem. B 2004, 108, 15782-15790.

[277] Schwartz, V.; Mullins, D. R.; Yan, W. F.; Zhu, H. G.; Dai, S.; Overbury, S. H. Structural investigation of Au catalysts on $\mathrm{TiO}_{2}-\mathrm{SiO}_{2}$ supports: Nature of the local structure of Ti and Au atoms by EXAFS and XANES. J. Phys. Chem. C 2007, 111, 17322-17332.

[278] Dmowski, W.; Yin, H. F.; Dai, S.; Overbury, S. H.; Egami, $\mathrm{T}$. Atomic structure of Au nanoparticles on a silica support by an X-ray PDF study. J. Phys. Chem. C 2010, 114,
6983-6988.

[279] Akita, T.; Okumura, M.; Tanaka, K.; Kohyama, M.; Haruta, M. Analytical TEM observation of Au nano-particles on cerium oxide. Catal. Today 2006, 117, 62-68.

[280] Akita, T.; Tanaka, K.; Kohyama, M.; Haruta, M. Analytical TEM study on structural changes of $\mathrm{Au}$ particles on cerium oxide using a heating holder. Catal. Today 2007, 122, 233-238.

[281] Majimel, J.; Lamirand-Majimel, M.; Moog, I.; Feral-Martin, C.; Tréguer-Delapierre, M. Size-dependent stability of supported gold nanostructures onto ceria: An HRTEM study. J. Phys. Chem. C 2009, 113, 9275-9283.

[282] Herzing, A. A.; Kiely, C. J.; Carley, A. F.; Landon, P.; Hutchings, G. J. Identification of active gold nanoclusters on iron oxide supports for CO oxidation. Science $\mathbf{2 0 0 8}$, 321, 1331-1335.

[283] González, J. C.; Hernández, J. C.; López-Haro, M.; del Río, E.; Delgado, J. J.; Hungría, A. B.; Trasobares, S.; Bernal, S.; Midgley, P. A.; Calvino, J. J. 3D characterization of gold nanoparticles supported on heavy metal oxide catalysts by HAADF-STEM electron tomography. Angew. Chem. Int. Ed. 2009, 48, 5313-5315.

[284] Allard, L. F.; Borisevich, A.; Deng, W. L.; Si, R.; Flytzani-Stephanopoulos, M.; Overbury, S. H. Evolution of gold structure during thermal treatment of $\mathrm{Au} / \mathrm{FeO}_{x}$ catalysts revealed by aberration-corrected electron microscopy. J. Electron Microsc. 2009, 58, 199-212. 